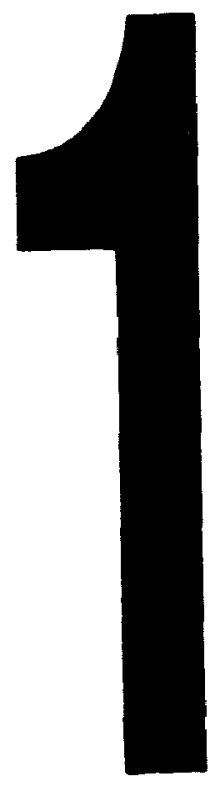

PM-1 3', "X4" PHOTOGRAPHIC MICROCOPY TARGET NBS 1010a ANSI/ISO \#2 EOUIVALENT

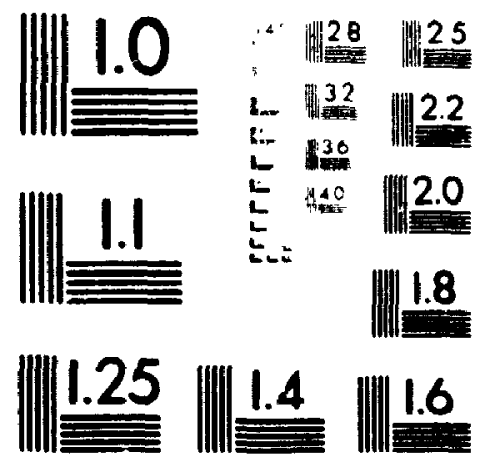

PRECISIONSM RESOLUTION TARGETS 
National Librany

ol Canada

Acquisitions and

Bibliographic Services Branch

395 Wellington Street

Ottawa. Ontarno

K1A ON4
Bibliotheque nationale

du Canada

Direction des acquisitions el

des services bibliographiques

395. rue Wellington

Ottawa (Ontario)

NOTICE

AVIS

The quality of this microform is heavily dependent upon the quality of the original thesis submitted for microfilming. Every effort has been made to ensure the highest quality of reproduction possible.

If pages are missing, contact the university which granted the degree.

Some pages may have indistinct print especially if the original pages were typed with a poor typewriter ribbon or is the university sent us an inferior photocopy.

Reproduction in full or in part of this microform is governed by the Canadian Copyright Act, R.S.C. 1970, C. C-30, and subsequent amendments.
La qualité de cette microforme dépend grandement de la qualité de la thèse soumise au microfilmage. Nous avons tout fait pour assurer une qualité supérieure de reproduction.

S'il manque des pages, veuillez communiquer avec l'université qui a conféré le grade.

La qualité d'impression de certaines pages peut laisser à désirer, surtout si les pages origiruales ont été dactylographiées à l'aide d'un ruban usé ou si l'université nous a fait parvenir une photocopie de qualité inférieure.

La reproduction, même partielle, de cette microforme est soumise à la Loi canadienne sur le droit d'auteur, SRC 1970, c. C-30, et ses amendements subséquents. 
EFFECTS OF YOUIJG OFFENDER GENDER, PRIOR RECORD, TYPE OF CRIME, AND FAMILY FUNCTIONING ON SENTENCING

Amel Loza

A thesis submitted to the Faculty of Graduate studies and Research in partial fulfilment of the requirements for the degree of Master of Arts

\author{
Department of Psychology \\ Carleton University \\ ottawa, ontario \\ August, 1995
}

Copyright c. Amel Loza, 1995 
National Library

of Canada

Acquisitions and

Bibliographic Services Branch

395 Wellington Street

Ottawa. Onlario

KIA ON4
Biblıotheque nationale

du Canada

Direction des acquisitions et

des senices bibliographiques

395. rue Wellington

Onawa (Ontarto)

KIA ONA

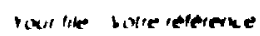

Dur pise Nurrepeperence
The author has granted an irrevocable non-exclusive licence allowing the National Library of Canada to reproduce, loan, distribute or sell copies of his/her thesis by any means and in any form or format, making this thesis available to interested persons.
L'auteur a accordé une licence irrévocable et non exclusive permettant à la Bibliothèque nationale du Canada de reproduire, prêter, distribuer ou vendre des copies de sa thèse de quelque manière et sous quelque forme que ce soit pour mettre des exemplaires de cette thèse à la disposition des personnes intéressées.

L'auteur conserve la propriété du droit d'auteur qui protège sa thèse. Ni la thèse ni des extraits substantiels de celle-ci ne doivent être imprimés ou autrement reproduits sans son autorisation.

ISBN $\quad 0-612-08909-6$ 


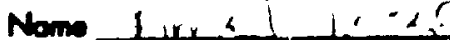

Divertetion Abutracts Inimotional is arronged by brood, generd subject cotegories Pleose select the one wbject which most nacty decribes the content of your dissertotion. Enver the corresponding four-digit code in the spaces provided.

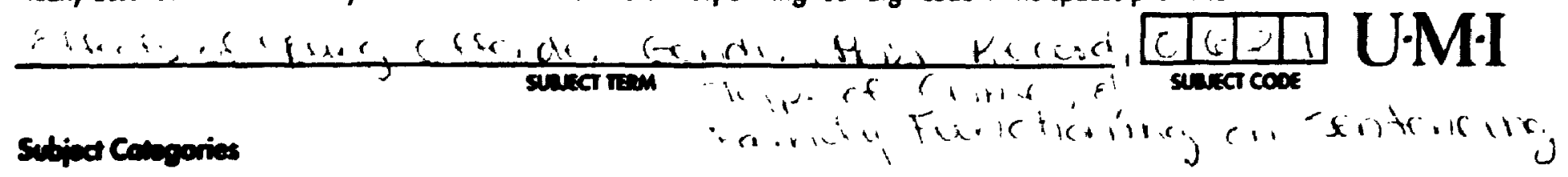

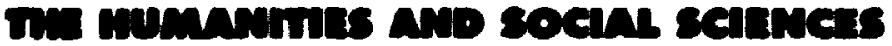

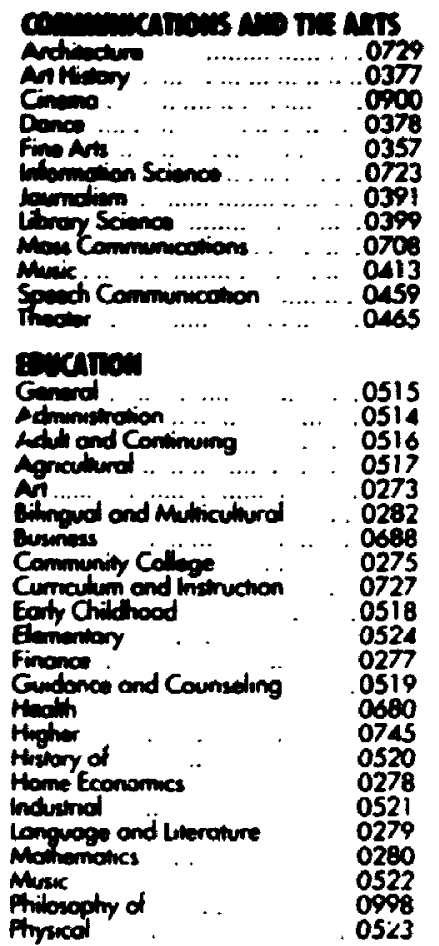

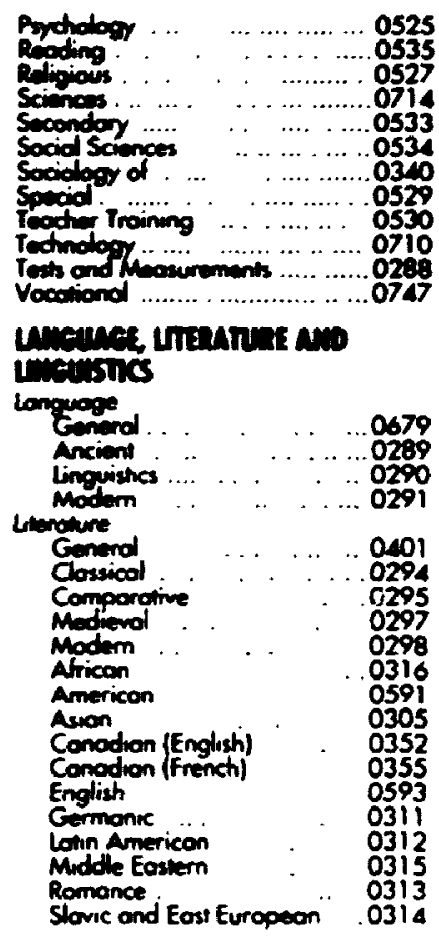

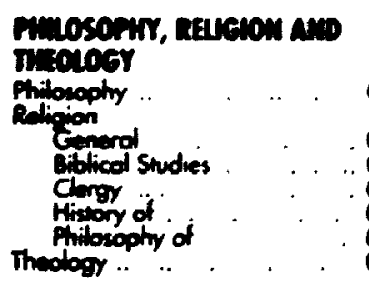

\section{sean seavas}

Americen Studies

Antropology

Authondogy : .. 0324

Culwird : ". 0320

Business Administrotion

Generol...

Aceouning

Monogemen

Conodion Studies

Economies

Gererd

Commerce-Busines:

Finance

History

lobor

Folldore

Geogrophy

Geromblogy

General
Monking
0422

0321

0319

0322
0.669

0323

0310

0272

0770

0338

0338
0385

0301

0501

0505

0508

.0509

0510

0511

0358
0366

0351

0578

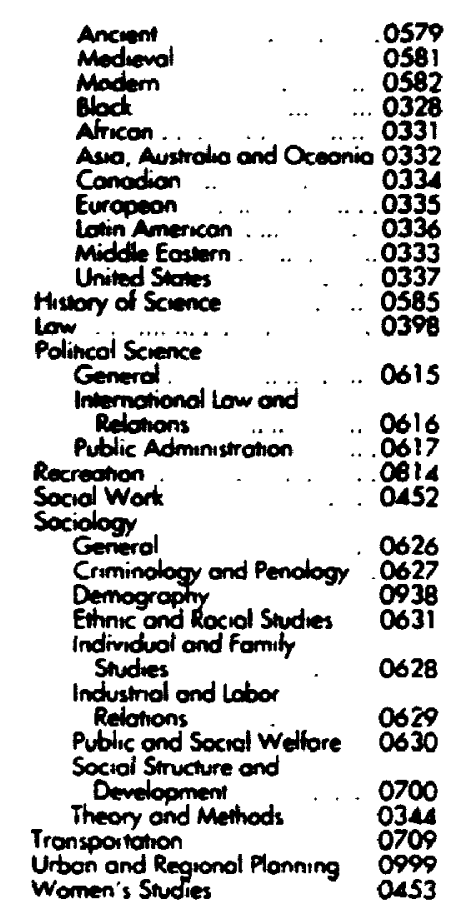



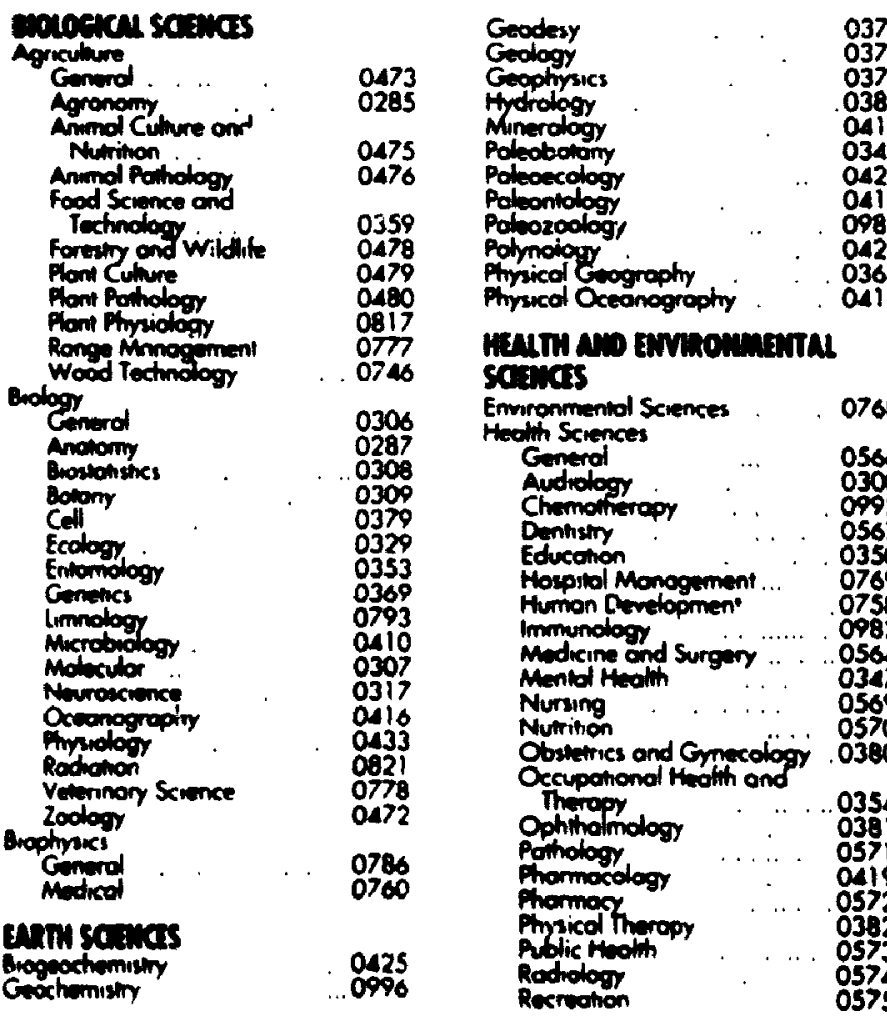

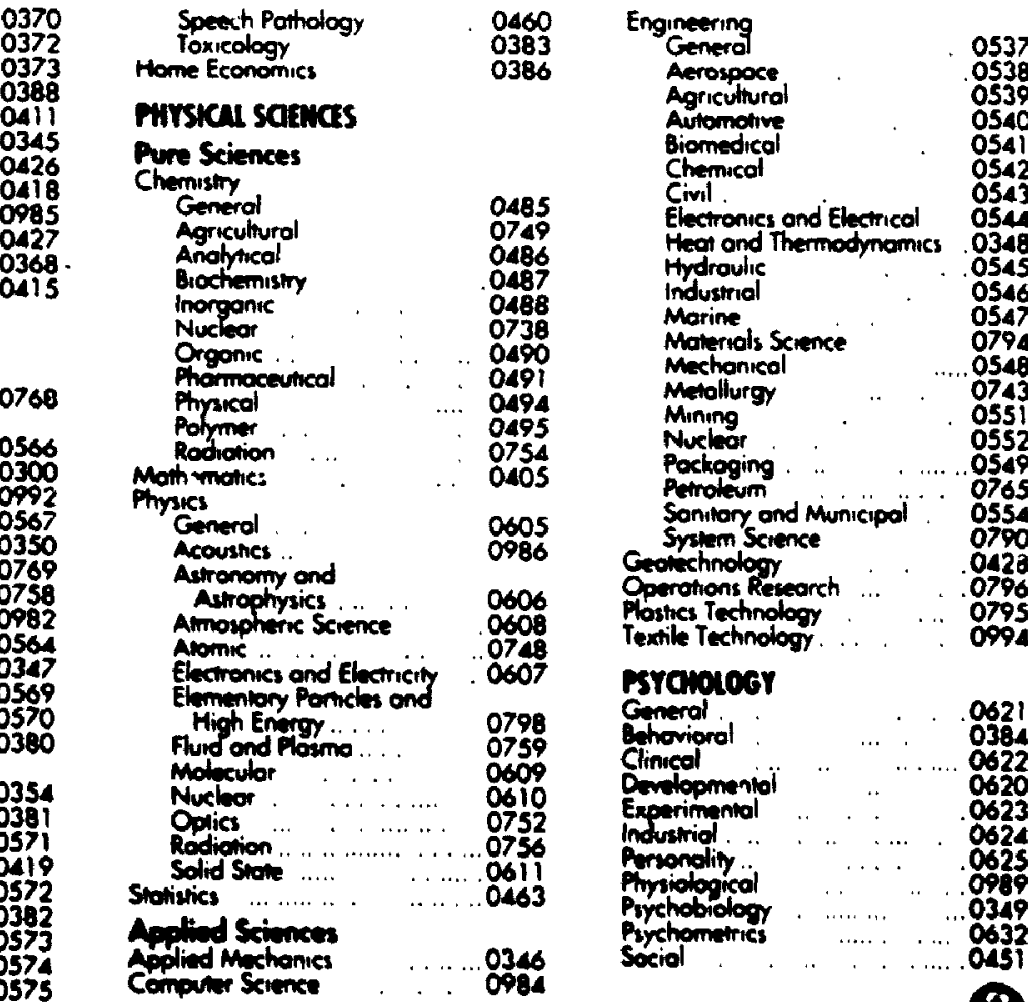

\section{Astavest}

\section{Gemeral}

Choviorol

Conclopmeniol

Experimantal

Industrial

Prronolity.".

Pirchobidoor

Piychometrics

Soxiol
2537

539

(1)

2544

0348

0546

0794

(a)

551

0552
0549

(1)

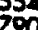

423

0795

0621

0384
0822

0.820

0623

062

0.025

\%o8

0349

0632 
Abstract

The present study examined the effects of four young offender characteristics (prior record, of fender gender, type of crime, history of abuse) on the sentences awarded to them. Participants, forty male and forty female, university students, were asked to assign sentences to sixteen vignettes with varying combinations of these four factors. Results indicate that females with a prior record are given harsher sentences, in general, than their male counterparts. However, males without a prior record were generally given the harsher sentences. Also, abused offenders with and without a prior record tended to receive harsher sentences than non-abused offenders. These results are discussed in relation to participants' stated goals of sentencing. 


\section{Acknowledgements}

I would like to take this opportunity to thank my supervisor, Dr Bob Hoge, for his encouragement, support, and guidance during this entire process. I would also like to extend my appreciation to Drs Don Andrews and Adelie Forth for their insightful comments and suggestions.

Also, a heartfelt thank you to my paren's and my sister for their encouragement and patience and for their immense support. Last, but definitely not least, a special thank-you to Michael for his patience, understanding, immense encouragement and motivation. 
Table of contents

Abstract............................

Acknowledgements........................ i i

List of Tables.........................

List of figures......................... viii

List of Appendices...................... ix

Introduction. .........................

Goals of sentencing....................

Principles of the Young offender Act........6

Disparity within the YOA..............13

Variables that Influence Sentencing Decisions..18

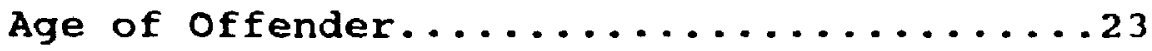

Gender of offender.......................

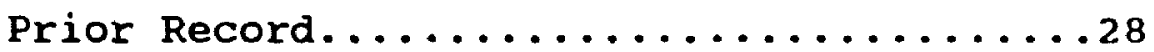

Type of crime...................29

Family Functioning...................

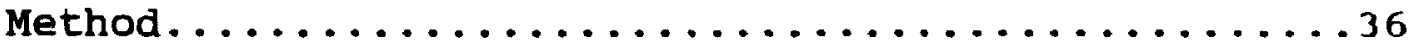

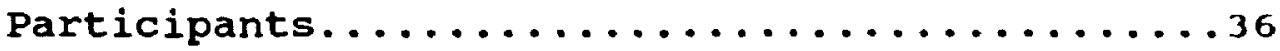

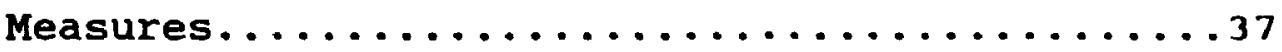

Procedures......................... 38

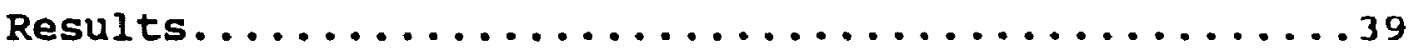

Discussion...........................

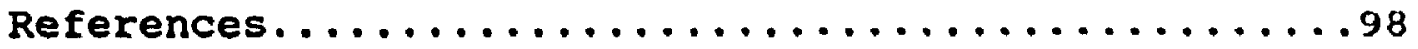

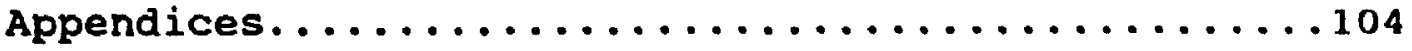


List of Tables

Table

Page

Table 1: Main Effects of the Analysis of Sentence Types..........................40

Table 2: Prior Record x Offender Gender Interaction..41

Table 3: Three-way Interaction of Prior Record $x$

offender Gender x Type of Crime.........47

Table 4: Three-way Interaction of Prior Record $x$

Type of crime x Family Functioning........49

Table 5: Simple and simple-simple Effects of the

offender Gender $x$ Type of Crime Interaction

for the Prior Record Condition..........52

Table 6: Simple and simple-simple Effects of the

offender Gender x Type of Crime Interaction

for the No prior Record Condition........54

Table 7: Simple and Simple-simple Effects of the

Type of crime $x$ Family Functioning

Interaction for the Prior Record Condition..56

Table 8: Simple and Simple-simple Effects of the Type

of Crime x Family Functioning Interaction for the No Prior Record Condition...........58

Table 9: Rated Importance of Goals for the offender Gender $x$ Type of Crime Interaction at the Prior Record Condition...............60 
List of Tables continued

Table 10: Rated Importance of Goals for the offender Gender $\times$ Type of crime Interaction at the No Prior Record Condition. ...........61

Table 11: Rated Importance of Goals for the Type of Crime $x$ Family Functioning Interaction at the Prior Record Condition.............62

Table 12: Rated Importance of Goals for the Type of Crime $x$ Family Functioning Interaction at the No Prior Record Condition...........63

Table 13: Correlations Between Assigned Sentences and their Corresponding Goals for the Prior Record Condition of the offender Gender $x$ Type of Crime Interaction. . . . . . . . . 65

Table 14: Correlations Between Assigned Sentences and their Corresponding Goals for the No Prior Record Condition of the offender Gender $x$ Type of crime Interaction...........66

Table 15: Correlations Between Assigned Sentences and their Corresponding Goals for the Prior Record Condition of the Type of crime $x$ Family Functioning Interaction.........68

Table 16: Correlations Between Assigned Sentences and their Corresponding Goals for the No Prior Record condition of the Type of crime $x$ vi 
List of Tables continued

Family Functioning Interaction...........69

Taile 17: Participant Mean Ratings of the Four Factors.71

Table 18: Additional Information Desired by

Participants.....................

Table 19: Percent of Participants' Convictions as

Youngoffenders.....................74

Table 20: Percent of Family Members' Convictions as

Youngoffenders....................76

Table 21: Percent of Friends' Convictions as Young

offenders......................78

Table 22: Percentage of Participants Victimized by Youngoffenders....................80

Table 23: Percentage of Family Members Victimized by Youngoffenders...................81

Table 24: Percentage of Close Friends Victimized by Youngoffenders..................... 82

Table 25: Experience as/with Adult offenders........84 
List of Figures

Figure

Page

Figure 1: Two-way Interaction of offender Gender $x$ Type of Crime for the prior Record condition.....................42

Figure 2: Two-way Interaction of offender Gender $x$ Type of Crime for the No Prior Record Condition.......................43

Figure 3: Two-way Interaction of Type of crime $x$ Family Functioning for the prior Record Condition......................44

Figure 4: Two-way Interaction of Type of crime $x$ Family Functioning for the No Prior Record Condition......................45 


\section{List of Appendices}

$\begin{array}{ll}\text { Appendix } & \text { Page }\end{array}$

A Instructions and crime vignettes.............104

B Consent Form............................ 142

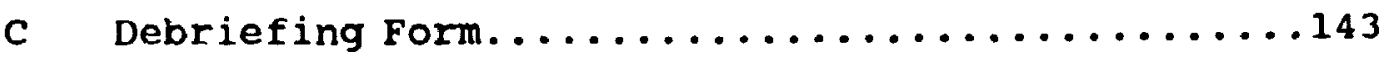

D Analysis Using Sentence Weights............. 144

E Assigned Sentence Weights................ 146 
Introduction

Public opinion polls are frequently used to support the establishment of laws that require mandatory minimum prison sentences (Stalans, 1993). They are also used to support harsher sentences by judges. The results of these polls indicate widespread public dissatisfaction with the sentencing system in Canada (Roberts \& Gebotys, 1989: Gebotys \& Roberts, 1987). According to the punitive public opinion of criminal offenders in Canada, what is required are more severe sentences than those currently imposed by the courts (Zamble \& Kalm, 1990).

In Canada, Doob and Roberts (1984) found that $80 \%$ of respondents favoured a harsher sentencing policy. The authors studied the impact of varying the amount of information given to respondents about a criminal case on the sentences they gave the offender. Half of the participants read a newspaper account of the case, and the other half read the court transcript. Eighty percent of the respondents who read the newspaper account indicated that the judge was too lenient in comparison to 14.88 of those who read the court transcript. Thus, it appears that the public would not prefer harsher sentences if given all the information about a case. These results also suggest that people are willing to evaluate a sentence with minimal information. Doob and Roberts (1984) assert that members of the public may be misinformed about crime in Canada and the reality of how the criminal justice system operates.

The public's main concern in the above study 
appeared to be with violent crime. Respondents who viewed the sentence of the courts as generally being too lenient were also slightly more likely to feel that the most important factors for the judge to take into account when sentencing were the violence of the offense, the harm done to the victim, the criminal record of the offender, and the premeditation of the crime. Thus, there appears to be an understanding that sentencing is a complex issue and that certain circumstances may warrant seemingly disproportionate sentences. The authors conclude that:

...the public views crime as being more violent than it seems to be; sees the justice system as responding too leniently, and in some instances more leniently than it in fact does; and feels changes should be made in this system (p.272).

They further suggest that:

policy-makers should not interpret the public's apparent desire for harsher penalties at face value; they should understand this widespread perception of leniency is founded upon incomplete and frequently inaccurate news accounts (p.277). Di.amond and Stalans (1989) assert that the news media present a highly selective and nonrepresentative selection of crime that focuses on the violent and extreme rather than the average. This leads the public to generalize from those specific cases, remembering and recalling more easily the negative and extreme behaviours. The effect is a biased picture of criminal behaviour, the offender, and their offenses leading to 
greater dissatisfaction with judicial sentencing.

stalans (1993) adds that unstable, uninformed opinions, the fear of becoming a victim of crime, and the perceived seriousness of crime in the neighbourhood, also help produce the demands for harsher punishment. Thus, in order for researchers to assess punishment preferences without the distorting effects of unrepresentative specific crimes or unrealistic stereotypes, it may be beneficial to publicize the nature of specific offenses and to find ways to reduce the recall of atypical, severe crimes reported in the media.

In summary, public opinion polls appear to reveal a general dissatisfaction with the sentencing system in Canada. However, these opinions seem to be based upon misinformation about the system and stereotypes of offenters and their offenses. The above studies suggest that, given accurate information, the public would not be as punitive as polls suggest. Further. it may be beneficial to determine what the public and judiciary believe to be the purpose or goal of sentencing and under which circumstances.

\section{coals of sentencing}

The purpose sentencing is supposed to serve may be a major determinant of the severity of a given sentence (Diamond stalans, 1989). The two most influential sentencing rationales at the present time are the 
utilitarian and the just desserts perspectives (Gebotys \& Roberts, 1987). The utilitarian approach includes the goals of general and individual deterrence, rehabilitation, and incapacitation. The utilitarian rationale aims to achieve some social benefit through the application of punishments (Roberts \& Gebotys, 1989). The just dessert rationale seeks only to impose a punishment that reflects the seriousness of the offence (i.e.. the degree of harm and blameworthiness of the offender)- regardless of whether that penalty will accomplish other goals such as deterrence (Andrews \& Bonta, 1994). According to this model, proper punishment levels are derived from societal norms rather than empirical data (Diamond \& Stalans, 1989). At times these two sentencing rationales can conflict.

Deterrence theory suggests that a severe sanction generates the fear of future punishment and will lead to decreased recidivism (Andrews \& Bonta, 1994). The advocates of general deterrence aim to reduce crime rates by punishing convicted offenders in the hope that other potential offenders will refrain from offending (Roberts \& Gebotys, 1989). In Canax., Doob (1989) suggests that there is variation across provinces and across judges within provinces on the importance placed on deterrence (Doob, 1989).

Gottfredson, Gottfredson, and Conly (1989) collected 
data in collaboration with 17 judges of a felony court in the U.S. on persons sentenced in 1976 and 1977. At the time of sentencing, the judges completed data collection forms designed to secord their opinions and judgements of the offense, offender, and the sentencing decision. It was proposed that if judges had an incapacitative intent, they would seek information about risk (the probability of new offenses), stakes (the harm expected if new offenses are committed), and the combination of risk and stakes. Persons classified as high on both dimensions would be expected to be sentenced to incarceration (and to longer confinement) while those classified as low on both dimensions would be expected to be sentenced to some other treatment.

Gottfredson and colleagues (1989) found no correlation between stakes and the judges' ratings of incapacitation as a sentencing goal, although the stakes dimension was correlated with the actual length of time served. Further, judges' intuitive assessments of risk were the stronger predictors of sentencing decisions although these assessments were not strongly correlated with empirically validated measures of risk. This evidence suggests that optimal decisions are not made with respect to predicting offender behaviours. Judges appeared to focus on factors that were not statistically related to the offender behavioral outcomes of interest. 
stakes and judges' prognoses of risk were independent of the decision to incarcerate and the determination of the length of time served. Further, the elements of the stakes variable, such as prior record and victim injury, were usually considered as measures of risk. Gottfredson and colleagues concluded that the best measures of risk are likely to be based on empirical rather than the intuitive models now in use.

It may be that different sentencing rationales lead to varying sentencing practices. Although incapacitation and deterrence seem to be more relevant in judges' minds for adults, it may be that treatment or rehabilitation is a more likely goal for youths (Doob. 1989). The following sections will discuss, first, the principles of the young offenders Act that are used as a guide to sentencing young offenders. A discussion of the disparity inherent in the Act will be presented before coverage of the factors that play a role in the sentencing decision.

Principles of the Young Offenders nct

The Young offenders Act (YOA) was enacted in 1982 and came into force on April 2, 1984 (Markham, 1994). since then, there have been substantial increases in the absolute number and duration of custodial dispositions (Doob \& Beaulieu, 1993). In Ontario, between 1984/1985 and $1987 / 1988$, the number of offenders sentenced to 
custody increased from 1476 to 2644 , an overall increase of 798 (Doob, 1993). Leschied and Jaffe (1993) suggest that the trend towards increased use of custody:

...would provide support for the belief that, despite the fact that there is a range of philosophies present within the YOA, the deterrence 'through punishment' model of controlling juvenile crime may be reigning supreme (p.122).

In part one of a two part investigation, Leschied and Jaffe (1993) determined that twice as many custody committals (open and secure) were being made under the YOA in comparison to the previous legislation (Juvenile Delinquents Act). study two determined that judges, under the YOA, expressed more concern for possible emotional disorders with the young offender. In comparison, judges were more concerned for family problems under the Juvenile Delinquents Act. Overall, the "findings would seem to give added credence to previous reports that,... deterrence through punishment as a means of crime control for young offenders has now become a popular concept" (p.125, Leschied \& Jaffe, 1993)

The YOA also seems to be having varying effects in different parts of the country (Doob, 1993). In many, but not all. provinces there has been an increase in the proportions of those cases going to court that are 
receiving custodial sentences. In each of the provinces, the proportion of custodial sentences of three months or less has increased dramatically during the first five years of the YOA. The decrease in the proportion of sentences of more than a year is equally dramatic and consistent. The overall pattern of dispositions varies across provinces and across time. Doob (1993) suggests that, in order to evaluate these trends, it is necessary to have a more detailed analysis and a clearer statement of purpose of dispositions under the present legislation. One of the most notable features of section 3 of the YOA is that it sets out a general philosophy for dealing with young offenders (YOs) who come into conflict with the criminal law (Markham, 1994). Section 3 provides as follows:

3. (1) It is hereby recognized and declared that

(a) while young persons should not in all instances be held accountable in the same manner or suffer the same consequences for their behaviour as adults, young persons who commit offenses should nonetheless bear responsibility for their contraventions:

(b) society must, although it has the responsibility to take reasonable measures to prevent criminal conduct by young persons, be afforded the necessary protection from illegal behaviour;

(c) young persons who commit offenses require supervision, discipline and control, but, because of their state of dependency and level of development 
and maturity, they also have special needs and require guidance and assistance;

(d) where it is not inconsistent with the protection of society, taking no measures or taking measures other than judicial proceedings under the Act should be considered for dealing with young persons who have committed offenses;

(e) young persons have rights and freedoms in their own right, including those stated in the canadian charter of Rights and Freedoms or in the canadian Bill of Rights, and in particular a right to be heard in the course of, and to participate in, the processes that lead to decisions that affect them, and young persons should have special guarantees of their rights and freedoms.

(f) in the application of this Act, the rights and freedoms of young persons include a right to the least possible interference with freedom that is consistent with the protection of society, having regard to the needs of young persons and the interests of their families;

(g) young persons have the right, in every instance where they have rights or freedoms they may be affected by this Act, to be informed as to what those rights and freedoms are; and

(h) parents have responsibility for the care and supervision of their children, and, for that reason, young persons should be removed from parental supervision either partly or entirely only when measures that provide for continuing parental 
supervision are inappropriate.

(2) This Act shall be liberally construed to the end that young persons will be dealt with in accordance with the principles set out in subsection (1).

Thus, the YOA recognizes that young persons should be dealt with differently from adults. It guides judicial discretion through reference to specific principles. For example, sentencing issues are referred to in paragraphs $3(a),(b)$, and (f) that outline the principles of accountability, public protection, and restraining, respectively. Paragraph $3(d)$ suggests the diversion of young persons from the judicial process when possible. Procedural fairness isst is are addressed in paragraphs $3(e)$ and $(g)$. Finally, the importance of supporting the parental-child relationship are recognized in paragraphs $3(\mathrm{c})$ and $(\mathrm{h})$.

The Declaration of Principle is to be relied upon when interpreting all provisions of the Act. However, the Declaration gives a rather inexact view of what should occur under the YOA (Markham, 1994). Many important values are listed, but no real guidance is given to the decision maker on what to do when the values are in conflict. The lack of clarity in principles guiding dispositions also makes it difficult to evaluate whether there is a problem of "disparity" in 
dispositions. In order to assess whether there really is a problem of unwarranted disparity, there has to be agreement on what the guiding principles are of the Act.

Many judges appear to take the view that the specific purpose of a disposition depends on many other factors- such as age, offense, mental capacity of the young person, financial ability to provide services or supervision by the parent, the criminal record of the youth, the time since the last offence, and the effectiveness of the previous disposition (Doob, 1989). Those who take the view that such a subjective approach is necessary, also accept the view that this section is workable. Changing it, they suggest, would mean the removal some of its flexibility. Since, each case is different, it must be dealt with differently. Thus, the guiding principles, such as they are in the YOA, are seen as ideal by some judges because maximum discretion is given to them (Doob, 1989).

The Declaration has been described as "philosophically ambivalent" in that it includes virtually anything one could imagine: and thus it can justify virtually any legal disposition in a particular case (Doob, 1989). Courts of Appeal have been reluctant or unwilling to prioritize these principles. In the more difficult area of dispositions for young offenders, appellate courts have not, as yet, fulfilled the vitally 
important function of providing guidance to trial judges (Doob, 1989). Courts of Appeal have routinely noted that there are and should be differences between the dispositions handed down for adults on the one hand, and young persons on the other. They have not explained what this means, other than to make it clear (generally) that dispositions should be less severe. Thus the statement to the effect that "Young offenders are different" gives limited guidance. In the area of principles, one clear purpose or principle that has been more or less accepted by Courts of Appeal is that rehabilitation is more relevant for young offenders than it is for adults. However, Doob (1989) suggests that:

no matter how the YOA is interpreted, the days of handing down a disposition solely in terms of how it might help, treat, or rehabilitate a young person, ended with the replacement of the Juvenile Delinquents Act with the YOA. However, it is equally clear that consideration of the youth's needs are still clearly within the YOA (p.204). Recent public concern with the YOA appears to be focused largely on the severity of sentence available for the most serious cases (Doob, 1989). For example, there was much concern about the three year maximum for murder. Some believe that the issue of disparity is not as much of a concern for young people as it is for adults. This may be because the public does not expect uniformity for adolescents the way they do for adults. However, it has 
been noted that public focus on the maximum penalties available under the Act may reflect two factors: (a) public concern about perceived leniency of penalties in criminal courts, and (b) the public's relative ignorance of other issues concerning the YOA. Before discussing the factors that have had an impact on sentencing decisions, evidence of the apparent disparity of sentences under the YOA will be reviewed. Disparity within the yon

The trends in dispositions across time and across provinces appears to reflect variation in interpretations of the Act by youth court judges (Doob, 1993). Different views of the principles that should guide dispositions are but one reasor for variation in treatment under the YOA. Others include variation in the behaviour of youth from community to community and province to province and differences across communities and provinces in the availability of less formal ways of handing troublesome youth.

As preparation for a three-day seminar for the Youth and Family Court Committee of the Canadian Association of Provincial Court Judges, participants read four hypothetical cases and answered a number of questions related to each (Doob, 1989). In the first case, two accused were involved in a shoplifting; in the second, two accused were involved in an assault. The judges were 
asked to indicate the disposition that they would give and how they viewed the case (i.e., the relative importance of the various purposes or principles in determining the dispositions). In each of the twn cases, judges gave quite varied dispositions for the identical case and they emphasized different purposes they thought to be important. For example, in the case involving assault causing bodily harm, the range of severity of the disposition was from a low of a term of probation or a fine to a period of time in custody. The term in custody also varied, ranging from less than a month in open custody to twelve months in secure custody in a single case.

similarly, the importance given to different principles guiding the disposition varied considerably (Doob, 1989). For one of the accused, for example, some judges saw "rehabilitation" as the most important principle to consider, other judges looking at the same case thought that it should be given no weight whatsoever. Some judges noted that eac.l of the dispositions could be "justified" in terms of the different values being emphasized; hence it is not possible to determine who is "right" and who is "wrong" when different dispositions are suggested for the same case.

Judges have also expressed the view that the lack of 
consistency in dispositions may reflect urban/rural differences on such things as the emphasis put on "deterrence" as a principle in the disposition. For example, it was suggested that deterrence may be more relevant in small communities where everyone has heard about the decisions of the Youth court.

with respect to inter-provincial variation. some judges expressed the view that their own court of Appeal has given them limited guidance on what a disposition should be. Repeatedly judges suggested that some of the disparity in dispositions relates to the non-availability of resources in some areas. Thus, for example, if the best program to deal with a certain problem exists in secure custody in a particular location, it is difficult not to hand down such a disposition even if it may not appear justified on other grounds.

Another study, by Doob and Beaulieu (1993), asked 43 judges from across canada to respond to two written descriptions of cases involving a total of four young offenders. After reading each case, the judges recommended sentences for each of the four offenders. They also indicated what purposes they were trying to accomplish with their disposition as well as what aspects of the case they found to be important in making their decision. The dispositions recommended for each of the four young persons greatly varied. Judges also 
prioritized the purposes they were trying to accomplish with the disposition in very different ways. Most judges also indicated that most of the factors of the case were important for each offender. The variability demonstrated by the judges in how they approached each disposition reflected what they believed to be an inherent variability in the YOA.

However, there seemed to be reliability within each judge (Doob * Beaulieu, 1993). For example, judges who tended to use severe dispositions for one youth tended to use them for other youths as well. The difference seemed to be between judges who favoured individual deterrence and those who gave precedence to rehabilitation. For each of the four offenders, over half of the judges indicated that rehabilitation was either the first or second most important goal of sentencing. However, this choice did not appear to be related to the disposition handed down. Further, there was still a large amount of variation in the recommended dispositions even among judges who favoured the same sentencing purpose for a given case.

Thus, the results as a whole suggest. that the lack of overall policy for dispositions under the YOA leads inevitably to widely different treatment of similar yos convicted of the identical offence. Under the YOA, there is not a single standard against which to assess an 
individual case (Doob \& Beaulieu, 1993). Judges may begin with different purposes, look at different factors and arrive at different decisions. one possible explanation is that, when arriving at a decision, judges may be trying to accomplish too much. Most judges found most goals or purposes to be either very important or somewhat important in determining the disposition (Doob \& Beaulieu, 1993). When choosing which of the five traditional goals of sentencing (e.g., rehabilitation, deterrence, etc.) were relevant, judges chose on average about 3.5 of the five as being relevant for every offender. This suggests that judges have set for themselves the almost impossible task of combining potentially contradictory goals to arrive at a disposition.

It should be remembered, of course, that the YOA itself requires this of judges. The Declaration of Principles does not give guidance on how to weigh prevention, protection of society, the special needs of the young person that require assistance, and making young persons accountable for their offenses. Each of these principles, taken by itself, could lead to very different dispositions. Leschied and Jaffe (1993) suggest that:

the overall theme of the legislation seeks to create an 'equitable' system of justice where dispositions are meant to fit the crime. 
In this context, discretion is seen as undesirable, particularly as the courts attempt to address special needs within what is arguably meant to be a 'mini criminal code for children' (p.121).

The following section will discuss certain factors that have demonstrably influenced sentencing decisions. It may be that emphasis is placed on specific factors or combinations of factors. If so, sentencing decisions may be a function of the availability or presence of specific information (as discussed previously). By identifying these factors, adolescents at risk of being more severely sentenced could be targeted for preventative measures or alternative programs.

\section{Variables That Influence sentencing Decisions}

The two factors that have been identified as primary determinants of sentence in most sentencing studies are objective measures of the seriousness of the of fence and prior record. Diamond and Stalans (1989) asked subjects to rate four different offense cases. Results indicate that cocaine sale is rated as more serious than burglary of a camera store and bar-room aggravated battery is seen as more serious than a purse robbery-assault. subjects also rated the offenses of the two offenders with criminal records as more serious than those of offenders. without criminal records.

There, however, has been little systematic research 
on public views of the factors relevant to sentencing. Gebotys and Roberts (1987) conducted two experiments that manipulated the type of crime, criminal record of the offender, and three offender characteristics (age, employment status, marital status). The effect of each of fender characteristic upon the sentences recommended by 112 respondents was observed. In the first experiment, participants were asked to make a series of sentencing decisions to see if they would take any offender characteristics into account when assigning penalties. Experiment two asked participants to do the same as the first experiment but they were further asked whether the manipulated variables (and others such as extent of victim harm, whether the crime was premeditated, whether the offender was likely to recidivate, etc.) should be taken into account when sentencing. Thus, experiment two provided a test of the view that self-reports give unreliable information regarding the mitigating and aggravating factors sanctioned by the public.

Results indicated that none of the manipulated offender characteristics affected respondents' sentences. The only predictors of severity of assigned sentences were the seriousness of the offense and the criminal history of the offender. Gebotys and Roberts (1987) concluded that sentencing decisions made by members of the public were desert-oriented. Further, there was a 
strong correlation between respondents' self-reports about the factors that influenced their decisions, and the results of the analyses. These results suggest that, for this aspect of sentencing, directly asking participants about the factors they favour is likely to yield reliable and valid results.

As can be seen by the above study, the offender's criminal record and the type of crime are important factors in the sentencing decision. However, the study only looked at adult offenders. It would be interesting to determine whether the same results would be obtained if the offenders were juveniles. For the criminal record variable, the authors also gave the option of no previous record and one robbery. It may be more beneficial to use a less serious offense for a prior record- such as break and entering or theft under $\$ 1000-$ to determine if prior record would still be an important predictor of sentencing. Gebotys and Roberts (1987) also did not determine whether the gender of the offender would have an impact on the sentence given. Further, the finding that the seriousness of the offense was a major predictor was not unanticipated taking into consideration that the two offenses employed were manslaughter and break and enter. Perhaps more variety in offenses would have produced a more varied pattern of sentencing results. Another study performed by Zamble and Kalm (1990) 
gathered more detailed information on how sentencing decisions vary with the characteristics of the case. The results of these procedures were also compared with answers to general evaluative questions about the judicial system. Participants were given questionnaires consisting of 16 vignettes that described the circumstances of a crime and the offender. The vignettes included: the offenses of theft, break and enter, robbery, and robbery with assault; offenders who were either 17-19 or 35-38 years of age; and previous criminal history (none or extensive with a previous prison term). The task was to choose the most appropriate sentence from a set of alternatives ranging from probation to imprisonment, given that guilt had already been established in each case.

Zamble and Kalm found that, in general, participants' perceptions of the criminal justice system were largely negative. Also, sentencing judgements were generally very similar to actual sentencing practices. There was evidence that respondents were more punitive than current practice for certain property offenses, especially household burglary. However, they were not more punitive for violent personal offenses such as robbery. These results were in contrast to the participants' own global evaluations of the leniency of the criminal justice system in the sentencing of 
offenders.

There was a strong general trend for the assigned sentence to increase with the seriousness of the offenses. The offender without a past record was sentenced consistently more leniently than offenders with a criminal record. The younger offeriders were also sentenced somewhat more leniently. Thus, significant main effects were found for the type of crime, the past criminal history of the offender, and the age of the offender. There was also a significant three-way interaction of offense, age, and record. There was significant two-way interaction between type of offense and past criminal record. However, neither of the twoway interactions involving age were significant. Thus, the severity of sentencing by respondents varied greatly with the circumstances of each case. For the most serious crimes, offender characteristics were less important than with less serious offenses.

zamble and Kalm concluded that by:

simply educating citizens better about how the system works across the great number and variety of cases it deals with would be the most effective way to reduce expressed public dissatisfaction (p.337).

The above study has also demonstrated that they type of crime, the criminal record of the offender, and the age of the offender all contribute to the sentencing 
decision. However, Zamble and Kalm (1990) did not specifically look at young offenders. Further, the offenses were either personal or property-related, leaving room for future comparison of differing types of crimes such as drug-related or sexual offenses. Finally, the prior record variable was considered "extensive", this may have inadvertently biased the severity of the sentences given. However, participants were able to deliver sentences similar to those from actual courts.

From the above studies, it can be seen that various factors have an impact on sentencing decisions. The following section is a more extensive look at the individual factors that were emphasized by the present study.

\section{Age of offender}

Harris (1988) performed a study to illustrate that the criminal behaviours of juveniles and adults are not of comparable seriousness. Prosecutors from one New Jersey county were asked to rate the seriousness of the behaviours of 500 adults and 500 juveniles charged with assault or robbery. With respect to both offenses, the behaviours of juveniles were regarded as substantially less serious than the behaviours of adults, particularly when comparing extent of injury inflicted, dollar loss incurred by victims, and weapon use.

These results highlight a need to determine how 
young offender crimes are viewed. The failure of juvenile court authorities under the Young offenders Act (1980-83) to impose more severe sanctions may say less about their views regarding the treatment of juveniles than about their views regarding the nature of injuries that are deserving of more severe penalties.

Smith and Hed (1979) found that older females were judged more harshly than young females for the crimes of swindle and burglary. They suggest that "perhaps there is a feeling of not wanting to spoil a young person's future and therefore the young person is given the benefit of the doubt. However, older persons may not be seen as having much of a future left, so why worry about them" (p.693).

Young (1989) points out that it is:

difficult to distinguish between our treatment of adult and young offenders except on the basis that the duration of sentence is usually less in the case of the youth. However, the manner of arriving at the applicable sentence appears no different in youth and adult court, as the judges appear to be guided by the same considerations and principles. The appellate courts have not successfully developed sentencing principles that promote a unique identity for juvenile justice. The special needs of young people are constantly alluded to but the courts appear uncertain as to what exactly these special needs are and how it is that these special needs can be translated into a distinct penal philosophy (p.104). 
Thus, it can be consistently seen that young offenders receive more lenient sentences than older offenders. For this reason, the present research focused solely on the sentencing of young offenders to determine if there is variability within this age group that depends upon the following factors.

\section{Gender of offender}

In everyday language, custom, laws, and organizations, females are frequently stigmatized as deviant from gender norms (Reitsma-street, 1991). They are considered less assertive, smart, strong, and creative than males: as well, they are labelled less beautiful, thin, caring, demure, nurturing or too bold, sexual, or aggressive than is expected of females.

The main reason that delinquency in female adolescents will be distinguished from delinquency in male adolescents is the differential sentencing of females (Henggeler, 1989). Recent examination of adolescent misconduct using self report delinquency data, as opposed to official statistics, indicate that female delinquency resembles more closely that of males in terms of rates, types, and patterns of deviant behaviour (Gomme, 1993). However, males are somewhat more frequently involved in delinquency and are more likely to engage in delinquent activities involving physical aggression (Henggeler, 1989; Gomme, 1993). 
Meeker, Jesilow, and Aranda (1992) looked at community sentencing of 106 first-time offenders to determine whether there existed any ethnic or gender bias. They determined that males were more likely than females and Hispanics were more likely than whites to receive a more severe sentence. "clearly the ethnicity and the sex of defendants are influencing discretionary decisions of where to place defendants in the alternative sentencing program" (p.202). They concluded that bias, if it exists, is most likely to occur when there is greater discretion by judges.

Most studies of the correlates of delinquent behaviour have examined samples of males. Of those that have examined female delinquents in comparison to their male counterparts, no significant differences were found between the two groups on risk factors for delinquency such as family or parental problems, school difficulties, temperament or misconduct problems, and endorsement of antisocial attitudes and antisocial peers (Henggeler, 1989 ; Simourd, Andrews, \& Hoge, 1993).

Thus, it appears that male and female adolescents are treated differently by the juvenile justice system independent of the prevalence, incidence, and correlates of their behaviour. Hoge, Andrews, and Leschied (1993) found that girls were somewhat less likely to receive a custody disposition than boys. It may be that female 
delinquency is concentrated in a smaller number of offence categories such as sexual promiscuity, incorrigibility, and running away from home (Gomme, 1993; Reitsma-street, 1991).

Armstrong (1977, cited in Henggeler, 1989) has argued that the disparate treatment of girls is the result of misguided chivalry and paternalism, and that many juvenile justice officials hold a double standard of morality that severely sanctions the sexual misconduct of girls. Likewise, Chesney-Lind (1977, cited in Henggeler, 1989) has suggested that the police tend to release girls accused of criminal activity (to avoid social stigma), but tend to arrest girls suspected of status offenses (especially sexual acting-out). This may be because parents are more likely to initiate police intervention for the incorrigibility of girls than of boys. Thus, the relatively harsh treatment of female delinquents is thought to result from differential parental expectations for the behaviour of girls versus boys, and from the discrimination and paternalism of the police and juvenile justice authorities.

Perhaps it is gender stereotypes that lead to differential sentencing. However, it appears that the results are mixed. Some studies report that females are treated more harshly than males, others report the opposite. There is evidence to suggest that the 
treatment of males and females depends on the types of crime with which they are charged (Reitsma-street, 1991). For this reason, the present research looked at personal, property-related, drug-related, and sexual offenses to determine whether the differential sentencing pattern for males and females depends upon the type of crime committed.

\section{Prior Record}

If one can derive anything form court of Appeal decisions, it is that in terms of the custody decision, the record of the young person is very important (Doob, 1989). As noted previously, measures of seriousness of the conviction offense and prior criminal record are strong correlates of sentences (Gottfredson et al.. 1989). This was also seen in the above studies by 2 amble and Kalm (1990) and Gebotys and Roberts (1987).

Wear (1984) asked 644 undergraduates to assign sentences to adult male or female defendants convicted of homicide, child molestation, embezzlement, fraudulent issuance of checks, heroin possession, and consensual homosexuality. Defendants had a reported history of psychiatric hospitalization, imprisonment, or neither. The results indicated that the sex of the defendant influenced sentenci.ig dispositions only in child molestation cases and, generally, harsher sentences were given to those with a prior criminal history. No 
differences were found in the sentencing patterns of male and female respondents.

Thus, prior record is a major contributing factor to the sentence assigned and was included in the present study.

\section{Type of crime}

Studies of sentencing have typically and consistently found some measure of offense seriousness to be an important correlate of dispositions (Gebotys \& Roberts, 1987; Diamond \& Stalans, 1989; Gottfredson et al., 1989; Zamble \& Kalm, 1990).

Gebotys and Roberts (1987) determined that seriousness of the offense was one of two major predictors of the severity of assigned sentences. Macrae and sheperd (1989) determined that the important factor contributing to respondents' sanctioning judgements was the nature of the crime. Participants recommended harsher punishments when the crime was considered to be serious and when it was likely to recur in the future. Diamond and stalans (1989) found that cocaine sale was rated as more serious than burglary and that aggravated battery is seen as more serious than robbery-assault. Finally, Zamble and Kalm (1990) found that assigned sentences increased with the increasing seriousness of the offense.

More consistency than variation is noted in types of 
crimes charged against females (Reitsma-street, 1991). over time and place, there is consistency in the infrequency of and distinctly nonviolent and nonaggressive nature of delinquencies by girls. The number of females who are arrested, however, varies by race, class, and residence. Real variatious by race, place, or class, as noted in official statistics, are not as striking in self-report studies. Girls, however, are treated more harshly than boys. Armstrong (cited in Henggeler, 1989) noted that more than 508 of incarcerated girls had not been arrested for criminal offenses, in comparison with 208 of incarcerated boys. Moreover, girls tended to be incarcerated for longer periods of time than boys. similarly, girls charged with status offenses were

treated more harshly than girls charged with crimes, and the status offenses of girls often received more drastic intervention than the criminal activities of boys.

Thus, the severity of an offense both predicts the severity of an assigned sentence and fuels public reactions. For this reason, the present study looked at the four offenses of break and enter, assault, prostitution, and drug-trafficking.

\section{Family Functioning}

While theories of male delinquency emphasize the etiological importance of peer relations and academic- 
career achievement, theories of female delinquency stress the roles of personality deficits and of dysfunctional family relations (Henggeler, 1989). However, research has not provided consistent support for the assumption that family relations are more important determinants of female delinquency than of male delinquency (ReitsmaStreet, 1991; simourd, 1993).

Henggeler (1989) found that family structure was highly related to the response of police and others to girls' delinquent behaviour. Reitsma-street (1991) suggests that sentencing may be heavier for girls if police, judges, or counsellors determine that the girl does not have strong ties to her family home. Almost all female young offenders are alike in that they commit a variety of delinquencies, but they do so infrequently. In a review by Reitsma-street (1991), delinquent behaviour in girls was found to be statistically more frequent if there was 1) an increase in sociodemographic, family, child-risk factors, such as subsidized housing, domestic violence, and poor friendships; 2) weakened bonding to family, school, and the law; and 3) increased participation in subcultural groups and activities.

Horwitz and Wasserman (1980) examined the extent to which a juvenile court uses legal, substantive, and discriminatory criteria in assessing dispositions. Indicators of substantive criteria were the presence of 
family and school problems. After examination of the dispositions given to 464 fourteen and fifteen year old young offenders, the results indicated that the court was as likely to use substantive criteria for decision-making as it is to use arrest history. More severe dispositions were given to those with family and school problems. Also, judges hardly ever institutionalized juveniles who have no record of family or school problems. However, of the 37 juveniles that had problems, 34 were placed in an institution.

Tolan and Lorion (1988) surveyed a sample of 337 adolescent males for demographic, individual, school, and familial functioning and delinquency status in order to predict delinquency proneness. Family functioning characteristics included cohesion, conflict, expressiveness, independence, achievement orientation, intellectual/cultural orientation, activity-recreation orientation, moral-religious emphasis, organization, and control. They determined that the only other significant stable variables, besides age of onset, were those related to family system characteristics. It appeared that lower levels of family conflict, higher family interdependence or cohesion, and greater emphasis on moral-religious ethics related to lower levels of delinquency.

Wells and Rankin (1991) performed a meta-analysis of 
existing research on broken homes and delinquency. One of their substantive findings from the 50 studies analyzed was that the effect of intact versus "broken" families demonstrates a consistent and real pattern with broken homes having a prevalence of delinquency 10-15 percent higher than intact homes. They also found that the correlation between broken homes and delinquency is stronger for minor forms of misconduct (i.e., status offenses) and weakest for serious forms of criminal behaviour (i.e., theft and interpersonal violence). There were no consistent or appreciable differences in the impact of broken homes between girls and boys.

Straus' (1991) Cultural Spillover Theory states that "violence in one sphere of life tends to enfender violence in other spheres, and that this carry-over

process transcends the bounds between legitimate and criminal use of force" (p.137). Using data from 3300 children and 6000 couples, straus performed a preliminary test of this theory. His results supported the theory in that, although physical punishment produced conformity in the immediate situation, it tended to increase the probability of deviance, including delinquency in adolescence and violent crime inside and outside of the family as an adult. Significantly more children who were physically punished engaged in both violent crime and property crime. These results remained when physical 
punishment by the father was used as the independent variable. Further, a study by Mccord (1991) suggests that the combined impact of a criminal father using physical punishment increases the likelihood that their sons will also become criminals.

In a critique of straus (1991), Kurz (1991) points to the failure of cultural spillover Theory to demonstrate how the physical punishment of children results in the adult use of violence towards children, spouse abuse, assault, and homicide. Kurz also points to the failure of the model to take into account the effects of gender, class, and race for interpreting an individual's experience and use of violent acts. Kurz suggests that the "pathway of violence by adults is heavily linked to gender" (p.157). For example, some girls who may have been influenced by physical punishment as they were growing may commit child abuse, comparatively few will commit spouse abuse, assault, and homicide. Also, some boys who may have been influenced by physical punishment will as adults commit child abuse, wife battery, assault, and humicide.

Thus, family problems play a role both as a risk factor for delinquency and in the sentencing decision. The present study aimed to clarify this role and determine, specifically, whether a history of physical abuse by the father will have more of an impact on the 
sentences of male or female young offenders.

The purpose of the present study was to determine: a) whether male and female young offenders would be given similar sentences depending on the type of crime committed, their prior record, and whether there was a history of physical abuse by the father; and b) the impact of these individual components on sentencing decisions and their interactions. The within-subjects independent variables used were: 1) gender of offender; 2) type of crime (assault, break and enter, prostitution, and drug trafficking); and 3) family functioning (no abuse, history of familial physical abuse by the father). The between-subjects independent variable was prior record (none, one theft under $\$ 1000$ ). The dependent variables were the type and length of sentence given (absolute discharge; fine; community service order; probation; and custody). Each of the 32 crime vignettes represented all possible combinations of independent variables.

It was hypothesized that there would be: a) a gender main effect (males would be given harsher sentences); b) a type of crime main effect (harsher sentences would be given for more serious offenses): c) A prior record main effect (offenders with prior records would be given harsher sentences); d) a family functioning main effect (more severe sentences would be given to those with a 
history of physical abuse); and e) several interactions between the four variables. specific hypothesized interactions included the harshest sentences for male offenders with prior records committing assault, break and enter, and drug trafficking and having a history of physical abuse. The most lenient sentences were hypothesized for female offenders without a previous criminal record that commit assault, break and enter, and drug trafficking without a history of physical abuse. It was also hypothesized that females convicted of prostitution would receive harsher sentences than males convicted of the same offense.

Method

\section{Participants}

Participants were 40 male and 40 female Carleton University students. Some participants were recruited through the psychology 100 subject pool and given one experimental credit for their participation. others volunteered after posters were distributed throughout the Carleton University residence complex. No deception was involved in the present study. Participants received both verbal and written assurance of the anonymity and confidentiality of their responses and advised of their right to terminate their participation at any stage of the survey without penalty.

The mean age of the respondents was 20.45 years, 
ranging from 18 years to 30 years. Male and female respondents did not significantly differ with respect to age. Further, participants in both conditions of the between-subjects factor of Prior Record did not differ in age.

\section{Measures}

Each of the thirty-two offense vignettes were printed on a separate page. There were two booklets (Appendix A) containing sixteen vignettes each. All booklets sampled the four types of crime for each gender and each level of abuse. However, the two levels of the Prior Record factor were represented separately in each booklet. After each vignette, participants were asked to assign an appropriate sentence and to rate, on a 7-point scale, the importance of each of six sentencing goals. Vignettes were randomly organized within each booklet to avoid any ordering bias. As well, the ordering of each factor within the vignettes was randomized.

Section $B$ of the survey required participants to rate each of the four factors in the order that they felt was most important. Respondents were also asked whether they felt that they would have liked to have had more information (i.e., victim gender, victim age, victim harm, premeditation of the crime, etc.) before making their sentencing judgement. The final question for this section involved participants' weighting of 19 offence 
categories between 0 (absolute discharge) and 100 (two years secure custody). The mean of these weights were tabulated to form a weighting scale representing all combinations of sentence type and sentence length that participants had assigned to the vignettes.

Finally, Section $c$ involved questions regarding the criminal past and victimization experience of the participants, their family, and their close friends.

\section{Procedures}

All participants were given a brief verbal

explanation of the survey and its purpose and were told of their option to terminate their involvement at anv time without consequence. They were then advised of the anonymity and confidentiality of their responses and were required to sign a consent form (Appendix B). The only personal information that was requested was their gender and age. The survey took approximately 45 minutes to complete.

In addition to written instructions, verbal instruction with a demonstration were given to assure that participants understood the task in each section of the survey.

After the survey was completed, respondents were given a debriefing form (Appendix C) with information about who to contact with questions or concerns or if they would like to know the final results. 
Results

Two sets of Analysis of Variance were performed. The first was based on the assigned sentence weights from section B of the survey, the other solely on sentence types. Due to the presence of several outliers in the former analysis, only the latter will be discussed. However, the analysis using the sentence weights can be found in Appendix D. Analyses of sentence types were based on Scheffe-corrected F-values.

Analyaes Vaing Bentence Types

The seven sentence types were absolute discnarge, fines, compensation, community service orders, probation, open custody, and secure custody. Results indicate that there were significant main effects for the betweensubjects factor, Prior Record, and the within-subjects factors of Type of Crime and Family Functioning. Summaries of these main effects are presented in Table 1. The two-way interaction of Prior Record $x$ Offender Gender just reached significance (refer to Table 2). Results indicate that females with a prior record and males without a prior record received harsher sentences than their opposite-sex counterparts.

Two three-way interactions were also significant: Prior Record $x$ offender Gender $x$ Type of Crime and Prior Record $x$ Type of Crime x Family Functioning. Plots of these interactions are presented in Figures 1 through 4. 
Table 1: Main Effects of the Analysis of Sentence Types

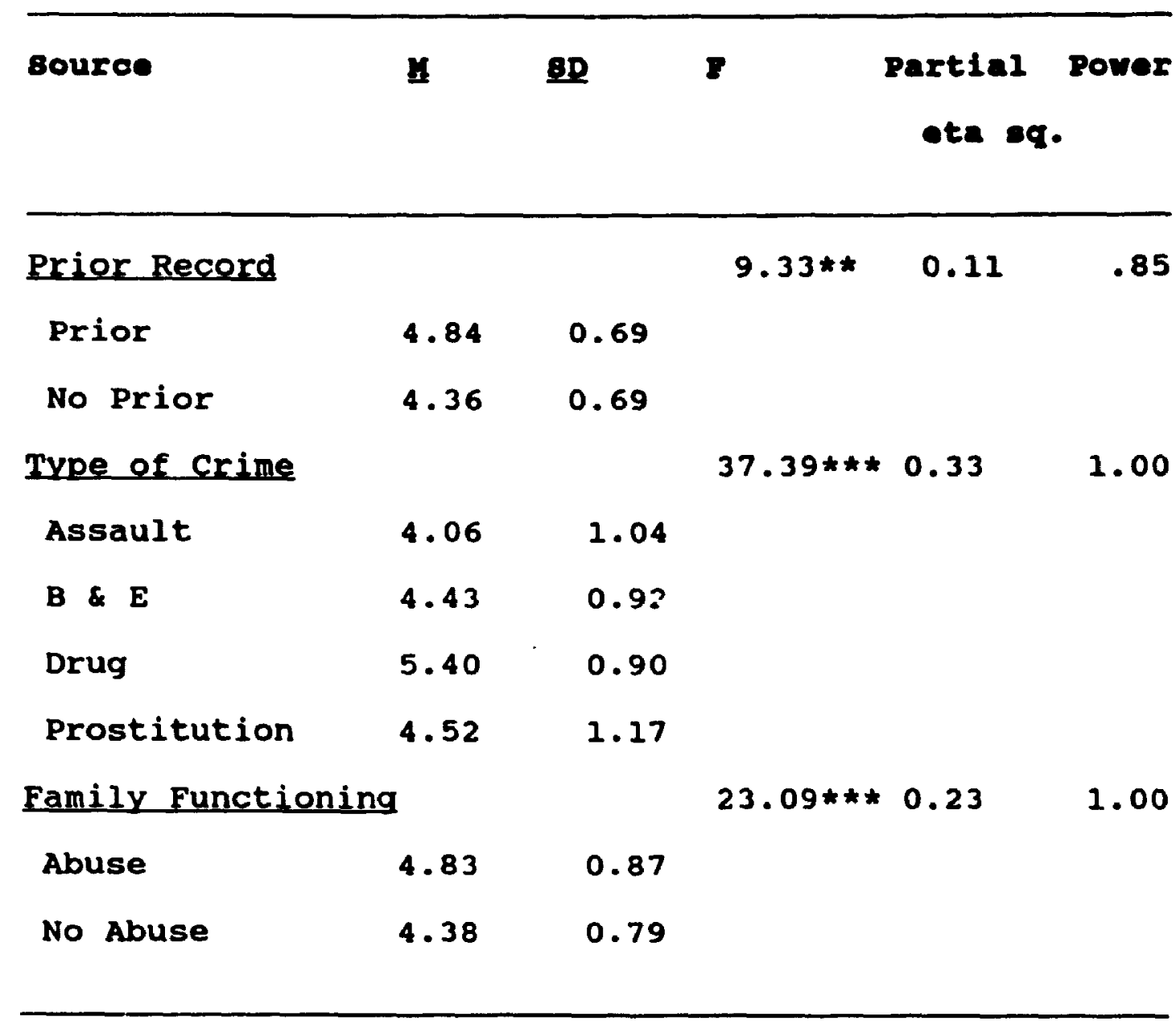

$* \underline{p}<.01$

$\star * \underline{p}<.001$

$\star \star \star \mathrm{Q}<.0001$ 
Table 2: Prior Record x Offender Gender Interaction

\begin{tabular}{|c|c|c|c|c|c|}
\hline \multirow[t]{3}{*}{ souroe } & \multirow[t]{3}{*}{$\mathbf{4}$} & \multirow[t]{3}{*}{ SD } & \multirow{3}{*}{$\frac{z}{3.95 \star}$} & \multirow{3}{*}{$\begin{array}{c}\text { Partial } \\
\text { eta oq. } \\
.05\end{array}$} & \multirow{3}{*}{$\begin{array}{r}\text { Powar } \\
.50\end{array}$} \\
\hline & & & & & \\
\hline & & & & & \\
\hline PriorxMale & 4.78 & 0.75 & & & \\
\hline PriorxFemale & 4.90 & 0.68 & & & \\
\hline NoPriorxMale & 4.40 & 0.64 & & & \\
\hline NoPriorxFemale & 4.33 & 0.80 & & & \\
\hline
\end{tabular}

$\star \underline{p}=.05$ 


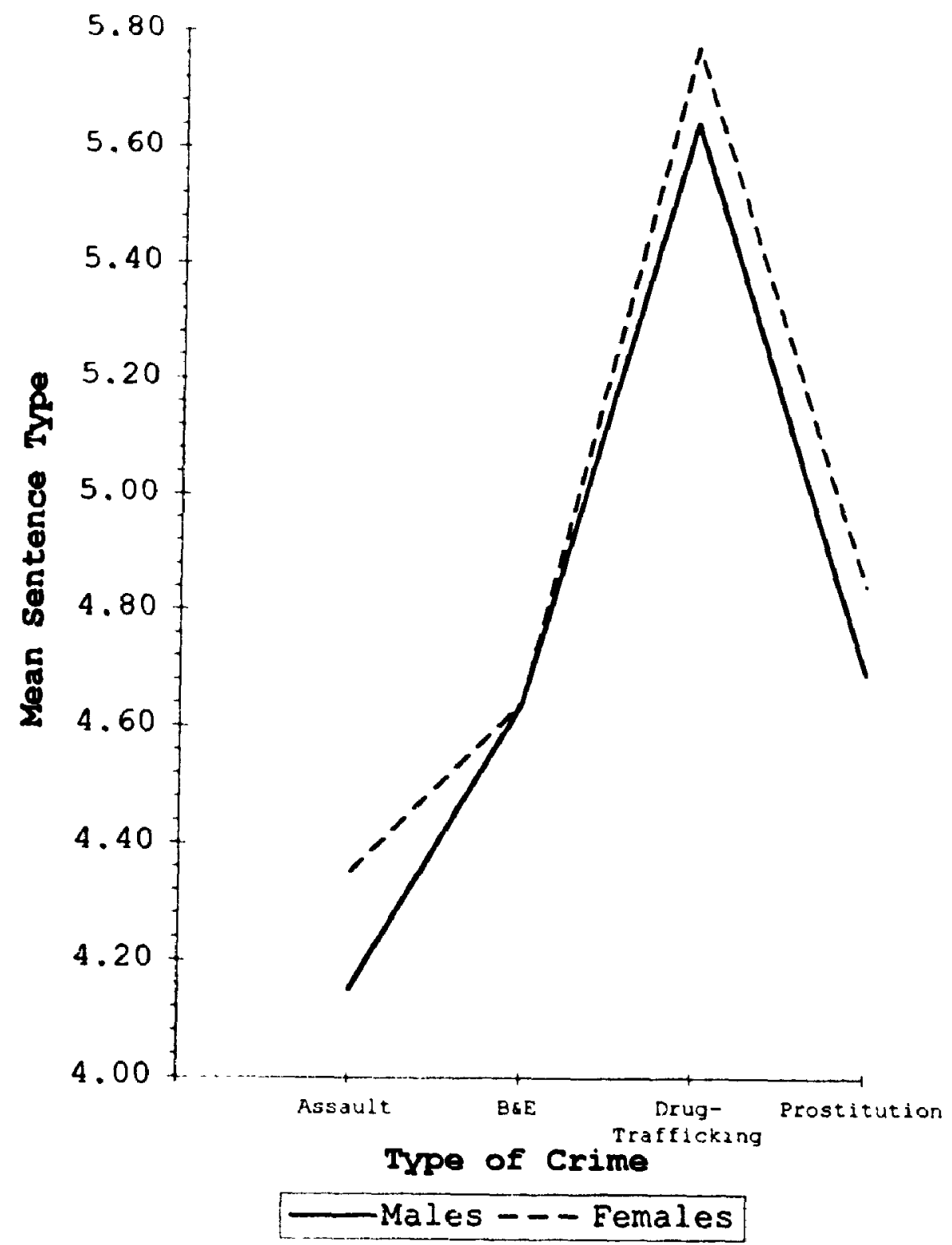

Figure 1: Two-way Interaction of offender Gender $\times$ Type of Crime for the Prior Record Condition 


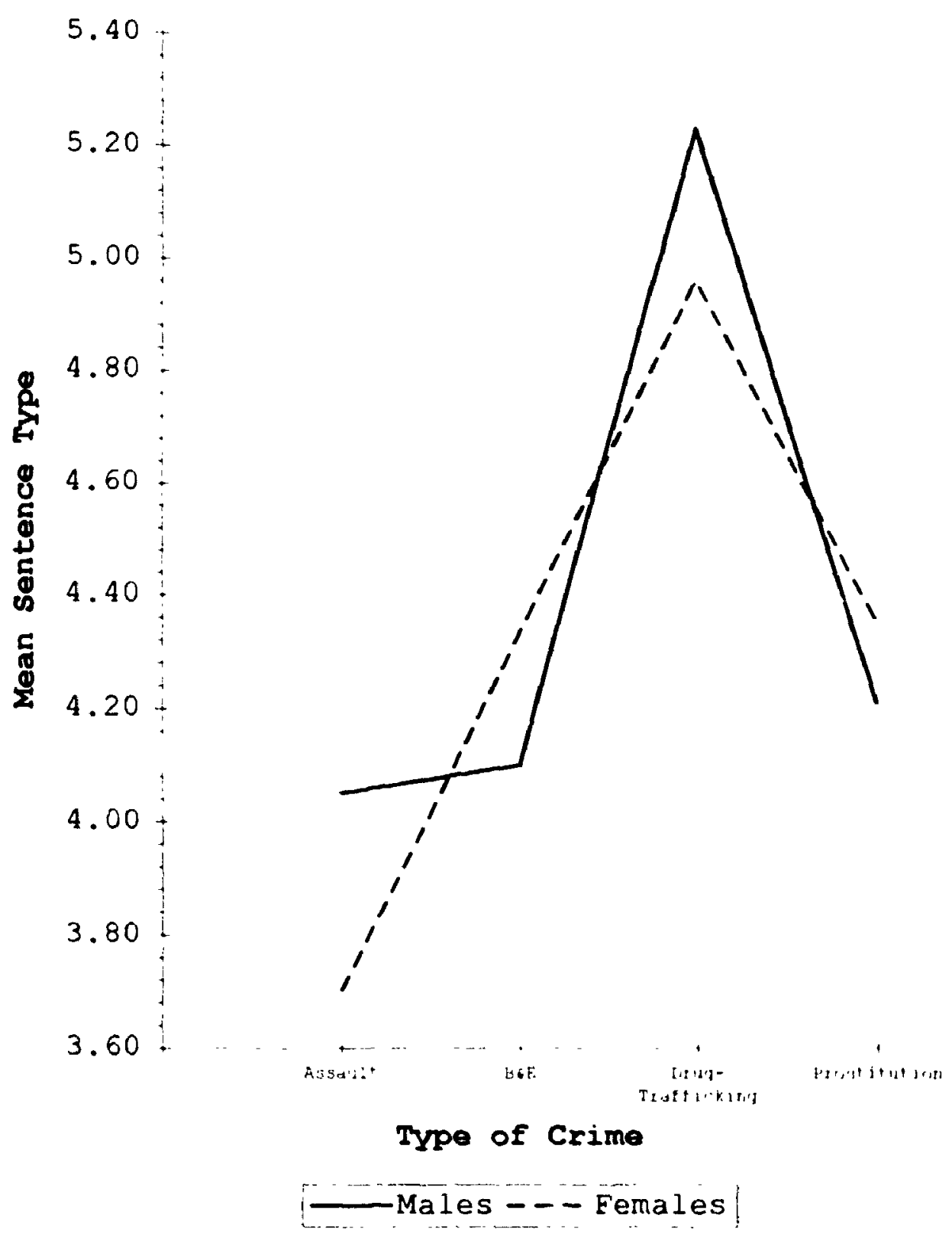

Figure 2: Two-way Interaction of offender Gender $x$ Type of Crime for the No Prior Record Condition 


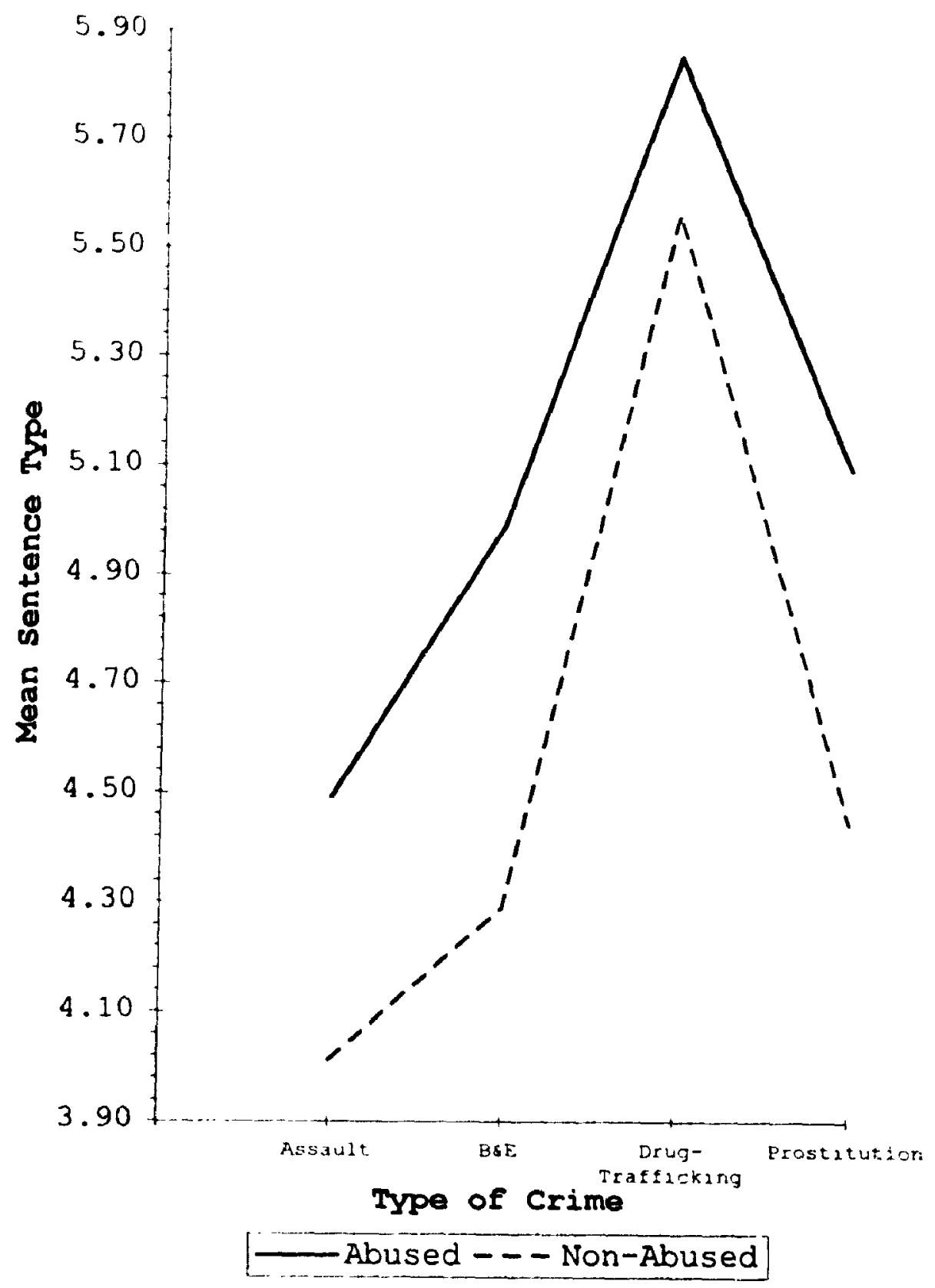

Figure 3: Two-way Interaction of Type of Crime $x$ Family Functioning for the Prior Record Condition 


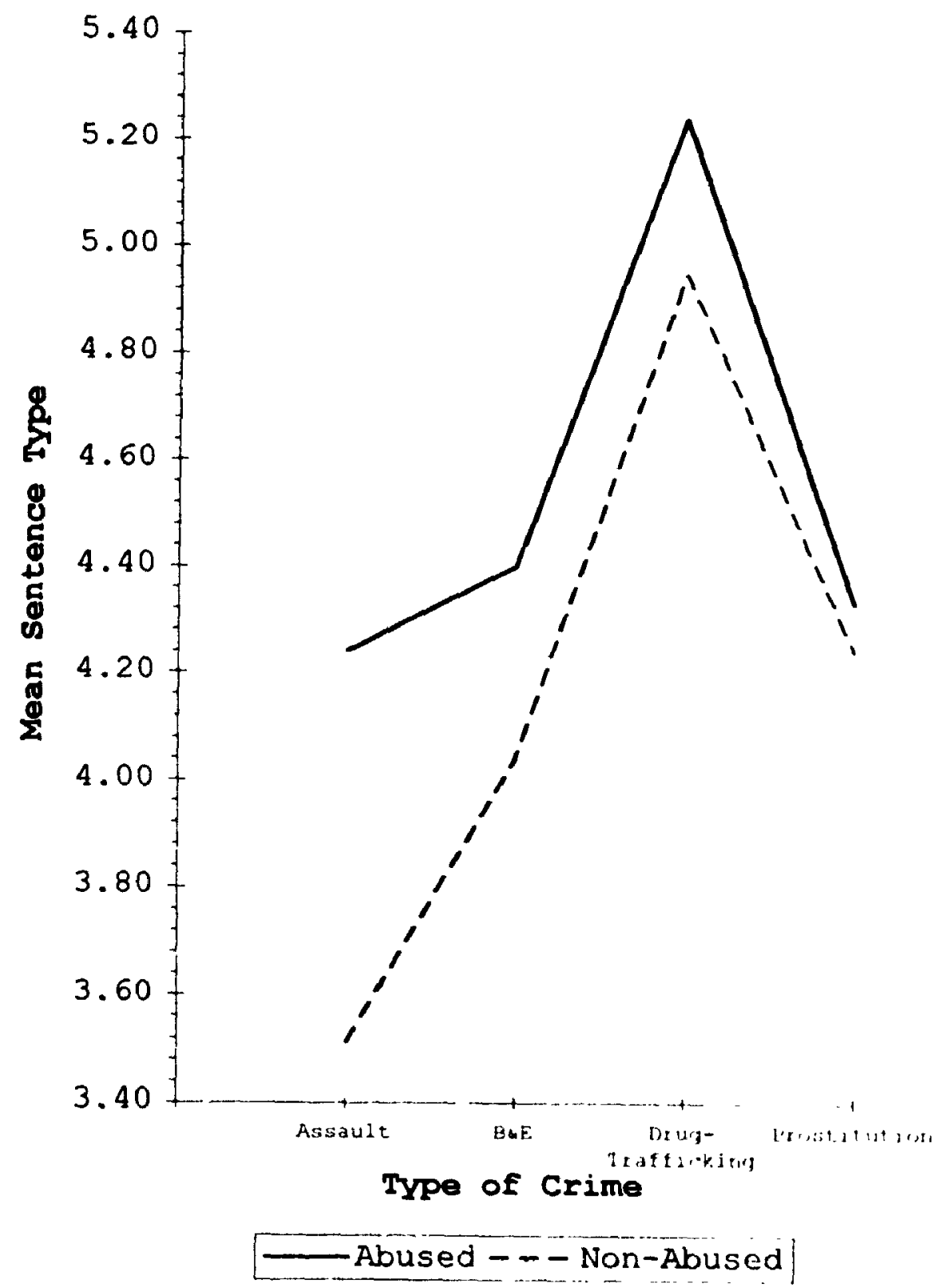

Figure 4: Two-way Interaction of Type of Crime $x$ Family Functioning for the No Prior Record Condition 
For the Prior Record $x$ offender Gender $x$ Type of Crime interaction, in general, offenders with a prior record received harsher sentences than those without and offenders convicted of drug-trafficking received more severe sentences than those convicted of other offenses. The summaries for this interaction are presented in Table 3 .

For offenders with a prior record, females received harsher sentences for assault, drug-trafficking, and prostitution. Males and females with a prior record received equally harsh sentences for $B \& E$. Male offenders without a prior record received harsher sentences for assault and drug-trafficking and females received harsher sentences for B\&E and prostitution. The harshest sentences were given to female offenders with a prior record convicted of drug-trafficking. The lightest sentences were given to female offenders without a prior record convicted of assault.

For the Prior Record $x$ Type of Crime $x$ Family Functioning interaction, abused offenders with and without a prior record consistently received harsher sentences than non-abused offenders with and without a prior record, respectively. Refer to Table 4 for the summaries of this interaction.

Further, offenders with a prior record, in general, received harsher sentences than those without a prior 
Table 3: Three-Way Interaction of Prior Record $x$ offender Gender $x$ Type of crime



$$
\star 2=.05
$$


Table 3 continued

Legend:

Pri= prior record

NoP= no prior record

Mal $=$ male

Fem $=$ female

Drug= drug trafficking

Prost/Prostit= prostitution 
Table 4: Three-Way Interaction of Prior Record $x$ Type of Crime $x$ Family Functioning

\begin{tabular}{|c|c|c|c|c|c|}
\hline \multirow{2}{*}{ Bource } & \multirow[t]{2}{*}{$\underline{4}$} & \multirow[t]{2}{*}{$\underline{\mathbf{B D}}$} & \multirow{2}{*}{$\frac{P}{2.95 \star}$} & \multirow{2}{*}{$\begin{array}{c}\text { Partial } \\
\text { eta }=9 \\
.04\end{array}$} & \multirow{2}{*}{$\begin{array}{r}\text { Pover } \\
.69\end{array}$} \\
\hline & & & & & \\
\hline PrixAssaultxAbu & 4.49 & 1.39 & & & \\
\hline PrixAssaultxNOAb & 4.01 & 0.96 & & & \\
\hline PrixB\&ExAbu & 4.99 & 1.17 & & & \\
\hline PrixB\&ExNOAb & 4.29 & 1.04 & & & \\
\hline PrixDrugxabu & 5.85 & 0.78 & & & \\
\hline PrixDrugxNOAb & 5.56 & 1.12 & & & \\
\hline PrixProstitxAbu & 5.09 & 1.05 & & & \\
\hline PrixProstitxNOAb & 4.44 & 1.21 & & & \\
\hline NoPxAssaultxAbu & 4.24 & i. 39 & & & \\
\hline NOPxAssaultxNOAb & 3.51 & 1.28 & & & \\
\hline NOPXB\&EXAbu & 4.40 & 1.03 & & & \\
\hline NOPXB\&EXNOAb & 4.04 & 0.94 & & & \\
\hline NoPxDrugxAbu & 5.24 & 0.97 & & & \\
\hline NOPXDrugxNOAb & 4.95 & 1.00 & & & \\
\hline NoPxProstitxAbu & 4.33 & 1.41 & & & \\
\hline NoPxProstitxNOAb & 4.24 & 1.37 & & & \\
\hline
\end{tabular}

$* \mathrm{p}=.05$ 
Table 4 continued

Legind :

Pri $=$ prior record

NoP= no prior record

Drug= drug trafficking

Prost $/$ Prostit $=$ prostitution

Abu = abuse

NOAb $=$ no abuse 
record. The harshest sentences were awarded to abused offenders with a prior record who were convicted of drugtrafficking. The lightest sentences went to non-abused offenders without a prior record convicted of assault.

The following sections will consider the simple and simple-simple effects of the two significant three-way interactions in order to determine the exact cause of the differences. Simple effects decompose a factorial design into smaller, more analytical components using a set of two-way analyses that hold constant the independent variable not involved (Keppel, 1991). In the present case, the independent variable held constant will be the Prior Record factor. similarly, simple-simple effects decompose simple effects into single-factor experiments.

since simple and simple-simple effects are based on the total number of cases present for each category (minimum of 0 and maximum of 40), and not on mean ratings, each dependent variable was turned into a separate binary variable and used separately in the analyses. So, for example, the two-way interaction of offender Gender $x$ Type of crime for the prior record condition was considered using solely absolute discharge as the dependent variable. This same two-way interaction was also analyzed using each of the other six sentence types. 
Thren-tiny Internotion of Prtor Becord $x$ offender ender

\section{$x$ Tree of crine}

Summaries of the simple and simple-simple effects for the offender Gender $x$ Type of crime interactions for the prior record condition are presented in Table 5. Sigrificant simple effects were found for the following sentence types for the prior record condition:

compensation, community service, probation, and open custody. The simple-simple effects of this analysis revealed that assignment of compensation and community service to male and female offenders differed for the crime of B\&E. Male and female offenders differed in the number of probation dispositions they received for assault and B\&E. Lastly, open custody dispositions differed between male and female offenders for the crimes of B\&E, drug-trafficking, and prostitution.

Summaries of the simple and simple-simple effects for the no prior record condition are presented in Table 6. Significant simple effects were found for the following dependent variables for the no prior record condition: absolute discharge, fines, probation, and open custody. Analyses of the simple-simple effects revealed significant differences in the assignment of absolute discharge for males and females convicted of assault. Assignment of fines differed between males and females convicted of B\&E. Probation dispositions given to males 
Table 5: Simple and simple-simple Effects of the offender Gender $x$ Type of crime Interaction for the prior Record Condition.

\begin{tabular}{|c|c|c|c|}
\hline & $\boldsymbol{r}$ & $\begin{array}{l}\text { Males } \\
\text { M(BD) }\end{array}$ & $\begin{array}{l}\text { Females } \\
y(8 D)\end{array}$ \\
\hline Compensation & $3.93 *$ & & \\
\hline $\mathbf{B} \& \mathbf{E}$ & $13.46 *$ & $2.00(1.41)$ & $5.50 \quad(2.12)$ \\
\hline Community service & $6.23 *$ & & \\
\hline $\mathbf{B} \& \mathbf{E}$ & $33.24 *$ & $13.00(4.24)$ & $7.50 \quad(3.54)$ \\
\hline Probation & $11.28 *$ & & \\
\hline Assault & $22.25 *$ & $9.00(1.41)$ & $13.50(0.71)$ \\
\hline $\mathbf{B} \& \mathbf{E}$ & $9.89 *$ & $12.00(0.00)$ & $9.00(5.66)$ \\
\hline Open Custody & $5.01 \%$ & & \\
\hline B\&E & $33.24 *$ & $8.00(5.66)$ & $13.50(13.43)$ \\
\hline Drug-Traffic & $27.58 *$ & $13.00(7.07)$ & $17.00(12.73)$ \\
\hline Prostitution & $6.87 *$ & $9.50(4.95)$ & $12.00(8.49)$ \\
\hline
\end{tabular}

$\star \underline{p}<.01$ 
and females convicted of assault and $B \& E$ also differed. Finally, males and females convicted of drug-trafficking and prostitution differentially received open custody dispositions.

To summarize, female offenders with a prior record received more severe sentences than their male counterparts for all four offenses. However, females with a prior record also received significantly more compensation and open custody dispositions for B\&E. Their male counterparts received significantly more community service and probation dispositions.

Males without a prior record received the harshest sentences for assault and drug-trafficking. Female offenders without a prior record received the more severe dispositions for $B \& E$ and prostitution.

Three-nay Interaction of Prior Record $x$ Trpe of crime $x$ Pantily Functioning

The simple and simple-simple effects of the threeway interaction of Type of Crime $x$ Family Functioning $x$ Prior Record were also analyzed. The simple and simplesimple effects for the prior record condition are summarized in Table 7. The following dispositions resulted in significant simple effects for the prior record condition: fines, community service, open custody, and secure custody. Analysis of the simple-simple effects resulted in significant differences in the 
Table 6: Simple and simple-simple Effects of the offender Gender $x$ Type of crime Interaction for the No Prior Record Condition.

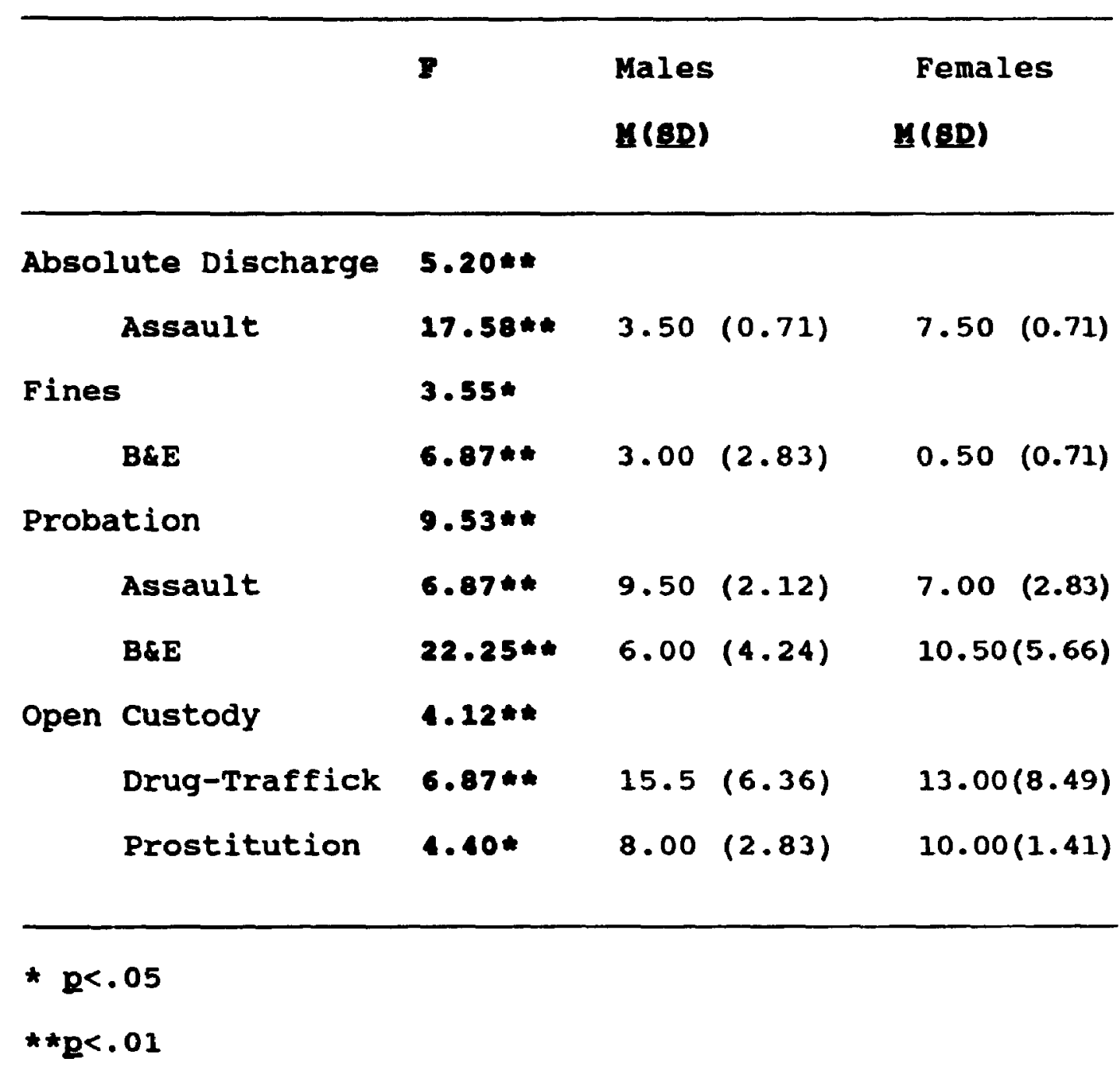


Table 7: Simple and simple-simple Effects of Type of Crime $x$ Family Functioning Interaction for the Prior Record Condition.

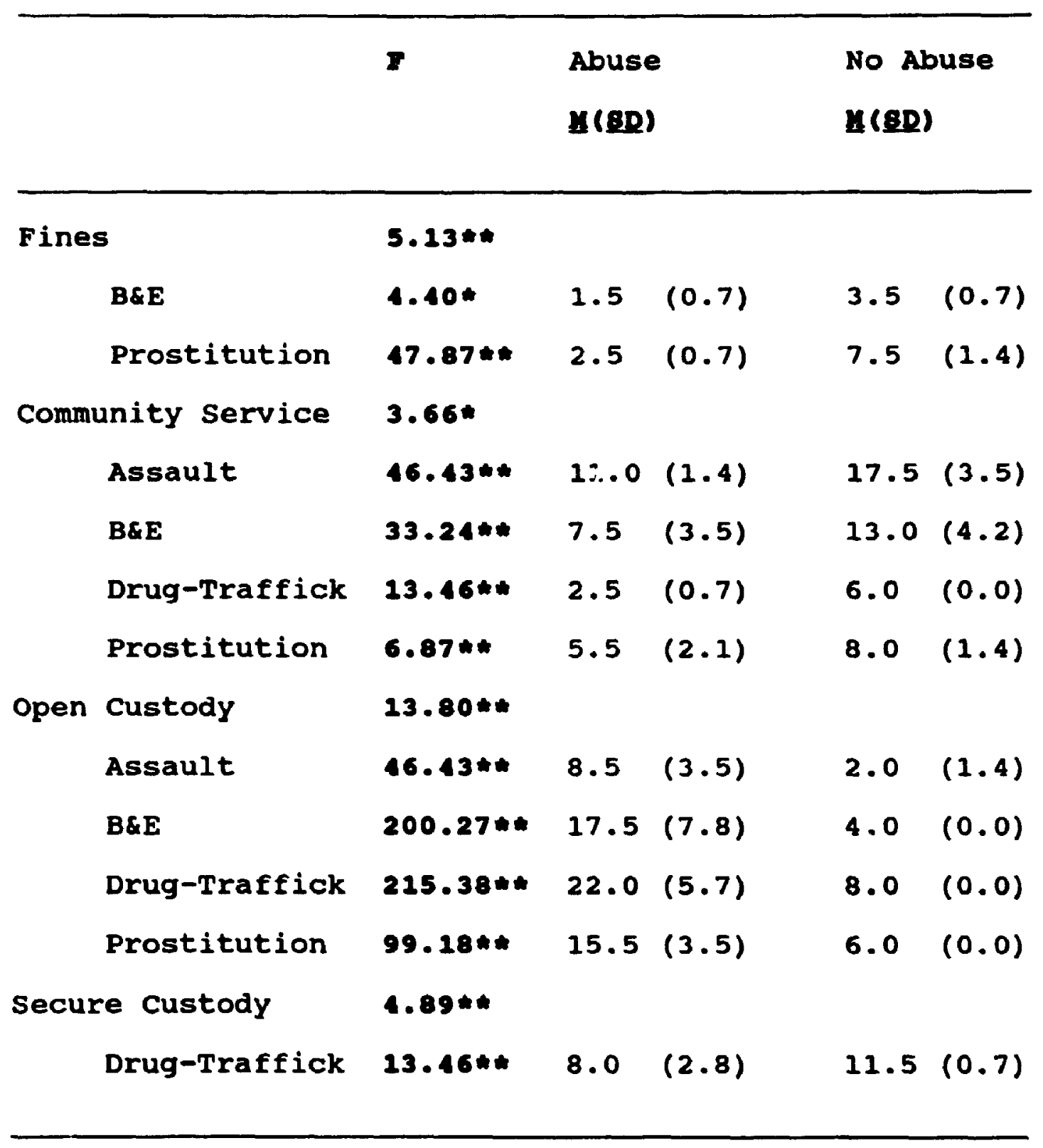

\footnotetext{
* $\underline{p}<.05$

$\star \star \underline{p}<.01$
} 
assignment of fines for abused and non-abused offenders convicted of B\&E and prostitution. Assignment of community service also differed between abused and nonabused offenders convicted of assault, B\&E, drugtrafficking, and prostitution. Abused and non-abused offenders received open custody differer.ily for assault, B\&E, drug-trafficking, and prostitution. Lastly, assignment of secure custody differed for abused and non-abused offenders convicted of drug-trafficking.

Analyses for the no prior record condition are summarized in Table 8 . Results demonstrated significant simple effects for the following dispositions: compensation, community service, probation, and open custody. Analysis of the simple-simple effects for the no prior record condition resulted in significan: differences between abused and non-abuse offenders in their assignment of for the no prior record condition: comsensation for B\&E; community service for assault, B\&E, and prostitution; probation for assault and drugtrafficking; and open custody for assault, B\&E, drugtrafficking, and prostitution.

To summarize, abused offenders with and without a prior record consistently received the harshest sentences for all four offenses with three exceptions. The first is that non-abused offenders with a prior record received the harshest sentence (secure custody) for drug- 
Table 8: Simple arid simple-simple Effects for the Type of crime x Family Functionisg Interaction for the No prior Record Condition.

\begin{tabular}{|c|c|c|c|c|c|c|}
\hline \multirow{2}{*}{\multicolumn{2}{|c|}{ Compensation }} & \multirow{2}{*}{$\frac{F}{4.95 *}$} & \multicolumn{2}{|c|}{$\begin{array}{l}\text { Abuse } \\
\text { M(BD) }\end{array}$} & \multicolumn{2}{|c|}{$\begin{array}{l}\text { No Abuse } \\
\underline{M}(\underline{B D})\end{array}$} \\
\hline & & & & & & \\
\hline & $\mathbf{B} \& \mathbf{E}$ & $13.46 *$ & 10.5 & $(0.7)$ & 7.0 & $(2.8)$ \\
\hline Commu & unity Service & $16.00 *$ & & & & \\
\hline & Assault & $99.18 *$ & 8.5 & $(2.1)$ & 18.0 & $(0.0)$ \\
\hline & $\mathbf{B} \& \mathbf{E}$ & $46.43 *$ & 11.0 & $(1.4)$ & 17.5 & $(2.1)$ \\
\hline & Prostitution & $17.58 *$ & 6.0 & $(0.0)$ & 10.0 & $(1.4)$ \\
\hline Proba & ation & $20.79 *$ & & & & \\
\hline & Assault & $23 \cdot 46 *$ & $1 n .0$ & $(1.4)$ & 6.5 & $(2.1)$ \\
\hline & Drug-Traffick & $46.43 *$ & 9.0 & $(1.4)$ & 15.5 & $(0.7)$ \\
\hline \multirow[t]{5}{*}{ Open } & Custody & $14.10 *$ & & & & \\
\hline & Assault & $99.18 *$ & 11.0 & $(0.0)$ & 1.5 & $(0.7)$ \\
\hline & B\&E & $2: .47 *$ & 8.5 & $(0.7)$ & 3.5 & $(0.7)$ \\
\hline & Drug-Traffick & $121.15 *$ & 19.5 & $(0.7)$ & 9.0 & $(2.8)$ \\
\hline & Prostitution & $9.89 *$ & 10.5 & $(0.7)$ & 7.5 & $(2.1)$ \\
\hline
\end{tabular}

$\star p<.01$ 
trafficking while their abused counterparts received more open custody dispositions. Secondly, abused offenders without a prior record received both the lightest (compensation) and the most severe (open custody) dispositions for B\&E. Lastly, abused offenders convicted of assault received more probation and open-custody dispositions while their non-abused counterparts received more community service.

\section{Bentencing Gosis}

Each sentencing goal was rated on a 7-point scale where 1 =not very important and $7=$ very important. Participants' ratings were averaged across all 32 vignettes for each goal separately. Results indicated that rehabilitation was most often given a rating of 7 with a mean of $5.89(s d=0.83)$. General deterrence was most often given a rating of $4(M=4.41,5 d=1.22)$. Individual deterrence was given most often a rating of 7 with a meall of $5.98(s d=0.73)$. Incapacitation was most often given a rating of 1 although the spread is almost equivalent across all 7 points $(M=3.75, s d=1.22)$. Just deserts was most often given a rating of 1 but had a mean rating of $3.03(s d=1.30)$. Finally, compensation was most often given a rating of 1 but had a mean rating of 3.34 $(s d=1.24)$. The rated importance of each goal for the two three-r.:y interactions are presented in Tables 9 through 12. 
Table 9: Rated Importance of Goals for the offender Gender $x$ Type of crime Interaction at the Prior Record condition.

$\begin{array}{llll}\text { Assault } & \text { B\&E } & \text { Drug } & \text { Prostit. } \\ M(\underline{S D}) & \underline{M}(\underline{S D}) & \underline{M}(\underline{S D}) & \underline{M}(\underline{S D})\end{array}$

\section{Male Offenders}

Rehabilitation $5.2(1.4) \quad 5.9(1.0) \quad 6.1(1.2) \quad 6.2(1.1)$ General

$$
\text { Deterrence } \quad 4.1(1.4) \quad 4.7(1.2) \quad 4.7(1.5) \quad 4.1(1.1)
$$

Individual

Deterrence $\quad 5.7(0.9) \quad 5.9(1.0) \quad 6.2(0.9) \quad 5.9(0.9)$

Incapacitation $3.2(1.6) \quad 3.9(1.7) \quad 4.8(1.5) \quad 3.7(1.7)$

Just Deserts: $3.0(1.2) \quad 3.2(1.3) \quad 3.4(1.6) \quad 2.8(1.4)$

Compensation $\quad 3.6(1.7) \quad 4.0(1.7) \quad 3.5(1.9) \quad 2.7(1.6)$

Female Offenders

Rehabilitation $5.6(1.2) \quad 6.1(1.1) \quad 6.3(0.8) \quad 6.1(1.1)$

General

Deterrence $\quad 3.9(1.2) \quad 4.4(1.1) \quad 4.8(1.4) \quad 4.1(1.4)$ Individual

Deterrence $\quad 5.6(1.1) \quad 6.0(0.9) \quad 6.1(0.9) \quad 5.8(1.1)$

Incapacitation $2.8(1.4) \quad 3.8(1.5) \quad 4.8(1.4) \quad 3.9(1.7)$

Just Deserts $\quad 3.0(1.5) \quad 3.2(1.4) \quad 3.3(1.6) \quad 2.9(1.4)$

Compensation $\quad 3.8(1.6) \quad 4.3(1.8) \quad 3.1(1.7) \quad 2.5(1.6)$ 
Table 10: Rated Importance of Goals for the offender Gender $x$ Type of crime Interaction at the No Prior Record Condition.

$\begin{array}{lllr}\text { Assault } & B \& E & \text { Drug } & \text { Prostit. } \\ \underline{M}(\underline{S D}) & \underline{M}(\underline{S D}) & \underline{M}(\underline{S D}) & \underline{M}(\underline{S D})\end{array}$

Male Offenders

Rehabilitation $5.5(1.1) \quad 5.4(1.5) \quad 6.1(0.9) \quad 6.0(1.3)$ General

Deterrence $\quad 4.0(1.5) \quad 4.7(1.7) \quad 5.1(1.7) \quad 4.3(1.7)$ Individual

Deterrence $\quad 5.7(1.3) \quad 6.2(0.8) \quad 6.2(0.8) \quad 6.0(1.2)$

Incapacitation $3.1(1.5) \quad 3.6(1.7) \quad 4.9(1.6) \quad 3.3(1.8)$

Just Deserts $3.0(1.5) \quad 3.3(1.7) \quad 3.2(1.7) \quad 2.8(1.7)$

Compensation $\quad 4.0(1.9) \quad 5.0(2.0) \quad 2.6(1.8) \quad 1.8(1.0)$

Iomale Offenders

Rehabilitation $5.4(1.2) \quad 5.3(1.0) \quad 5.9(1.2) \quad 6.4(0.7)$

General

Deterrence $\quad 3.7(1.7) \quad 4.5(1.6) \quad 5.1(1.6) \quad 4.1(1.6)$

Individual

Deterrence $\quad 5.6(1.3) \quad 6.0(0.8) \quad 6.5(0.7) \quad 6.1(0.9)$

Incapacitation $3.2(1.8) \quad 3.3(1.6) \quad 4.6(1.4) \quad 3.5(1.7)$

Just Deserts $2.6(1.4) \quad 3.1(1.7) \quad 3.4(1.6) \quad 2.7(1.7)$

Compensation $\quad 3.4(1.9) \quad 4.8(1.8) \quad 2.8(1.7) \quad 1.9(1.1)$ 
Table 11: Rated Impurtance of Goals for the Type of crime $x$ Family Functioning Interaction at the prior Record condition.

\begin{tabular}{lllcc}
\hline Assault & B\&E & Drug & Prostit. \\
$\underline{M}(\underline{S D})$ & $\underline{M}(\underline{S D})$ & $\underline{M}(\underline{S D})$ & $\underline{M}(\underline{S D})$ \\
\hline
\end{tabular}

\section{Abuse}

Rehabilitation $5.8(1.3) \quad 6.1(1.1) \quad 6.4(0.8) \quad 6.2(1.0)$ General

Deterrence $\quad 3.7(1.4) \quad 4.2(1.3) \quad 4.6(1.5) \quad 3.8(1.3)$ Individual

Deterrence $5.5(1.2) \quad 5.8(1.1) \quad 6.1(0.8) \quad 5.7(1.3)$

Incapacitation $3.2(1.6) \quad 3.9(1.7) \quad 5.0(1.3) \quad 4.0(1.6)$

Just Deserts $2.8(1.3) \quad 2.8(1.4) \quad 3.2(1.6) \quad 2.8(1.4)$

Compensation $\quad 3.5(1.5) \quad 3.8(1.8) \quad 3.2(1.7) \quad 2.6(1.6)$

No Abuse

Rehabilitation $5.4(1.1) \quad 5.8(1.1) \quad 6.0(1.1) \quad 6.0(1.1)$ General

Deterrence $4.3(1.3) \quad 4.9(1.1) \quad 4.9(1.3) \quad 4.4(1.2)$ Individual

Deterrence $5.8(0.8) \quad 6.1(0.7) \quad 6.1(0.9) \quad 6.0(0.9)$

Incapacitation $2.9(1.5) \quad 3.8(1.6) \quad 4.6(1.6) \quad 3.6(1.8)$

Just Deserts $3.2(1.4) \quad 3.6(1.6) \quad 3.5(1.6) \quad 3.0(1.5)$

Compensation $\quad 3.9(1.5) \quad 4.4(1.7) \quad 3.4(1.7) \quad 2.7(1.7)$ 
Table 12: Rated Importance of Goals for the Type of Crime $x$ Family Functioning Interaction at the No Prior Record Condition.

$\begin{array}{llcr}\text { Assault } & \text { B\&E } & \text { Drug } & \text { Prostit. } \\ M(\underline{\text { SD }}) & \mathbf{M}(\underline{\mathrm{SD}}) & \mathbf{M}(\underline{\mathrm{SD}}) & \mathbf{M}(\underline{\mathrm{SD}})\end{array}$

\section{Abuse}

Rehabilitation $6.2(0.9) \quad 5.6(1.4) \quad 6.3(1.0) \quad 6.3(1.0)$ General

Deterrence $3.7(1.6) \quad 4.3(1.7) \quad 4.8(1.8) \quad 4.0(1.6)$ Individual

Deterrence $5.7(1.0) \quad 6.1(0.9) \quad 6.3(0.9) \quad 5.9(1.0)$ Incapacitation $3.3(1.8) \quad 3.3(1.7) \quad 4.7(1.6) \quad 3.5(1.8)$ Just Deserts $2.7(1.4) \quad 3.1(1.9) \quad 2.8(1.7) \quad 2.6(1.7)$ Compensatir, $\quad 3.5(1.8) \quad 5.0(1.9) \quad 2.5(1.7) \quad 1.7(1.0)$ No Abuse

Rehabilitation $4.7(1.5) \quad 5.1(1.2) \quad 5.7(1.4) \quad 6.1(1.0)$ General

Deterrence $4.0(1.6) \quad 4.9(1.6) \quad 5.4(1.5) \quad 4.5(1.8)$ Individual

Deterrence $\quad 5.7(1.3) \quad 6.1(0.8) \quad 6.4(0.7) \quad 6.1(0.9)$ Incapacitation $2.9(1.7) \quad 3.6(1.8) \quad 4.8(1.3) \quad 3.3(1.8)$ Just Deserts $2.9(1.5) \quad 3.3(1.7) \quad 3.7(1.8) \quad 2.9(1.7)$ Compensation $\quad 4.0(2.1) \quad 4.8(2.1) \quad 2.9(1.7) \quad 1.9(1.2)$ 
On average, rale offenders with a prior record obtained significant correlations between the sentence type awarded and a mean number of 2.75 goals compared to a mean number of 2.25 goals for their female counterparts. Two-tailed Pearson product-moment correlations were performed between the sentencing goals (rated from 1 to 7 ) and the awarded sentence types (ranked from 1 to 7 ). For the offender Gender $x$ Type of Crime interaction at the prior record condition, results indicate a positive correlation between the type of sentence awarded to male offenders convicted of assault and the goals of rehabilitation $(R=.38, \underline{2}<.05)$, general deterrence $\left(R=.33, Q^{<.05)}\right.$, and incapacitation $(R=.40$, p<.05). For their female counterparts, the only significant correlation was for the goal of rehabilitation $(\mathrm{R}=.54, \mathrm{p}<.001)$. These correlations are presented in Table 13.

For the offense of prostitution, male offenders with a prior record obtained significant correlations for rehabilitation $(R=.32, \quad 2<.05)$, incapacitation $(R=.32$, $\mathrm{p}<.05)$, and compensation $(\mathrm{R}=-.34, \mathrm{Q}<.05)$. Their female counterparts, however, obtained significant correlations for general $(R=.34, R<.05)$ and individual $(R=.41, R<.01)$ deterrence and incapacitation $(R=.53,2<.001)$.

Fewer goals obtained significant correlations with awarded sentence types for both male $(M=1.5)$ and female 
Table 13: Correlations Between Assigned Sent znces and their Corresponding Goals for the Prior Record Condition of the offender Gender $x$ Type of Crime Interaction

Assault B\&E Drug prostit.

\section{Male Offonders}

Rehabilitation .38*

.18

.20

.32 *

General

Deterrence

$.33 *$

.24

$.40 *$

.16

Individual

\begin{tabular}{|c|c|c|c|c|}
\hline Deterrence & .29 & $.32 *$ & .28 & .23 \\
\hline Incapacitation & $.40 *$ & $.45 * \star$ & $.56 \star \star \star$ & $.32 \star$ \\
\hline Just Deserts & .06 & .18 & .26 & -.04 \\
\hline Compensation & -.20 & $-.38 *$ & -.22 & $-.34 \star$ \\
\hline \multicolumn{5}{|c|}{ Fomale offenders } \\
\hline Rehabilitation & $.54 * \star \star$ & .14 & .23 & .06 \\
\hline \multicolumn{5}{|l|}{ General } \\
\hline Deterrence & .04 & $.46 * *$ & $.52 \star \star$ & $.34 *$ \\
\hline \multicolumn{5}{|l|}{ Individual } \\
\hline Deterrence & .29 & .16 & $.41 * \star$ & $.41 * \star$ \\
\hline Incapacitation & .23 & .16 & $.63 \star \star \star$ & $.53 \star \star \star$ \\
\hline Just Deserts & -.15 & .13 & $.41 \star \star$ & .12 \\
\hline Compensation & .15 & -.20 & -.02 & -.21 \\
\hline
\end{tabular}

$\star 2<.05 \quad * \star 2<.01 \quad \star * \star p<.001$ 
$(M=1.0)$ offenders without a prior record. For male offenders without a prior record convicted of assault, significant correlations were found for the goals of rehabilitation $(R=.35,2<.05)$ and incapacitation $(R=.40$, $\mathrm{Q}<.05)$ compared to individual deterrence $(R=.40,2<.05)$ and incapacitation $(R=.40, g<.05)$ for their female counterparts. These correlations are presented in Table 14. Both male $(R=.38, R<.05)$ and female $(R=.36$, p<.05) offenders, without a prior record, who were convicted of prostitution obtained a significant correlation between their awarded sentence types and the goal of incapacitation.

Abused offenders with a prior record obtained a mean of 3.0 significant correlations between their awarded sentence types and the goals assigned to them. In comparison, non-abused offenders: with a prior record obtained a mean of 1.75 significant correlations. These correlations are presented in Table 15. Rehabilitation did not significantly correlate with any of the sentences awarded to any of the four offenses committed by nonabused offenders with a prior record. However, for abused offenders with a prior record, it was a significant correlate for the offenses of assault $(R=.60,2<.001)$ and drug-trafficking $(R=.32,2<.05)$. For abused offenders with a prior record convicted of prostitution, significant correlations were found for 
Table 14: Correlations Between Assigned Sentences and the Corresponding Goals for the No Prior Record Condition of the offender Gender $x$ Type of crime Interaction

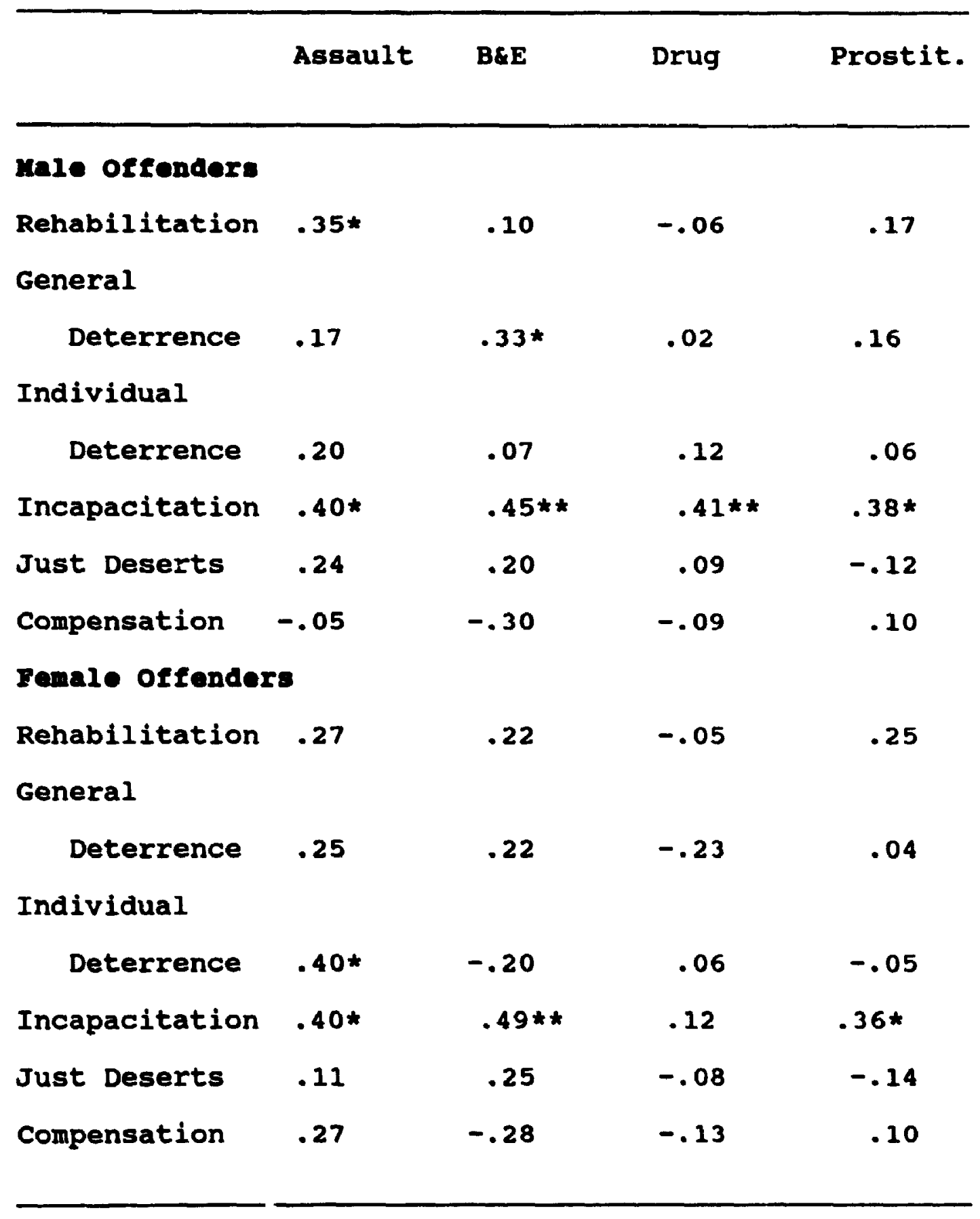

$\star 2<.05 \quad * \star 2<.01$ deserts $(R=.30,2<.05)$ 
Table 15: Correlations Between Assigned Sentences and the Corresponding Goals for the Prior Record Condition of the Type of Crime $x$ Family Functioning Interaction

Assault B\&E Drug Prostit.

\section{Nbuee}

Rehabilitation . $60 * * *$

.22

$.32 *$

.02

General

Deterrence $.19 \quad .33 * \quad .43 * * \quad .22$

Individual

Deterrence . .35*

.21

.32 *

.29

Incapacitation .50**

.38 *

$.45 *$ *

.40 *

Just Deserts $\quad .01$

.25

.20

$.33 *$

Compensation $\quad-.05$

$-.46 \star \star$

$-.11$

$-.19$

No Rbuse

Rehabilitation .17

.08

.20

.30

General

Deterrence $\quad .22$

.23

$.51 \star \star$

.22

Individual

$\begin{array}{rrrrr}\text { Deterrence } & .36 * & .31 * & .37 * & .29 \\ \text { Incapacitation } & .28 & .25 & .68 * * & .44 * \\ \text { Just Deserts } & .08 & .10 & .34 * & -.16 \\ \text { Compensation } & -.15 & -.29 & -.13 & -.27\end{array}$

$\star \mathrm{g}<.05 \quad * \star_{2}<.01 \quad \star \star \star \mathrm{g}<.001$ 
the goals of incapacitation $(R=.40, g<.05)$ and just This is in comparison to solely incapacitation ( $R=.44$, 2<.01) for non-abused offenders.

Abused and non-abused offenders without a prior record had few significant correlations between assigned sentences and their corresponding goals. These correlations are presented in Table 16. Rehabilitation was significant only for non-abused offenders convicted of assault $\left(R=.42, L^{<.01)}\right.$. There were also no significant correlations found for abused and non-abused offenders convicted of drug-trafficking.

Overall, significantly assigned goals were mainly for incapacitation and general deterrence for the Prior Record $x$ offender Gender $x$ Type of Crime interaction. For the Prior Record $x$ Type of Crime $x$ Family Functioning interaction, significantly assigned goals were mainly for incapacitation and individual deterrence.

\section{Bentenoing ouegtione}

Participants were asked to rate the four factors of Prior, Crime, Gender, and Abuse on a 7-point scale in order of importance where $1=$ not very important and $7=$ very important. The mean ratings are presented in Table 17.

Results indicate that the type of crime is regarded as the most important factor and offender gender is the least important factor. Fifty percent $(n=40)$ of 
Table 16: Correlations Between Assigned Sentences and the Corresponding Goals for the No Prior Record Condition of the Type of Crime $x$ Family Functioning Interaction

\begin{tabular}{|c|c|c|c|c|}
\hline & Assault & $\mathbf{B} \& \mathbf{E}$ & Drug & Prostit. \\
\hline \multicolumn{5}{|l|}{ abue } \\
\hline Rehabilitation & .24 & .23 & -.02 & .18 \\
\hline \multicolumn{5}{|l|}{ General } \\
\hline Deterrence & .06 & .23 & -.04 & .21 \\
\hline \multicolumn{5}{|l|}{ Individual } \\
\hline Deterrence & -.03 & -.08 & .04 & .06 \\
\hline Incapacitation & $.49 * \star$ & .30 & .08 & $.36 *$ \\
\hline Just Deserts & -.03 & .16 & -.12 & -.03 \\
\hline Compensation & -.15 & $-.44 * *$ & -.08 & .28 \\
\hline \multicolumn{5}{|l|}{ Mo Mbuse } \\
\hline Rehabilitation & $.42 \star *$ & .04 & -.16 & .16 \\
\hline \multicolumn{5}{|l|}{ General } \\
\hline Deterrence & .28 & .32 & -.17 & .03 \\
\hline \multicolumn{5}{|l|}{ Individual } \\
\hline Deterrence & $.49 * \star$ & -.05 & .05 & -.22 \\
\hline Incapacitation & .30 & $.49 \star \star$ & .18 & $.33 *$ \\
\hline Just Deserts & .27 & .31 & -.03 & -.25 \\
\hline Compensation & .28 & -.21 & -.15 & .00 \\
\hline
\end{tabular}

$\star 2<.05 \quad * \star_{2}<.01$ 
Table 17: Participant Mean Ratings of the Four Factors

\begin{tabular}{lcccc}
\hline & H & SD & min. & max. \\
\hline Offender Gender & 2.04 & 1.36 & 1 & 6 \\
Type of Crime & 6.65 & 0.64 & 4 & 7 \\
Prior Record & 5.79 & 1.15 & 3 & 7 \\
History of Abuse & 5.19 & 1.49 & 1 & 7 \\
\hline
\end{tabular}


participants believed that offender gender was not very important, giving it a rating of 1 , whereas only $2.5 \%$ believed it was importar. (giving offender gender a rating of 6). Fifty-seven respondents (71\%) gave crime a "very important" rating of 7 while only $1.3 \%(n=1)$ gave crime its lowest rating of 4 or "moderately important". Prior record was given a rating of 7 by $35 \%(n=28)$ of participants and its lowest rating of 3 by $1.38 \quad(n=1)$. Abuse was rated as moderately important by 2.1 (26\%) respondents, rot very important by 1 respondent, and very important by $19(24 \%)$.

Participants were also asked to check from a list of options the information they would have liked to have before making their sentencing decision. Their responses are sulmarized in Table 18. The majority of participants would have liked to have known the amount of victim harm (768), the premeditation of the crime (73\%), the specific age of the offender (63\%), and if the offender had any psychological problems (89\%). "Other" information that was requested by $34 \%$ of respondents included the criminality of the family, the tyoe of peers (i.e., social vs antisocial), and the amount of drugs that were found on the offenders convicted of drug trafficking. Only $20 \%$ of the pirticipants wanted information about victim gender, $48 \%$ wanted victim age, and $26 \%$ wanted to know how well the offender was doing in school. 
Table 18: Additional Information Desired ty Participants

\begin{tabular}{|c|c|c|}
\hline & $\mathbf{n}$ & $\$$ \\
\hline Victim Gender & 16 & 20.00 \\
\hline Victim Age & 38 & 47.50 \\
\hline Amount of Victim Harm & 61 & 76.30 \\
\hline Premeditation of Crime & 58 & 72.50 \\
\hline How well offender was & & \\
\hline doing in school & 21 & 26.30 \\
\hline $\begin{array}{l}\text { Specif.c Age of offender } \\
\text { Psychological Problems of }\end{array}$ & 50 & 62.50 \\
\hline Offender & 71 & 88.80 \\
\hline other & 27 & 33.80 \\
\hline
\end{tabular}


For a list of the sentence weights found for the 19 categories of offenses rated in the last part of section B, refer to Appendix E.

\section{Criminal Involvenent as Young offenders}

Nine participants (11\%) were previously convicted as Young offenders with a combined total of 21 convictions. The type of participant convictions are presented in Table 19. Note that "the past 12 months" refers to the time period between January 1, 1994 and January 1, 1995. "Ever" refers to any point in time prior to January 1 , 1994

Correlations were performed between the types of sentences awarded and participants' convictions as young offenders. There was a positive correlation between the sentences awarded to non-abused offenders with a prior record convicted of assault and participants' convictions as young offenders $(R=.35$, p<.05). The same correlation was found for abused offenders with a prior record convicted of drugtrafficking $(R=.32, p<.05)$.

Thirteen (16\%) respondents had family members that had been convicted as Young offenders totalling 27 convictions between them. Four (5\%) were not sure if a family member had ever been convicted. The types of familial convictions are presented in Table 20.

The sentences awarded to the following were 
Table 19: Percentage of Participants' Convictions as Young offenders

Past 12 Honths

Ever

$\begin{array}{lll}\text { once } & 2-5 & 6-10 \\ & \text { times } & \text { times }\end{array}$

\begin{tabular}{lllll}
\hline Assault & 2.5 & 0 & 0 & 3.8 \\
B\&E & 1.3 & 0 & 0 & 7.5 \\
Drug-related & 1.3 & 0 & 0 & 2.5 \\
Sexual & 0 & 0 & 0 & 1.3 \\
Other & 1.3 & 0 & 0 & 5.0 \\
\hline
\end{tabular}


Table 20: Percentage of Family Members' Convictions as Young offenders

Past 12 Monthe

Ever

$\begin{array}{lll}\text { once } & 2-5 & 6-10 \\ & \text { times } & \text { times }\end{array}$

Assault

$1 \cdot 3$

$\mathbf{0}$

6.0

$\mathrm{B} \& \mathrm{E}$

7.5

0

0

7.5

Drug-related

0

0

0

2.5

Sexual

0

0

0

1.3

other

$1 \cdot 3$

0

0

5.0 
correlated with having a family member that was convicted as a young offender: a) males offenders with a prior record convicted of $B \& E(R=.33, \underline{Q}<.05)$; b) females without a prior record convicted of assault $(R=.38$, $\mathrm{Q}<.05)$ and prostitution $(\mathrm{R}=.36, \mathrm{Q}<.05)$; and $\mathrm{c})$ abused offenders without a prior record convicted of assault $(R=.36, p<.05)$, drug-trafficking $(R=.38, p<.05)$, and prostitution $(\mathrm{R}=.48, \mathrm{Q}<.01)$.

Forty-five (56\%) respondents had close friends that were convicted as Young offenders with a total of 103 convictions. Six (7.5\%) participants were not sure if their fri-nds had been convicted as yos. The types of convictions incurred by close friends are presented in Table 21.

The sentences awarded to the following were correlated with having a close friend that was convicted as a young offender: a) males with a prior record convicted of $B \& E(R=.41, p<.01) ; b)$ males without a prior record convicted of assault $(R=.32, \underline{p}<.05)$; c) females without a prior record convicted of assault ( $R=.42$, p<.01): d) abused offender with a prior record convicted of $B \& E(R=.32, \underline{p}<.05)$; e) non-abused offenders without a prior record convicted of assault (R=.42, $\mathrm{Q}<.01)$; I) abused offenders without a prior record convicted of drug-trafficking $(R=.36, \quad \mathrm{R}<.05)$.

In sum, participants' and family members' 
Table 21: Percentage of Friends' Convictions as Young offenders

past 12 Months

once

$2-5$

times
Ever

$6-10$

times

\begin{tabular}{lllll}
\hline Assault & 15.0 & 5.0 & 2.5 & 18.0 \\
B\&E & 3.7 & 6.0 & 1.3 & 25.0 \\
Drug-related & 9.0 & 5.0 & 0 & 13.0 \\
Sexual & 1.3 & 0 & 0 & 5.0 \\
Other & 9.0 & 0 & 0 & 11.0 \\
\hline
\end{tabular}


convictions as YOs were mainly for B\&E. Friends' convictions were mainly for assault. There does not appear to be any clear pattern between criminal involvement and sentences awarded.

\section{Iictinization Experience}

Twenty-one (26\%) participants had been victims of a yo with 41 instances between them. Ten (13\%) were not sure if they were victimized by a yo. The types of participant victimization experience are presented in Table 22. Two (2.58) participants were victims of a sexual offenses in the last year: one (1.3\%) was victimized 2-5 times and the other was not sure how many times. There were two significant correlations between the types of sentences awarded to offenders and having been victimized by a young offender. The first was for femsle offenders without a prior record convicted of $B \& E$ $\left(R=-.34, Q^{<.05}\right)$. The second was for non-bused offenders without a prior record convicted of assault $(R=.40$, $2<.05)$

sixteen (20\%) respondents had family members victimized by yos for a total of 27 instances. Nineteen were not sure if their family members were victimized by yos. The types of victimization experience by family members are presented in Table 23. There were no significant correlations found between the sentence types awarded to offenders and having family members that were 
Table 22: Percentage of Participants Victimized by Young of fenders

Past 22 Months

Ever

$\begin{array}{lll}\text { once } & 2-5 & 6-10 \\ & \text { times } & \text { times }\end{array}$

Assault

6.0

1.3

$\mathbf{0}$

10.0

B\&E

10.0

3.7

0

8. 0

Sexual

0

$1 \cdot 3$

0

2.5

other

2.5

0

$1 \cdot 3$

3.8 
Table 23: Percentage of Family Members victimized by Young offenders

past 12 Months

$\begin{array}{lll}\text { once } & 2-5 & 6-10 \\ & \text { times } & \text { times }\end{array}$

\begin{tabular}{lllll}
\hline Assault & 2.5 & 0 & 0 & 3.8 \\
B\&E & 10.0 & 1.3 & 0 & 9.0 \\
Sexual & 0 & 0 & 0 & 2.5 \\
Other & 1.3 & 0 & 0 & 3.8
\end{tabular}


victimized by young offenders.

Thirty (38\%) respondents had friends that were victimized by a yo with a total of 65 instances. The types of victimization experienced by close friends are presented in Table 24. The sentences awarded to the following were correlated with having a close friend that was victimized by a young offender: a) males w:th a prior record convicted of $B \& E(R=.35, \underline{Q}<.05)$ and drugtrafficking $(R=.37, p<.05)$; b) female offenders with a prior convicted of drug-trafficking ( $R=.40, \underline{Q}<.05)$; c) abused offenders with a prior record convicted of assault $(\mathrm{R}=-.39, \mathrm{Q}<.05)$; d) non-abused offenders with a prior record convicted of $B \& E(R=.31, \underline{Q}<.05)$; and e) non-abused offenders with a prior record convicted of drugtrafficking $(R=.38, p<.05)$.

To summarize, B\&E was the main type of victimization experienced by participants and their family members. Assault was the main type of victimization experienced by friends. Again, there does not appear to be a clear pattern between sentences awarded to offenders and victimization experience.

\section{Frperience as/uith nault offenders}

Participants were also asked whether or not they, their family members, or their friends were convicted as adult offenders or were victimized by adult offenders. Table 25 presents the victimization by adult offenders 
Table 24: Percentage of close Friends Victimized by Young offenders

Pat 12 Months

Bver

$\begin{array}{lll}\text { once } & 2-5 & 6-10 \\ & \text { times } & \text { times }\end{array}$

\section{Assault}

10.0

3.8

0

16.0

$B \& E$

15.0

2.5

0

10.0

Sexual

2.5

0

0

6.0

other

1.3

3.8

0

9.0 
Table 25: Experience as/with Adult Offenders

\begin{tabular}{llll}
\hline & Participants & Family & Friends \\
& $(\xi)$ & $(z)$ & $(8)$ \\
\hline Convictions & 3.8 & 11.3 & 41.3 \\
Victimization & 20.0 & 21.3 & 31.3 \\
\hline
\end{tabular}


and criminal experiences as adult offenders of participants, family members, and close friends.

There were no significant correlations between participants' adult convictions and those of family members with the types of sentences awarded. However, two correlations between the types of sentences awarded and friends' convictions as adult offenders were significant. The first was for male offenders with a prior record convicted of $B \& E(R=.37, \underline{2}<.05)$. The second was for non-abused offenders with a prior record convicted of assault $(R=.32, \underline{p}<.05)$

There were two significant correlations between the types of sentences awarded to offenders and participants' victimization experience by adult offenders. The first was for non-abused offenders with a prior record conviraed of prostitution $(R=.32, p<.05)$. The second was for non-abused offenders without a prior record convicted of assault $(R=.32, \underline{Q}<.05)$

There was a significant correlation between having a family member victimized by an adult offender and the sentences awarded to non-abused offenders with a prior record convicted of prostitution ( $R=.38, \quad \underline{p}<.05)$. Finally, there was a significant correlation between the types of sentences awarded to non-abused nffenders with a prior record convicted of prostitution and having a friend victimized by an adult $(R=.40,2<.05)$. 

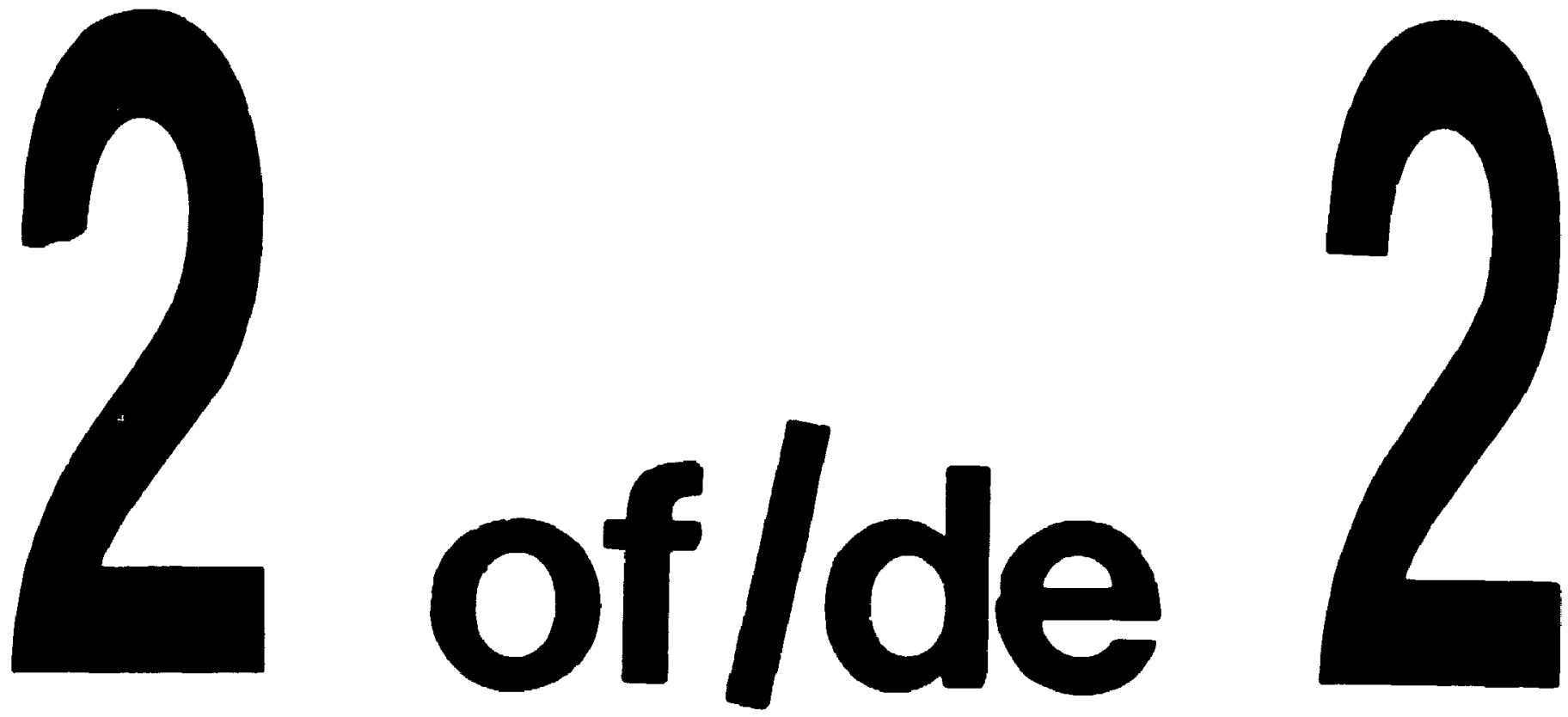

PM-1 31/2" 4 " PHOTOGRAPHIC MICROCOPY TARGET NBS 1010 a ANSIIISO $\# 2$ EOUIVALENT

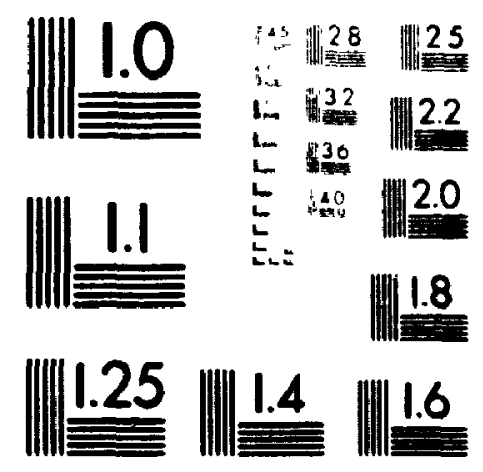

PRECISION ${ }^{\text {SM }}$ RESOLUTION TARGETS 
In summary, more friends than participants or family members had experience as adult offenders and as victims of adult offenders. There was no clear pattern between sentences awarded and either victimization experience or criminal involvement as adults.

\section{Discussion}

It was hypothesized that there would be a main effect for each of the four factors of offender Gender, Type of Crime, Prior Record, and Family Functioning. Results of the present study support these hypotheses for all factors except for that of offender Gender. This indicates that if gender was the sole defining factor, it would not be considered relevant to sentencing. In general, offenders with a prior record recejved harsher sentences than those without a prior record and abused offenders received harsher sentences than non-abused offenders.

The harshest seitences were given to offenders convicted of drug-trafficking followed by prostitution, $B \& E$, and assault. The implication is that drugtrafficking and prostitution are viewed as more threatening, perhaps because of their long-standing and serious societal repercussions (e.g., the further spread of AIDS, creating addictions etc.). However, assault and $B \& E$ are less ambiguous, lacking the same societal impact and, hence, received lighter sentences. 
Further hypotheses included a four-way interaction betreen the factors. This was not observed. However, the significant two-way interaction and the two significant three-way interactions suggest that there is a more complex relationship between the factors.

Females with a prior record received harsher sentences than males with a prior record. However, males without a prior record received slightly harsher sentences than females without a prior record. This relationship between gender and prior record is further complicated when the type of crime committed is taken into consideration. Howerer, the relationship does not seem to exist if the offenders have a history of physical abuse. According to Macrae and Shepherd (1989) participants take account of situational pressures that can contribute to the occurrence of criminal behaviour. Furthe:, this situational information appeared to take precedence even in the presence of a stereotypical explanation for the behaviour. Thus, even in the face of an alternate explanation (i.e., perceived male-female differences), abuse may have been considered as a more relevant precipitating factor for offenders' criminality.

More females with a prior record received probation for assault convictions than did their male counterparts. Females with a prior record also received more open custody dispositions for B\&E and drug-trafficking. Males 
with a prior record, however, received more community service and probation for $B \& E$. The harsher sentences received by female offenders with a prior record for assault, B\&E, and drug-trafficking imply that these offenses are considered, stereotypically, to be more masculine. Thus, when females commit such acts, they are seen as particularly deviant from the "female norm" and are dealt with in a more rigid fashion. Support for this indication is found when the goals that correlated with the sentences awarded to male and female offenders with a prior record convicted of drug-trafficking are considered. The goals for male offenders were generally more utilitarian whereas they were a combination of utilitarian and desert-oriented for females. Thus, it appears that the sentences awarded females arise from a more punitive intent than those awarded to males.

The finding that females without a prior record convicted of $B \& E$ receive both the harshest (probation) and the more lenient (compensation) sentences further supports the contention that this offense is seen as more of an exception than a norm for females. However, the manner with which the deviation is dealt appears to depend more on the person sentencing than on the crime itself.

Females with and without a prior record were awarded the harshest dispositions for prostitution. This finding 
supports Armstrong's (cited in Henggeler, 1989) contention that there is a double standard of morality that severely sanctions the sexual misconduct of girls. This double standard appears to have been supported by the correlations found for the goals awarded to male and female offenders convicted of prostitution. Both males and females, with and without a prior record, obtained significant correlations between the sentences they were awarded and the goal of incapacitation. Hciwever, males with a prior record obtained the added goal of rehabilitation, while their female equivalents received the added goals of general and individual deterrence. According to Reitsma-street (1991): "discriminatory sentencing patterns and inadequate, indifferent interventions are rooted in femininity norms that assume a male's sexual behaviour was only one facet of his total character, whereas a female was actually defined by her sexuality" (p.270). Figueira-McDonough (1985) adds that "girls are 'treated' and 'punished' not because of the damage they do to society but because their behavior deviates from traditional sex roles. Attaching a criminal label to girls for behavior that is tolerated among boys constitutes not only unfair treatment but a clear attempt at conditioning girls to their 'proper' place" (p.285).

Males without a prior record received harsher 
sentences for assault and drug-trafficking than their female counterparts. These findings are supported by those of Meeker et al. (1992) who found that male first time offenders were more likely than females to receive more severe sentences. Further support for this finding is found when the goals of sentencing are considered for male and female first time offenders. While males convicted of B\&E obtained the goals of general deterrence and incapacitation, females received solely the goal of incapacitation. Also, males convicted of drugtrafficking were awarded the goal of incapacitation while there were no significant goals awarded to their female counterparts. Lastly, for male offenders without a prior record who were convicted of assault, there were significant correlations between the type of sentences that they were assigned and the goals of rehabilitation, general deterrence, and incapacitation. For their female equivalents, the only significant correlation found was for the goal of rehabilitation. Thus, in general, goals awarded to male first-time offenders were more punitive in intent.

overall, it appears that female offenders with a prior record and male offenders without a prior record are treated more severely than their opposite-sex equivaleits. This may be because, in general, judges did not believe that female offenders would continue with 
their criminal careers but that male offenders would. Thus, being harsher on male first time offenders is an attempt to curb their criminality early on. However, once a female continues with her criminal career, especially one considered more masculine or against the norm of femininity, they are regarded as especially deviant and are dealt with more severely. This perception could be damaging to females. According to Figuiera-McDonough (1985), restricting females' freedom through institutionalization during the 'autonomous phase' of development could lead to either outright rebelition or over-dependence.

Abused offenders with a prior record received the more severe sentences for assault, B\&E, and prostitution. These results are supported by those of Horwitz and Wasserman (1980) who found that more severe and custodial dispositions were awarded to young offenders with family problems.

Perhaps the aim of judges was to remove abused offenders from the abusive home and place them in a safer, perhaps more rehabilitative environment. This indication is supported by evidence from correlations fourd between sentences that were awarded and the goals assigned them. Abused offenders with a prior record convicted of assault obtained significant correlations for the goal of rehabilitation whereas their non-abused 
counterparts did not.

Further, non-abused offenders with a prior record received more community service and secure custody for drug-trafficking whereas their abused equivalents received more open custody for the same offense. If the intent of judges was solely punitive towards abused offenders, they would have assigned them the more severe sentence of secure custody. However, since this was not the case, it would appear that judges' intentions were more benevolent in nature. Also, abused offenders with a prior record convicted of drug-trafficking obtained the more utilitarian goals whereas their non-abused counterparts additionally obtained more desert-oriented goals.

However, abused offenders with a prior record convicted of prostitution were awarded more desertoriented goals whereas non-abused offenders were awarded the sole utilitarian goal of incapacitation. These correlations indicate the decreased tolerance for this type of offense, and the unwillingness to accept abuse as an excuse.

Abused offenders without a prior record convicted of assault obtained harsher sentences than their non-abused counterparts and a significant correlation with the goal of incapacitation. Their non-abused counterparts obtained the goals of rehabilitation and individual 
deterrence. Thus, in the case of assault, the increased punitiveness towards abused offenders may be a result of judges viewing this offense as a propagation of the abusiveness learned at home. Hence, the intention would be to curb the cycle at the outset.

Abused offenders without a prior record who were convicted of $B \& E$ received both the lightest (compensation) and the harshest (open custody) dispositions. They also received the harsher dispositions for drug-trafficking and prostitution. Therefore, as with abused offenders with a prior record, it appears that judges may be trying to remove the abused offenders from their abusive environments (as indicated by several participants) without overly restricting their behaviour (i.e., with secure custody).

Again, both abused and non-abused offenders without a prior record convicted of prostitution obtained the goal of incapacitation suggesting the decreased tolerance of this offense, irrespective of abuse or having a prior record.

Overall, abused offenders with and without a prior record received more severe dispositions for all four offenses. The exception is for drug-trafficking- nonabused offenders with a prior record also received more secure custody dispositions. However, the goals assigned to the sentences of abused offenders with a prior record 
appear to be more "benevolent" than those assigned to their non-abused counterparts. Open custody was defined as "a group home or wilderness camp" that monitors the offenders but that is not as restrictive as secure custody. Thus, while an open custody disposition would remove the offender from the abusive situation, it may not be considered as overly restrictive of their behaviour. Further, community service and probation dispositions may have been considered as demanding and less rehabilitative serving to discourage non-abused offenders with a prior record from future crime.

Altnough there were correlations found between sentences awarded to offenders and participants' criminal past and victimization experience, no clear inferences or conclusions could be reached. Rugge (1994) determined that sentences imposed by participants did not relate to anti-social behaviour but they were related to victimization experience. Perhaps future research could determine the extent to which criminal past and victimization experience have an impact on the sentencing decision. It would be beneficial to compare the various sentencing practices and rationales imposed by different community groups (i.e., judges, adults, professionals and non-professionals, lawyers, yos etc.).

since physical abuse in the family was considered an influential factor in the sentencing decision, perhaps an 
alternative to harsher sentencing would be some form of family-based intervention. Further, the finding that females receive harsher sentences than males for prostitution confirms Reitsma-street's (1991) assertion that females are still being unfairly punished for their sexual misconduct. She states that "those delinquencies and attitudes that are construed as deviating from standards expected of good girls are penalized with disproportionately harsh, intrusive interventions" (p. 269)

The implication of the above results is that stereotypes and biases exist against female and abused offenders. Reitsina-street (1991) summarized the available research on female delinquency and concluded that criminal justice practice and policy "ignores the infrequent, minor crimes committed by females but harshly reacts to deviations from norms of femininity" (p.275) . Thus, although the YOA attempts to promote fairness and accountability in juvenile justice, it will inevitably fail unless these biases and stereotypes are realized and controlled.

It should be noted that the gender of participants had did not have an effect on the obtained results. suggesting that males and females perceived offenders in the same manner. Also to be noted, a seriousness of offence scale was not used to determine the rank 
orderings of the offenses. However, given the results of the present study, it is suggested that perhaps a new scale should be constructed that would reflect the increased intolerance of sexual and drug-related offences.

Limitations to the present study include the nature and size of the participant sample. Generalizability is limited to university students between the ages of 18 and 30 years. Further, the presence of several outliers put the assumption of normality into question for the multivariate results of the originally intended sentencing weights. These outliers increase the error variance and thus may have decreased the probability of finding significant $F$ values. The resulting use of sentence types (or categories), although plagued less with outliers, may have somewhat distorted the perceived intervals of seriousness between the different sentences. Thus, future research should consider the best alternative to combining both sentence types with the lengths or amounts awarded them. However, Zamble and Kalm (1990) have noted that the results from the categorical and weighted methods were virtually identical.

Relatively few means were used to replace some missing values. This procedure, if performed frequently. would have had the effect of lowering the correlations 
between variable and mean (e.g., sentence types and victimization experience or criminal past). Since multivariate solutions are sometimes sensitive to slight changes in correlation coefficients, a variable is placed at a disadvantage if several means are inserted. However, this was not necessarily the case in the present study.

Lastly, perhaps the wording of the vignettes were too similar, causing participants to overlook the subtle differences between them. However, this effect would have led to less variability between sentences awarded to different vignettes. This was not the case in the present study.

Future research needs to determine: whether the sentencing of abused offenders was in fact benevolent, why abuse was an "equalizing" factor for the genders, and why drug-trafficking and prosti ition were seen as deserving of more severe sentences than assault and B\&E.

To conclude, we must consider the complexity of crime perceptions to determine the connection between criminal behaviour and its sanctioning. Until existing biases against females and those have been abused are considered and countered, it is unlikely that sentencing patterns will differ from the above findings. 
References

Andrews, D.A., \& Bonta, J. (1994). The psychology of criminal conduct. Anderson Publishing co.: Cincinnati, Ohio.

Diamond, S.S., \& Stalans, L.J. (1989). The myth of

judicial leniency in sentencing. Behavioral

Sciences and the Law, $7(1), 73-89$.

Doob, Anthony N. (1993). Trends in the use of custodial dispositions for young offenders. In T. O'ReillyFleming \& B. Clark (Eds.): Youth injustice: Canadian perspectives. Canadian Scholars' Press Inc.:

Toronto.

Doob, A.N. (1989). Dispositions under the Young Offenders Act: Issues without answers? In Lucien A. Beaulieu (ed.), Young offender Dispositions:

Perspectives on Principles and Practice. Wall and Thompson Inc.: Toronto.

Doob, A.N., \& Beaulieu, L.A. (1993). Variation in the exercise of judicial discretion with Young offenders. In T. O'Reilly-Fleming and B. Clark (Eds.): Youth injustice: Canadian perspectives. Canadian Scholars' Press Inc.: Toronto. 
Doob, A., \& Roberts, J.V. (1984). Social psychology, social attitudes, and attitudes towards sentencing. Special Issue: Social psychology applied to social issues in Canada. Canadian Journal of Behavioural Science, $16(4), 269-280$.

Figueira-McDoncugh, J. (1985) . Are girls different? Gender discrepancies between delinquent behavior and control. Special issue: Toward a feminist approach to child welfare. Child Welfare, $64(3)$, 273-289.

Gebotys, R.J., \& Roberts, J.V. (1987). Public views of sentencirg: The role of offender characteristics. Canadian Journal of Behavioural Science, 19(4), 479488 .

Gomme, I.M. (1993). Predictors of status and criminal offenses among male and female adolescents in an Ontario community. In T. O'Reilly-Fleming and B. clark (Eds.): Youth injustice: Canadian perspectives. Canadian Scholars' Press Inc.: Toronto.

Gottfredson, D.M., Gottfredson, S.D., \& Conly, C.H. (1989). Stakes and risk: Incapacitative intent in sentencing decisions. Behavioral sciences and the Law, 7(1), 91-106.

Hansel, M. (1987). Citizen crime stereotypes-Normative consensus revisited. Criminology, 25(3), 455- 485 . 
Sentencing Young of fenderes

Harris, P.M. (1988). Juvenile sentence reform and its evaluation: A demonstration of the need for more precise measures of offence seriousness in juvenile justice research. Evaluation Review, 12, (6), 655-666. Henggeler, S.W. (1989). Delinquency in adolescence.

Sage: $N \cdot Y$.

Hoge, R., Andrews, D., \& Leschied, A.W. (In Press). An investigation of factors associated with probation and custody dispositions in a sample of juveniles. Journal of Clinical Child Psychology.

Horwitz, A., \& Wasserman, M. (1980). Formal

rationality, substantive justice, and

discrimination: A study of a juvenile court. Law and Human Behavior, 4(1/2), 103-115.

Keppel, G. (1991). Design and analysis (third edition). Prentice Hall, New Jersey.

Kurz, D. (1991). Corporal punishment and adult use of violence: A critique of "Discipline and Deriance". Social Problems, 38(2), 155-161.

Leschied, A.W., Jaffe, P.G. (1993). Impact of the Young offenders Act on court dispositions: A comparative analysis. In T. O'Reilly-Fleming and B. Clark (Eds.): Youth injustice: Canadian perspectives. Canadian Scholars' Press Inc.: Toronto. 
Macrae, C.N., \& Sheperd, J.W. (1989). Stereotypes and social judgements. British Journal of Social Psychology, 28, 319-325.

Markham, K. (1994). Assessing the Young Offenders Act as a philosophical basis for sentencing young persons. A paper submitted to the Department of Justice.

Mccord, J. (1991). Questioning the value of punishment. Social Problems, 38(2), 167-179.

Meeker, J.W., Jesilow, P., \& Aranda, J. (1992). Bias in sentencing: A preliminary analysis of community service sentences. Behavioral sciences and the Law, 10, 197-206.

Ortet-Fabregat, G., \& Perez, J. (1992). An assessment of the attitudes towards crime among professionals in the criminal justice system. British Journal of Criminology, 32(2), 193-207.

Parton, D.A., Hansel, M., Stratton, J.R. (1991).

Measuring crime seriousness: Lessons from the National survey of crime severity. British Journal of Criminology, $\underline{3}^{1}(1), 72-85$. Reistma-street, M. (1991). A review of female delinquency. In A.W. Leschied, P.G. Jaffe, and W. Willis (Eds.): The Young offenders Act: A revolution in canadian juvenile justice. University of Toronto Press: Toronto. 
Roberts, J.V., and Gebotys, R.J. (1989). The purposes of sentencing: Public support for competing aims. Behavioral sciences and the Law, I(3i, 387-402.

Rossi, P.H., Waite, E, Bose, C.E., \& Berk, R.E. (1974). The seriousness of crimes: Normative structure individual differences. American Sociological Review, 39, 224-237.

Rugge, T. (1994). The effects of gender, victimization, and criminal behaviour on sentencing by mock judges. Unpublished research paper. Carleton University Psychology Department: Ottawa, Canada.

Simourd, L., Hoge, R., \& Andrews, D.A. (1992). Gender differences in the correlates of iuvenile delinquency. Paper presented and the annual meeting of the Canadian Psychological Association, Quebec City, June, 1992 .

simourd, L. (1993). A meta-analytic review of gender differences in the correlates of delinquency. A comprehensive examination submitted to the Department of Psychology, Carleton University, ottawa.

Smith, E.D., \& Hed, A. (1979). Effects of offenders' age and attractiveness on sentencing by mock juries. Psychological Reports, 44(3,pt 1), 691-694. 
Stalans, L.J. (1993). Citizens' crime stereotypes, biased recall, and punishment preferences in abstract cases: The educative role of interpersonal sources. Law and Human Behaviour, 17(4), 451-470. Straus, M.A. (1991). Discipline and deviance: Physical punishment of children and violence and other crime in adulthcod. Social Problems, 38(2), 133-151.

Tolan, P.H., \& Lorion, R.P. (1988). Multivariate approaches to the identification of delinquency proneness in adolescent males. American Journal of Community Psychology, 16(4), 547-561.

Travis, L.F., Cullen, F.T., Link, B.G., \& Wozniak, J.F. (1986). The impact of instructions on seriousness ratings. Journal of Criminal Justice, 14, 433-440. Wear, D.A. (1984). Defendant's previous history and mock sentencing. Journal of clinical Psychology, $40(3), 867-874$

Wells, L.E. \& Rankin, J.H. (1991). Families and delinquency: A meta-analysis of the impact of broken homes. Social problems, 38(1), 71-93.

Yaworsky, K.B. (1981). Effect of penalty information on judgement of seriousness of crimes. Perceptual and Motor Skills, 53(3), 715-719. 
104

Young, A. (1989). Appellate court sentencing principles for young offenders. In Lucien A. Beaulieu (ed.), Young offender dispositions: Perspectives on principles and practice. Wall and Thompson Inc.: Toronto.

Young offenders Act. Statutes of Canada 1980-81-82-83, c. 110 .

Ramble, E., Halm, K.L. (1990). General and specific measures of public attitudes toward sentencing. Canadian Journal of Behavioural Science, 22(3), 327337 . 
Appendix $A$

Instructions and crime vignettes

Section A:

Exime Vianettes

Please indicate below your gender and age:

Male:

Femaie:

Age:

This booklet describes a series of violations of the law; each violation is different. Your task is to determine the type and length of sentence an offender between the ages of 12 to 17 should receive. Do not consider what the law says or how the courts might act, only your opinion

matters. A list of the sentencing options and their definitions is provided for you. Read each carefully and feel free to refer to it when necessary.

on each page there will be seven choices. Check one and then write down the length or amount of the sentencing option that you believe is appropriate for each crime. Please choose only one. Afterwards, read each sentencing goal and rate the importance of each in every case.

Take your time. Finish each page in the order it is given to you in the booklet. Every page should have a clear choice of sentence that can be seen by the check placed beside it and the length or amount written in the box. Do not turn back once you have finished a page. Remember, this is not a test. The important thing is how you feel about each violation. Do not write your name on any of the sheets so that you will not be identified. However, do not forget to indicate above your gender and age.

At the end of the survey, there will be a few questions. Take your time and answer according to what you believe. You are not under any obligation to answer any of the questions that you are not comfortable with. However, keep in mind that there is no way that you can be identified. Thank you for your participation. 
Sentencing options and Definitions

These are your sentencing options. Please read each carefully before you begin.

Absolute Discharge: a sentence that does not carry with it any obligations or restrictions on the young person's freedom.

Eine: a sentence that requires a payment of not more than $\$ 1000$ to be paid by a certain time and on terms that the court decides.

Compensation: a sentence that requires the young person to give back to the victim the equivalent of the loss caused by the young person. For example, working for the victim to make up for the loss or aamage to the victim's property, the loss of the victim's income, or personal injury caused to the victim.

Community service order: a sentence that requires the young person to perform a community service. The maximum number of hours that can be assigned is 240 .

Probation: a sentence that is used mainly as a way of providing supervision for the young person. It requires that the young person report to and is supervised by a person designated by the court. The young person may also have to do one or more of the following: tell their probation officer if they change their address, remain living within a certain area, find work, remain in school, or obey a curfew. The maximum length that can be given is two years.

Custody: a sentence that requires the young person's placement in a residence appointed by the court. The Young offender Act distinguishes between two types of custody:

a) Open custody- a residence such as a group home, wilderness camp, or any like place where the young person is closely supervised. This residence is not usually locked. However, the young person is still required to remain within its property boundary or face further penalty. The maximum length of sentence in open custody is two years.

b) Secure custody: a residence that is locked up in a secure fashion such that the young person can not leave. The young person is strictly monitored and confined to the residence. The maximum length of sentence in secure custody is two years. 
Book 1

Joanne has a prior conviction of theft under $\$ 1000$ for stealing stereo equipment from a neighbourhood shop. She was just caught attempting to sell cocaine to a neighbour's son and was convicted of drugtrafficking. During the trial, it was revealed that her home environment was not stable and that she had been physically abused by her father.

i) What sentence would you give her?

a) absolute discharge

b) fine

c) compensation

d) community service order

e) probation

f) open custody

g) secure custody

ii) Rate how important you believe the following goals of sentencing are for the offender in this case (where $1=$ least important, $4=$ moderately important, and $7=$ very important) .

Least Moderately Most

Important Important Important

a) rehabilitation (to provide treatment in order to reduce reoffending)

b) general deterrence (to make an example of the offender so that others will not offend) check one length or amount

c) individual deterrence (to deter the individual from reoffending in the future)

$\begin{array}{lllllll}1 & 2 & 3 & 4 & 5 & 6 & 7\end{array}$

d) incapacitation (to make sure that the offender does not reoffend during the period of sentencing by placing him/her in custody)

e) just deserts (to give the offender a punishment that fits the crime without considering treatment or other alternatives)

f) compensation (making the offender give back to the victim the equivalent of the loss that was caused: i.e., through money or work hours, etc.)

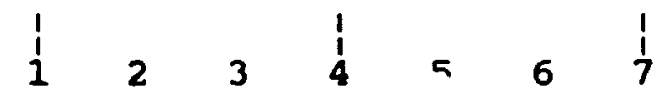

$\begin{array}{lllllll}1 & & & 1 & & & 1 \\ 1 & 2 & 3 & 4 & 5 & 6 & 7\end{array}$

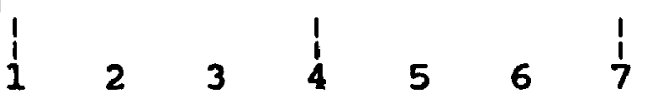


After punching his friend's father, Jeff was convicted of assault. Jeff'B criminal history revealed that he had a prior conviction of theft under $\$ 1000$. This resulted from his stealing a leather jacket from a locker in the shopping centre. According to testimony at his trial, Jeff's father had been physically abusive.

i) What sentence would you give him?

check one length or amount
a) absolute discharge
b) fine
c) compensation
d) community service order
e) probation
f) open custody
g) secure custody

ii) Rate how important you believe the following goals of sentencing are for the offender in this case (where $1=$ least important, $4=$ moderately important, and $7=$ very important).

a) rehabilitation (to

Least Moderately Important Important Most provide treatment in order to reduce reof fending)

b) general deterrence (to make an example of the offender so that others will not offend)

$\begin{array}{lllllll}1 & 2 & 3 & 1 & & & 1\end{array}$

c) individual deterrence (to deter the individual from reoffending in the future)

d) incapacitation (to make sure that the offender does not reoffend during the period of sentencing by placing him/her in custody)

e) Just deserts (to give the offender a punishment that fits the crime without considering treatment or other alternatives)

f) compensation (making the offender give back to the victim the equivalent of the loss that was caused; i.e., through money or work hours, etc.) 
Christine was previously convicted of theft under $\$ 1000$ for stealing a pair of gold earrings from a jewelry store. Her family was not very supportive and it was discovered that her father had been physically abusing her. She has just been convicted of break and enter after she was caught in her neighbour's house.

i) What sentence would you give her?

check one length or amount
a) absolute discharge
b) fine
c) compensation
d) community service order
e) probation
f) open custody
g) secure custody

ii) Rate how important you believe the following goals of sentencing are for the offender in this case (where $1=$ least important, $4=$ moderately important, and $7=$ very important).

a) rehabilitation (to

Least Important Moderately provide treatment in order to reduce reoffending)

b) general deterrence (to make an example of the offender so that others will not offend) Important Most Important

c) individual deterrence (to deter the individual from reoffending in the future)

$\begin{array}{lllllll}1 & 2 & 3 & 4 & 5 & 6 & 7\end{array}$

d) incapacitation (to make sure that the of fender does not reoffend during the period of sentencing by placing him/her in custody)

e) just deserts (to give the offender a punishment that fits the crime without considering treatment or other alternatives)

f) compensation (making the offender give back to the victim the equivalent of the loss that was caused; i.e., through money or work hours, etc.) 
Pete has just been convicted of soliciting (prostitution). The undercover officer at his trial testified that pete was arrested after trying to solicit money for his sexual services. Further testimony from his friends and neighbours indicated that pete has been physically abused by his natural father. A prior record check showed that Pete was previously convicted of theft under $\$ 1000$ for stealing a mountain bike from a local secondary school. i) what sentence would you give him?
a) absolute discharge
b) fine
c) compensation
d) community service order
e) probation
f) open custody
g) secure custody check one length or amount

ii) Rate how important you believe the following goals of sentencing are for the offender in this case (where $1=$ least important, $4=$ moderately important, and $7=$ very important).

a) rehabilitation (to Least Important Important provide treatment in order to reduce reoffending)

b) general deterrence (to $\begin{array}{lllllll}1 & & & 1 & & & 1\end{array}$ make an example of the offender so that others will not offend)

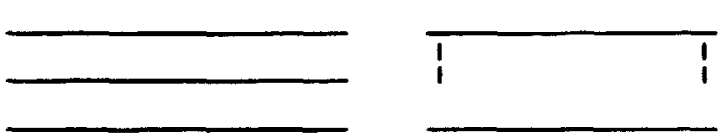

c) individual deterrence (to deter the individual from reoffending in the future)

d) incapacitation (to make sure that the offender does not reoffend during the period of sentencing by placing him/her in custody)

e) just daserts (to give the offender a punishment that fits the crime without considering treatment or other alternatives)

f) compensation (making the offender give back to the victim the equivalent of the loss that was caused; i.e., through money or work hours, etc.) Moderately Most Important

$\begin{array}{lllllll}1 & & & 1 & & & 1 \\ 1 & 2 & 3 & 4 & 5 & 6 & 7 \\ 1 & & & & & & \\ 1 & 2 & 3 & 4 & 5 & 6 & 7\end{array}$

$\begin{array}{lllllll}1 & & & 1 & & & 1 \\ 1 & 2 & 3 & 4 & 5 & 6 & 7\end{array}$


During his current trial, relatives testified that Dave's father had been physically abusing him. It was also revealed that Dave was previously convicted of theft under $\$ 1000$ for stealing a canoe from a nearby campground. He was currently convicted of break and enter after he was caught forcing his way into a locked summer cottage.

i) That sentence would you give him?

a) absolute discharg: check one length of amount

b) fine

c) compensation

d) community service order

e) probation

f) open custody

g) secure custody

ii) Rate how important you believe the following goals of sentencing are for the offender in this case (where $1=$ least important, $4=$ moderately important, and $7=$ very important) .

a) rehabilitation (to provide treatment in order to reduce reoffending)

b) general deterrence (to make an example of the offender so that others will not offend)

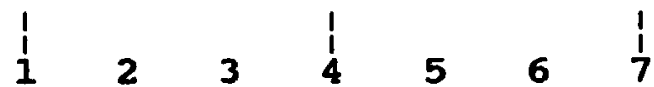

c) individual deterrence (to deter the individual from reoffending in the future)

d) incapacitation (to make sure that the offender does not reoffend during the period of sentencing by placing him/her in custody)

e) just deserts (to give the offender a punishment that fits the crime without considering treatment or other alternatives)

f) compensation (making the offender give back to the victim the equivalent of the loss that was caused; i.e.' through money or work hours, etc.) Important 
Liz has a history of physical abuse caused by her natural father. Her current conviction of soliciting (prostitution) resulted from an undercover investigation during which Liz attempted to solicit money for her sexual services. Iiz's prior record consisted of one previous conviction of the ft under \$1000 for stealing video-game equipment from a local

video store.

1) What sentence would you give her?
a) absolute discharge
b) fine
c) compensation
d) community service order
e) probation
f) Open custody
g) secure custody

check one length or amount

ii) Rate how important you believe the following goals of sentencing are for the offender in this case (where $1=$ least important, $4=$ moderately important, and $7=$ very important).

a) rehabilitation (to Least Moderately Most Important Important Important provide treatment in order to reduce reoffending)

b) general deterrence (to make an example of the offender so that others will not offend)

c) Individual deterrence (to deter the individual from reoffending in the future)

d) incapacitation (to make $\begin{array}{lllllll}1 & 2 & 3 & 4 & 5 & 6 & 7\end{array}$ sure that the offender does not reoffend during the period of sentencing by placing him/her in custody)

e) just deserts (to give the offender a punishment that fits the crime without considering treatment or other alternatives)

f) compensation (making the offender give back to the victim the equivalent of the loss that was caused; i.e., through money or work hours, etc.)

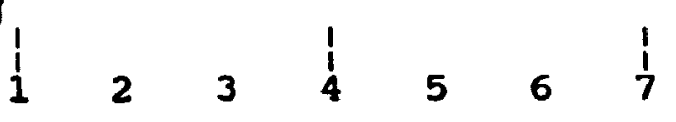

$\begin{array}{lllllll}1 & & & 1 & & & 1\end{array}$

$\begin{array}{lllllll}i & 2 & 3 & 4 & 5 & 6 & 7\end{array}$


Angela's current conviction of assault resulted from a physical fight with her neighbour. Diring trial, it was revealed that she had a previous conviction of theft under $\$ 1000$. The theft was of a pair of cowboy boots from a locker room at school. Angela's friends and a few relatives testified that Angela had been experiencing physical abuse by her father. i) What sentence would you give her?

a) absolute discharge

b) fine

c) rompensation

d) community service order

e) probation

f) open custody

g) secure custody check one length or amount

ii) Rate how important you believe the following goals of sentencing are for the offender in this case (where $1=$ least important, $4=$ moderately important, and $7=$ very important).

a) rehabilitation (to provide treatment in order to reduce reof fending) Moderately Most Important Important Important

b) general deterrence (to make an example of the offender so that others will not offend)<smiles>[2H][V]I</smiles>

c) individu 1 deterrence (to deter the individual from reoffending in the future)

d) incapacitation (to make sure that the offender does not reoffend during the period of sentencing by placing him/her in custody)

e) just deserts (to give the offender a punishment that fits the crime without considering treatment or other alternatives)

f) compensation (making the offender give back to the victim the equivalent of the loss that was caused; i.e., through money or work hours, etc.) 
Mike has a prior conviction of theft under $\$ 1000$ for stealing roller blades from an unattended picnic area. He has just been convicted of drugtrafficking for attempting to sell cocaine to a class-mates' younger brother. During the trial, it was revealed that he had been physically abused by his father.

i) What sentence would you give him?
a) absolute discharge
b) fine
c) compensation
d) community service order
e) probation
f) open custody
g) secure custody check one length or amount

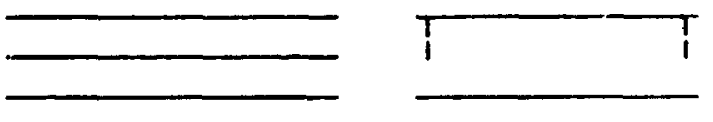

ii) Rate how important you believe the following goals of sentencing are for the offender in this case (where $1=$ least important, $4=$ moderately important, and $7=$ very important)

a) rehabilitation (to Moderately Most Important Important Important provide treatment in order to reduce reoffending)

b) general deterrence (to make an example of the offender so that others will not offend)<smiles>[2H][Al]I</smiles>

c) individual deterrence (to deter the individual from reoffending in the future)

d) incapacitation (to make sure that the offender does not reoffend during the period of sentencing by placing him/her in custody)

e) just deserts (to give the offender a punishment that fits the crime without considering treatment or other alternatives)

f) compensation (making the offender give back to the victim the equivalent of the loss that was caused: i.e., through money or work hours, etc.) 
After Debbie was caught stealing computer equipment from a neighbourhood shop, she was convicted of theft under $\$ 1000$. Her recent conviction of break and enter resulted when she was found in her neighbour's house. Both of her parents were present at her trial and appeared supportive. Relatives testified that Debbie's parents provided a loving family environment.

i) What sentence would you give her?
a) absolute discharge
b) fine
c) compensation
d) community service order
e) probation
f) open custody
g) secure custody check one length or amount

ii) Rate how important you believe the following goals of sentencing are for the offender in this case (where $1=$ least important, $4=$ moderately important, and $7=$ very important).

Least Moderately Most

Important Important Important
a) rehabilitation (to provide treatment in order to reduce reoffending)
b) general deterrence (to make an example of the offender so that others will not offend) $\begin{array}{lllllll}1 & 2 & 3 & 4 & 5 & 6 & 7\end{array}$ c) individual deterrence
(to deter the individual
from reoffending in the future)
d) incapacitation (to make

$\begin{array}{lllllll}1 & & & 1 & & & 1 \\ 1 & 2 & 3 & 4 & 5 & 6 & 7\end{array}$
sure that the offender
does not reoffend during
the period of sentencing by placing him/her in custody)
e) just deserts (to give the offender a punishment that fits the crime without considering treatment or other alternatives)
f) compensation (making the offender give back to the victim the equivalent of the loss that was caused; i.e.' through money or work hours, etc.) 
Mandy comes from a caring family and her home life was described as understanding and nurturing. She has a prior record of theft under $\$ 1000$ that occurred after she was caught with a leather jacket that she had stolen from a locker in the shopping centre. Mandy's current conviction for assault resulted after she punched her friend's father.

i) What sentence would you give her?

a) absolute discharge check one length or amount

b) fine

c) compensation

d) community service order

e) probation

f) open custody

g) secure custody

ii) Rate how important you believe the following goals of sentencing are for the offender in this case (where $1=$ least important, $4=$ moderately important, and $7=$ very important).

a) rehabilitation (to Least Moderately Most Important Important Important provide treatment in order to reduce reoffending)

b) general deterrence (to make an example of the offender so that others will not offend)

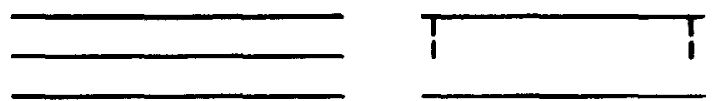

c) individual deterrence (to deter the individual from reoffending in the future)

d) incapacitation (to make $\begin{array}{lllllll}1 & 2 & 3 & 4 & 5 & 6 & 1\end{array}$ sure that the offender does not reoffend during the period of sentencing by placing him/her in custody)

e) just deserts (to give the offender a punishment that fits the crime without considering treatment or other alternatives)

f) compensation (making the offender give back to the victim the equivalent of the loss that was caused: i.e.' through money or work hours, etc.) 
Laura has just been convicted of soliciting (prostitution) for asking for money to perform sexual acts. It was recognized during the trial that Laura came from a rewarding home environment and had encouraging parents. Laura has one prior conviction of theft under $\$ 1000$ for stealing gold earrings from a jewelry store.

i) What sentence would you give her?
a) absolute discharge
b) fine
c) compensation
d) community service order
e) probation
f) open custody
g) secure custody check one length or amount

ii) Rate how important you believe the following goals of sentencing are for the offender in this case (where $1=$ least important, $4=$ moderately important, and $7=$ very important).

a) rehabilitation (to provide treatment in order to reduce reoffending) Moderately Most Important Important Important

b) general deterrence (to make an example of the offender so that others will not offend)

$$
\begin{array}{lllllll}
1 & 2 & 3 & 4 & 5 & 6 & 7
\end{array}
$$

c) individual deterrence (to deter the individual from reoffending in the future)

d) incapacitation (to make sure that the offender does not reoffend during the period of sentencing by placing him/her in custody)

e) just deserts (to give

$\begin{array}{lllllll}1 & 2 & 3 & 4 & 5 & 6 & 7\end{array}$
the offender a punishment that fits the crime without considering treatment or other alternatives)

$\begin{array}{lllllll}1 & & & 1 & & & 1 \\ 1 & 2 & 3 & 4 & 5 & 6 & 7\end{array}$

f) compensation (making the offender give back to the victim the equivalent of the loss that was caused: i.e.. through money or work hours, etc.) 
Tina has a prior conviction of theft under $\$ 1000$ for stealing a mountain bike from a local amusement park. Both of her parents were at her present trial and were said to be understanding and devoted to $T$ ina. Her current conviction for drug-trafficking was a result of her attempt to sell cocaine to a neighbour's son.

i) What sentence would you give her?

a) absolute discharge

b) fine

c) compensation

d) community service order

e) probation

f) open custody

g) secure custody

i1) Rate how important you believe the following goals of sentencing are for the offender in this case (where $1=$ least important, $4=$ moderately

important, and $7=$ very important).

check one length or amount

Least Moderately Most

Important Important Important

a) rehabilitation (to

provide treatment in

order to reduce

reoffending)

b) general deterrence (to

make an example of the

offender so that others will not of fend)

$\begin{array}{lllllll}1 & & & 1 & & & 1\end{array}$

c) individual deterrence

(to deter the individual from reoffending in the future)

d) incapacitation (to make

$\begin{array}{lllllll}1 & & & \mid & & & !\end{array}$ sure that the offender

does not reoffend during the period of sentencing by placing him/her in custody)

e) just deserts (to give

$\begin{array}{lllllll}1 & 2 & 3 & 4 & 5 & 6 & 7\end{array}$

the offender a punishment

that fits the crime

without considering

treatment or other

alternatives)

f) compensation (making the offender give back to the victim the equivalent of the loss that was caused; i.e., through money or work hours, etc.)

$\begin{array}{lllllll}1 & 2 & 3 & 1 & 5 & 6 & 1\end{array}$

$\begin{array}{lllllll}1 & 2 & 3 & 4 & 5 & 6 & 7\end{array}$


During Doug's trial, both parents appeared supportive and were said to provide a loving family environment. Doug has just been convicted of soliciting (prostitution). This resulted when Doug asked for money to perform sexual services. Doug has one prior conviction of theft under $\$ 1000$ that occurred after he stole a some camping gear from a nearby campground.

i) What sentence would you give him?

a) absolute discharge

check one

b) fine

c) compensation

d) community service order

e) probation

f) open custody

g) secure custody

ii) Rate how important you believe the following goals of sentencing are

for the offender in this case (where $1=$ least important, $4=$ moderately important, and $7=$ very important) .

Least Moderately Most

Important Important Important

a) rehabilitation (to provide treatment in order to reduce reoffending)

b) general deterrence (to $\begin{array}{lllllll}1 & 2 & 3 & 4 & 5 & 6 & 7\end{array}$ make an example of the offender so that others will not of fend)

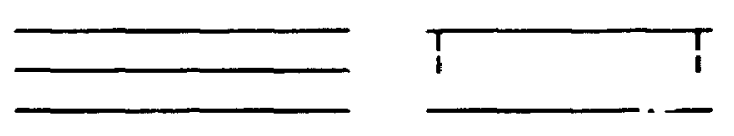

c) individual deterrence (to deter the individual from reoffending in the future)

d) incapacitation (to make sure that the offender does not reoffend during the period of sentencing by placing him/her in custody)

e) just deserts (to give the offender a punishment that fits the crime without considering treatment or other alternatives)

f) compensation (making the offender give back to the victim the equivalent of the loss that was caused; i.e., through money or work hours, etc.)

$\begin{array}{lllllll}1 & & & \mid & & & 1 \\ 1 & 2 & 3 & 4 & 5 & 6 & 7\end{array}$

$\begin{array}{lllllll}1 & 2 & 3 & 4 & 5 & 6 & 7\end{array}$


Rob has just been convicted of assault after a physical fight with his neighbour. He has a previous conviction of theft under $\$ 1000$ for stealing video-game equipment from a local video store. Both parents were said to provide a rewarding home environment and appeared caring at his trial.

i) What sentence would you give him?
a) absolute discharge
b) fine
c) compensation
d) community service order
e) probation
f) open custody
g) secure custody check one length or amount

ii) Rate how important you believe the following goals of sentencing are for the offender in this case (where $1=$ least important, $4=$ moderately important, and $7=$ very important) .

Least Moderately Most Important Important Important

a) rehabilitation (to provide treatment in order to reduce reoffending)

b) general deterrence (to make an example of the offender so that others will not offend)

$\begin{array}{lllllll}1 & 2 & 3 & 4 & 5 & 6 & 7\end{array}$

c) individual deterrence (to deter the individual from reoffending in the future)

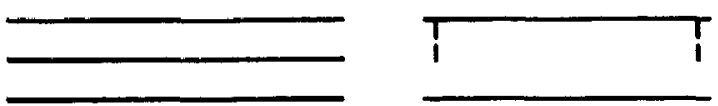

d) incapacitation (to make sure that the offender does not reoffend during the period of sentencing by placing him/her in custody)

e) just deserts (to give the offender a punishment that fits the crime without considering treatment or other alternatives)

f) compensation (making the offender give back to the victim the equivalent of the loss that was caused; i.e." through money or work hours, etc.)

$\begin{array}{lllllll}1 & 2 & 3 & 4 & 5 & 6 & 7\end{array}$
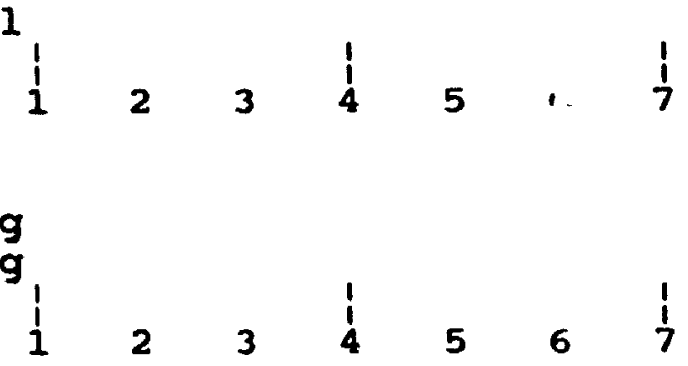
Andrew has a prior conviction of theft under $\$ 1000$ that resulted from his theft of a pair of running shoes from a locker room at school. His current conviction of drug-trafficking resulted from his attempt to sell cocaine to a friend's younger brother. Andrew's parents appeared devoted and caring, providing him with support at his trial.

i) What sentence would you give him?
a) absolute discharge
b) fine
c) compensation
d) community service order
e) probation
f) open custody
g) secure custody check one length or amount

ii) Rate how important you believe the following goals of sentencing are for the offender in this case (where $1=$ least important, $4=$ moderately important, and $7=$ very important).

a) rehabilitation (to Moderately Important Important Important Most provide treatment in order to reduce reof fending)

b) general deterrence (to make an example of the offender so that others will not of fend)

$\begin{array}{lllllll}1 & 2 & 3 & 4 & 5 & 6 & 7\end{array}$

c) individual deterrence (to deter the individual from reoffending in the future)

d) incapacitation (to make sure that the of fender does not reoffend during the period of sentencing by placing him/her in custody)

e) just deserts (to give the of fender a punishment that fits the crime without considering treatment or other alternatives)

f) compensation (making the offender give back to the victim the equivalent of the loss that was caused; i.e., through money or work hours, etc.)

$\begin{array}{lllllll}1 & 2 & 3 & 4 & 5 & 6 & 7\end{array}$

$\begin{array}{lllllll}1 & 2 & 3 & 4 & 5 & 6 & 7\end{array}$
i
\begin{tabular}{ll|llll}
2 & 3 & 4 & 5 & 6 & 7
\end{tabular} 
Bill has just been convicted of break and enter after he was caught breaking into a locked storage facility. He has a prior conviction of thert under $\$ 1000$ that he received for stealing roller-blades from an unattended picnic area. Bill came from a supportive home environment with both parents providing him with love and understanding.

i) What sentence would you give him?

a) absolute discharge

check one

length or amount

b) fine

c) compensation

d) community service order

e) probation

f) open custody

g) secure custody

ii) Rate how important you believe the following goals of sentencing are for the offender in this case (where $1=$ least important, $4=$ moderately important, and $7=$ very important).

a) rehabilitation (to provide treatment in order to reduce reoffending) Moderately Most Important Important

Important

b) general deterrence (to make an example of the offender so that others will not of fend)

$\begin{array}{lllllll}1 & 2 & 3 & 4 & 5 & 6 & 7\end{array}$

c) individual deterrence (to deter the individual from reoffending in the future)

d) incapacitation (to make sure that the offender does not reoffend during the period of sentencing by placing him/her in custody)

e) just deserts (to give the offender a punishment that fits the crime without considering treatment or other alternatives)

f) compensation (making the offender give back to the victim the equivalent of the loss that was caused; i.e.' through money or work hours, etc.)

$\begin{array}{lllllll}1 & & & & & 1 \\ 1 & 2 & 3 & 4 & 5 & 6 & 7\end{array}$


Section B:

Sentencing Ouestions

1. Rate the following on a 7 point scale according to how important you think they are when deciding the length of sentence to give (where $1=$ not very important, $4=$ moderately important and $7=$ very important) . Not Very Moderately very

\begin{tabular}{llllllll} 
& Not Very & Moderately & \multicolumn{2}{c}{ Very } \\
\hline \multicolumn{3}{c}{ Important } & Important & Important \\
\hline a) gender of offender & 1 & 2 & 3 & 4 & 5 & 6 & 7 \\
b) type of crime & 1 & 2 & 3 & 4 & 5 & 6 & 7 \\
c) criminal record & 1 & 2 & 3 & 4 & 5 & 6 & 7 \\
d) family functioning & 1 & 2 & 3 & 4 & 5 & 6 & 7
\end{tabular}

2. What other type of information would you have liked to have before making your sentencing decision (put a check mark

beside the information you would have wanted):

a) gender of the victim

b) age of the victim

c) amount of harm to the victim

d) whether the crime was planned

e) how well the offender was doing in school

f) the specific age of the offender

g) if the offender had any psychological problems

h) other:

3. The following is a list of possible sentences. The first two have been done for you. Absolute discharge was weighed 0 because it is the lightest possible sentence. Secure custody of 18-24 months was weighed 100 because it is the most severe sentence that can be given. Weigh the remaining sentences between 0 and 100 according to how severe you believe them to be.

absolute discharge

probation (18 to 24 months)

open custody (18 to 24 months)

compensation

fine under $\$ 500$

community service order (1 to 100 hours)

probation (under 6 months)

secure custody (12 to under 18 months)

open custody (under 6 months)

probation ( 6 to under 12 months)

open custody ( 12 to under 18 months)

fine ( $\$ 501$ to $\$ 1000$ )

secure custody (under 6 months)

community service order ( 201 to 240 hours)

secure custody ( 6 to under 12 months)

open custody ( 6 to under 12 months)

probation (12 to under 18 months)

community service order (101 to 200 hours)

secure custody (18 to 24 months) 
Section C: Victimization and criminal Involvement

A. Personal Familial and Peer Involvement

1. Have you been convicted as a young of fender?

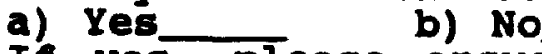
b) No

question 2 .

the following questions. If no, proceed to

within past 12 months 6-10 ever once $2-5 \quad 6-10$
times times

i) Have you been convicted of physical assault or assault causing bodily harm?

ii) Have you been convicted of breaks enter, theft or car theft?

iii) Have you been convicted of any drugrelated offences (i.e.. trafficking, possesion)?

iv) Have you been convicted of any sex-related offences (i.e., prostitution. sexual assault)?

$v)$ Have you been convicted of any other offence not including the above?

2. Has a family member ever been convicted as a young of fender? a) Yes b) No c) Unsure. ever

If yes, please answer question 3 .

\section{$\frac{\text { Within past once } 2-5}{12 \text { months }} \frac{6-10 \text { ever }}{12}$}

i) Have they been convicted of physical assault or assault causing bodily harm?

ii) Have they been convicted of break enter. theft or car theft?

iii) Have they been convicted of any drugrelated offences (i.e., trafficking, possesion)?

$i v)$ Have they been convicted of any sex-related offences (i.e., prostitution. sexual assault)?

v) Have they been convicted of any other offence not including the above? 
section $c$ cont...

3. Has a close friend ever been convicted as a young offender?
a) Yes
b) No
c) Unsure

If yes, please answer the following questions. If no, proceed to section $B$.

\begin{tabular}{l} 
within past once $2-5 \quad 6-10$ \\
12 months ever \\
\hline times times
\end{tabular}

i) Have they been convicted of physical assault or assault causing bodily harm?

ii) Have they been convicted of breaks enter. theft or car theft?

iii) Have they been convicted of any drugrelated offences (i.e.. trafficking, possesion)?

iv) Have they been convicted of any sex-related

offences (i.e., prostitution. sexual assault)?

v) Have they been convicted of any other offence not including the above?

B. Victimization Experience

1. Have you ever been the victim of an offence committed by a young of fender?
a) Yes
b) No
c) Unsure question 2 . answe

\section{$\frac{\text { within past once } 2-5 \quad 6-10 \text { ever }}{12 \text { months }}$}

i) Have you been physic-

ally assaulted?

ii) Has your place of residence ever been broken in to, have you ever had property stolen (over \$50), or has your car ever been stolen?

iii) Have you ever been sexually assaulted?

iv) Have you ever been victimized in any other way not including the above?

2. Has a family member ever been victimized by a young offender?
a) Yes.
b) No
c) Unsure

If yes. question $i$.

please answer the following questions.

If no, proceed to 
Section $c$ cont...

within past once $2-5$ 6-10 ever 12 months times times

i) Have they been physic-

ally assaulted?

ii) Has their place of residence ever been broken in to, have they ever had property stolen (over $\$ 50)$, or has their car ever been stolen?

iii) Have they ever been sexually assaulted?

iv) Have they ever been victimized in any other way not including the above?

3. Has a close friend ever been victimized by a young offender?
a) Yes
b) No
c) Unsure

If yes, please answer the following questions. If no, proceed to section $C$.

$\begin{array}{lll}\text { within past once } 2-5 & 6-10 \text { ever } \\ \frac{12 \text { months }}{\text { times times }}\end{array}$

i) Have they been physically assaulted?

ii) Has their place of residence ever been broken in to, have they ever had property stolen (over $\$ 50)$, or has their car ever been stolen?

iii) Have they ever been sexually assaulted?

iv) Have they ever been victimized in any other way not including the above?

c. Experience with Adult offenders

1. Have you ever been convicted as an adult offender?
a) Yes
b) No

2. Has a family member ever been convicted as an adult offender?
a) Yes
b) No
c) Unsure

3. Has a close friend ever been convicted as an adult offender?
a) Yes
b) No
c) Unsure
4. Have you been victimized by an adult offender?
a) Yes
b) No
c) Unsure

5. Has a family member been victimized by an adult offender?
a) Yes
b) No
c) Unsure

6. Has a close friend been victimized by an adult offender?
a) Yes
b) No
c) Unsure 
Book 2:

Ian is a first-time offender. His current conviction of assault resulted after he punched a friend's father. During the trial, it was revealed that Ian was physically abused by his father.

i) What sentence would you give him?

a) absolute discharge

b) fine

c) compensation

d) community service order

e) probation

f) open custody

g) secure custody

ii) Rate how important you believe the following goals of sentencing are for the offender in this case (where $1=$ least important, $4=$ moderately important, and $7=$ very important). Moderately Most Important Important Important

a) rehabilitation (to provide treatment in order to reduce reoffending) check one length or amount

b) general deterrence (to make an example of the offender so that others will not offend)

$\begin{array}{lllllll}1 & 2 & 3 & 4 & 5 & 6 & 7\end{array}$

c) individual deterrence (to deter the individual from reoffending in the future)

d) incapacitation (to make sure that the offender does not reoffend during the period of sentencing by placing him/her in custody)

e) just deserts (to give the offender a punishment that fits the crime without considering treatment or other alternatives)

f) compensation (making the of render give back to the victim the equivalent of the loss that was caused; i.e. through money or work hours, etc.)

$$
\text { ent }
$$

1

1

(1)


Testimony by friend's and relatives during Jason's trial revealed that he had been physically abused by his father. Jason is a first-time offender. His recent conviction of break and enter resulted after he was caught in his neighbour's house.

i) What sentence would you give him?

a) absolute discharge

b) fine

c) compensation

d) community service order

e) probation

f) open custody

g) secure custody check one length or amount

ii) Rate how important you believe the following goals of sentencing are for the offender in this case (where $1=$ least important, $4=$ moderately important, and $7=$ very important).

\section{Least} Moderately Most Important Important

a) rehabilitation (to provide treatment in order to reduce reoffending)

b) general deterrence (to make an example of the offender so that others will not offend) $\begin{array}{lllllll}1 & & & 1 & & & 1 \\ 1 & 2 & 3 & 4 & 5 & 6 & 7\end{array}$

c) individual deterrence (to deter the individual from reoffending in the future)

d) incapacitation (to make sure that the offender does not reoffend during the period of sentencing by placing him/her in custody)

e) just deserts (to give the offender a punishment that fits the crime without considering treatment or other alternatives)

f) compensation (making the offender give back to the victim the equivalent of the loss that was caused: i.e. " through money or work hours, etc.)

$\begin{array}{lllllll}1 & 2 & 3 & 4 & 5 & 6 & 7\end{array}$

$\begin{array}{lllllll}1 & 2 & 3 & 4 & 5 & 6 & 7\end{array}$


Helen has just been convicted of break and enter after being caught breaking into a locked summer cottage. During her trial, testimony by friend's and neighbours revealed that she has been physically abused by her father. This is Helen's first conviction.

i) What sentence would you give her?

a) absolute discharge

check one length or amount

b) fine

c) compensation

d) community service order

e) probation

f) open custody

g) secure custody

ii) Rate how important you believe the following goals of sentencing are for the offender in this case (where $1=$ least important, $4=$ moderately important, and $7=$ very important).

Important Important Most

$-\frac{\text { Least }}{\text { Important Important Important }}$

a) rehabilitation (to provide treatment in order to reduce reoffending)

b) general deterrence (to make an example of the offender so that others will not offend)

$\begin{array}{lllllll}1 & 2 & 3 & 1 & & & 1 \\ 1 & 2 & 3 & 5 & 6 & 7\end{array}$

c) individual deterrence (to deter the individual from reoffending in the future)

d) incapacitation (to make sure that the offender does not reoffend during the period of sentencing by placing him/her in custody)

e) just deserts (to give the offender a punishment that fits the crime without considering treatment or other alternatives)

f) compensation (making the offender give back to the victim the equivalent of the loss that was caused; i.e." through money or work hours, etc.)

$\begin{array}{lllllll}1 & 2 & 3 & 4 & 5 & 6 & 7\end{array}$

$\begin{array}{lllllll}1 & 2 & 3 & 4 & 5 & 6 & 7\end{array}$


Jim is a first-time oftender that has been experiencing physical abuse by his father. His current conviction of drug-trafficking resulted when $\mathrm{J}$ im was caught trying to sell cocaine to a classmate's younger brother.

i) What sentence would you give him?

a) absolute discharge check one length or amount

b) fine

c) compensation

d) community service order

e) probation

f) open custody

g) secure custody

ii) Rate how important you believe the following goals of sentencing are for the offender in this case (where $1=$ least important, $4=$ moderately important, and $7=$ very important).

a) rehabilitation (to provide treatment in order to reduce reoffending)

b) general deterrence (to make an example of the offender so that others will not offend)

$\begin{array}{lllllll}1 & 2 & 3 & 4 & 5 & 6 & 7\end{array}$

c) Individual deterrence (to deter the individual from reoffending in the future)

d) incapacitation (to make sure that the of fender does not reoffend during the period of sentencing by placing him/her in custody)

$\begin{array}{lllllll}i & & & i & & & 1\end{array}$

e) just deserts (to give the offender a punishment that fits the crime without considering treatment or other alternatives) $\begin{array}{lllllll}1 & 2 & 3 & 4 & 5 & 6 & 7\end{array}$

f) compensation (making the offender give back to the victim the equivalent of the loss that was caused: i.e.' through money or work hours, etc.) 
Trish's current conviction of soliciting (prostitution) was the result of an undercover investigation during which she tried to solicit money for her sexual services from an officer. During the trial, it was revealed that she has been abused physically by her father. This current conviction was her first.

i) What sentence would you give her?

a) absolute discharge

check one length or amount

b) fine

c) compensation

d) community service order

e) probation

f) open custody

g) secure custody

ii) Rate how important you believe the following goals of sentencing are for the offender in this case (where $1=$ least important, $4=$ moderately important, and $7=$ very important).

Least Moderately Most

Important Important Important

a) rehabilitation (to provide treatment in order to reduce reoffending)

b) general deterrence (to $\begin{array}{lllllll}1 & 2 & 3 & 4 & 5 & 6 & 7\end{array}$ make an example of the offender so that others will not offend)

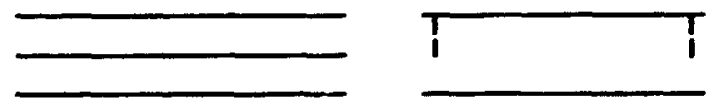

c) individual deterrence (to deter the individual from reoffending in the future)

d) incapacitation (to make sure that the offender does not reoffend during the period of sentencing by placing him/her in custody)

e) just deserts (to give the offender a punishment that fits the crime without considering treatment or other alternatives)

f) compensation (making the offender give back to the victim the equivalent of the loss that was caused: i.e., through money or work hours, etc.)

$\begin{array}{lllllll}1 & 2 & 3 & 4 & 5 & 6 & 7\end{array}$


During Heather's trial, testimony revealed that she was being physically abused by her father. Her conviction of assault resulted from a physical fight with her neighbour. This was Heather's first conviction.

1) What sentence would you give her?

a) absolute discharge check one

length of amount

b) fine

c) compensation

d) community service order

e) probation

f) open custody

g) secure custody

ii) Rate how important you believe the following goals of sentencing are for the offender in this case (where $1=$ least important, $4=$ moderately important, and $7=$ very important) Most

Important Important Important

a) rehabilitation (to provide treatment in order to reduce reoffending)

$\begin{array}{lllllll}1 & 2 & 3 & 4 & 5 & 6 & 7\end{array}$

b) general deterrence (to make an example of the offender so that others will not offend)

c) Individual deterrence (to deter the individual from reoffending in the future)

d) incapacitation (to make sure that the offender does not reoffend during the period of sentencing by placing him/her in custody)

e) just deserts (to give the offender a punishment that fits the crime without considering treatment or other alternatives)

$\begin{array}{lllllll}1 & 2 & 3 & 4 & 5 & 6 & 7\end{array}$

f) compensation (making the offender give back to the victim the equivalent of the loss that was caused; i.e., through money or work hours, etc.)

$\begin{array}{lllllll}1 & & & ! & & & 1\end{array}$

\section{i}

$\begin{array}{lll}1 & 3 & 4\end{array}$

$\begin{array}{lll}5 & 6 & 1\end{array}$

$$
\text { i }
$$$$
\begin{array}{lll}
2 & 3 & 1
\end{array}
$$$$
\begin{array}{lll}
5 & 6 & 1
\end{array}
$$

\begin{tabular}{ll|llll}
2 & 3 & 4 & 5 & $c$ & 7
\end{tabular}


Andrea has just been convicted of drug-trafficking. She was caught trying to sell cocaine to a neighbour's son. This is Andrea's first conviction. Testimony from neighbours during her trial revealed that she was physically abused by her father.

i) What sentence would you give her?
a) absolute discharge
b) fine
c) compensation
d) community service order
e) probation
f) open custody
g) secure custody

ii) Rate how important you believe the following goals of sentencing are for the offender in this case (where $1=$ least important, $4=$ moderately important, and $7=$ very important). Moderately Most

Important Important Important

a) rehabilitation (to provide treatment in order to reduce reoffending)

b) general deterrence (to make an example of the offender so that others will not offend) check one length or amount

c) individual deterrence (to deter the individual from reoffending in the future)

d) incapacitation (to make<smiles>[3H]I</smiles>
sure that the offender does not reoffend during the period of sentencing by placing him/her in custody)

e) just deserts (to give the offender a punishment that fits the crime without considering treatment or other alternatives)

f) compensation (making the offender give back to the victim the equivalent of the loss that was caused; i.e.. through money or work hours, etc.)

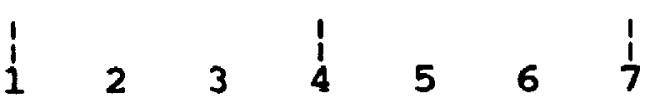


Glen is a first-time offender. His recent conviction of soliciting (prostitution) resulted when he tried to solicit money for his sexual services from an undercover police officer. Glen's file indicated that he had been abused physically by his father.

i) What sentence would you give him?

a) absolute discharge check one

length or amount

b) fine

c) compensation

d) community service order

e) probation

f) open custody

g) secure custody

ii) Rate how important you believe the following goals of sentencing are for the offender in this case (where $1=$ least important, $4=$ moderately important, and $7=$ very important).

a) rehabilitation (to provide treatment in Moderately Most Important Important Important order to reduce reoffending)

b) general deterrence (to make an example of the offender so that others will not offend)

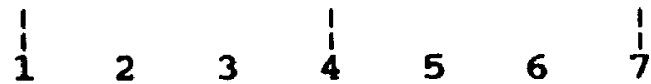

c) individual deterrence (to deter the individual from reoffending in the future)

d) incapacitation (to make sure that the offender does not reoffend during the period of sentencing by placing him/her in custody)

e) just deserts (to give the offender a punishment that fits the crime without considering treatment or other alternatives)

f) compensation (making the offender give back to the victim the equivalent of the inss that was caused; i.e. , through money or work hours, etc.)

$\begin{array}{lllllll}1 & 2 & 3 & 4 & 5 & 6 & 7\end{array}$

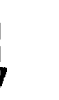


Joe is a first-time offender. His current conviction of assault resulted from a fight during which he punched his friend's father. During the trial, both parents were supportive and were said to provide a loving family environment.

i) What sentence would you give him?

a) absolute discharge

b) fine

c) compensation

d) community service order

e) probation

f) open custody

g) secure custody check one length or amount

ii) Rate how important you belleve the following goals of sentencing are for the offender in this case (where $1=$ least important, $4=$ moderately important, and $7=$ very important).

a) rehabilitation (to provide treatment in order to reduce reof fending)

b) general deterrence (to make an example of the of fender so that others Least Moderately Most Important Important Important will not offend)

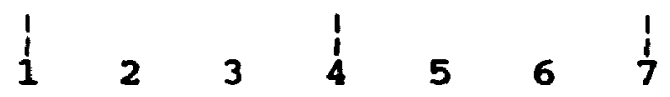

c) individual deterrence (to deter the individual from reoffending in the

d) incapacitation (to make

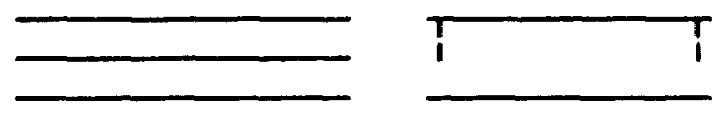
sure that the offender does not reoffend during the period of sentencing by placing him/her in custody)

e) just deserts (to give the offender a punishment that fits the crime without considering treatment or other alternatives)

f) compensation (making the offender give back to the victim the equivalent of the loss that was caused; i.e., through money or work hours, etc.)

$\begin{array}{lllllll}1 & 2 & 3 & 4 & 5 & 6 & 7\end{array}$

$\begin{array}{lllllll}1 & 2 & 3 & 4 & 5 & 6 & 7\end{array}$

$\begin{array}{lllllll}1 & 2 & 3 & 4 & 5 & 6 & 7\end{array}$ 
During Paul's current trial, both of his parents were present. Testimony by relatives indicated that his parents provided a happy and nurturing home environment. This is paul's first conviction. It occurred when he was caught breaking and entering a locked storage area.

i) What sentence would you give him?

a) absolute discharge check one

length or amount

b) fine

c) compensation

d) community service order

e) probation

f) open custody

g) secure custody

ii) Rate how important you believe the following goals of sentencing are for the offender in this case (where $1=$ least important, $4=$ moderately important, and $7=$ very important) .

a) rehabilitation (to Least Moderately Most Important Important Important provide treatment in order to reduce reoffending)

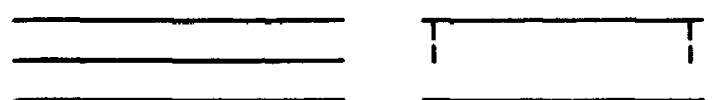

b) general deterrence (to make an example of the offender so that others will not offend)

$\begin{array}{lllllll}1 & & & 1 & & & 1 \\ 1 & 2 & 3 & 4 & 5 & 6 & 7\end{array}$

c) individual deterrence (to deter the individual from reoffending in the future)

d) incapacitation (to make sure that the offender does not reoffend during the period of sentencing by placing him/her in custody)

e) just deserts (to give the offender a punishment that fits the crime without considering treatment or other alternatives)

f) compensation (making the offender give back to the victim the equivalent of the loss that was caused; i.e., through money or work hours, etc.)

\section{i}

234

$5 \quad 6 \quad 7$

$\begin{array}{llllll}2 & 3 & 4 & 5 & 6 & 7\end{array}$


Dianne was just convicted of break and enter. This resulted after she was caught trying to enter a locked convenience store. During her current trial, both of her parents were present to support her and were said to be understanding and caring. This is Dianne's first conviction.

i) What sentence would you give her?
a) absolute discharge
b) fine
c) compensation
d) community service order
e) probation
f) open custody
g) secure custody

\section{check one length or amount}

ii) Rate how important you belicve the following goals of sentencing are for the offender in this case (where $1=$ least important, $4=$ moderately important, and $7=$ very important).

a) rehabilitation (to provide treatment in order to reduce reoffending) Moderately Most Important Important Important

b) general deterrence (to make an example of the offender so that others will not offend)

$\begin{array}{lllllll}1 & & & 1 & & & !\end{array}$

c) individual deterrence (to deter the individual from reoffending in the future)

d) incapacitation (to make sure that the offender does not reoffend during the period of sentencing by placing him/her in custody)

e) just deserts (to give

$\begin{array}{lllllll}i & 2 & 3 & 4 & 5 & 6 & 7\end{array}$
the offender a punishment that fits the crime without considering treatment or other alternatives)

f) compensation (making the offender give back to the victim the equivalent of the loss that was caused; i.e.' through money or work hours, etc.)

$\begin{array}{lllllll}1 & 2 & 3 & 4 & 5 & 6 & 7\end{array}$


Mark is a first-time offender. During his current trial, testimony Indicated that his parents were loving and caring people that provided support to their son. Mark's conviction was for drug-trafficking. witnesses saw Mark trying to sell cocaine to a class-mate's younger brother.

1) What sentence would you give him?
a) absolute discharge check one
b) fine
c) compensation
d) community service order
e) probation
f) open custody
g) secure custody

11) Rate how important you believe the following goals of sentencing are for the offender in this case (where $1=$ least important, $4=$ moderately important, and $7=$ very important).

a) rehabilitation (to Moderately Most Important Important Important provide treatment in order to reduce reoffending)

b) general deterrence (to make an example of the offender so that others will not offend)

$\begin{array}{lllllll}1 & 2 & 3 & 4 & 5 & 6 & 7\end{array}$

c) individual deterrence (to deter the individual from reoffending in the future)

d) incapacitation (to make sure that the offender does not reoffend during the period of sentencing by placing $\mathrm{him} / \mathrm{her}$ in custody)

e) just deserts (to give the offender a punishment that fits the crime without considering treatment or other alternatives)

f) compensation (making the offender give back to the victim the equivalent of the loss that was caused: i.e.. through money or work hours, etc.)
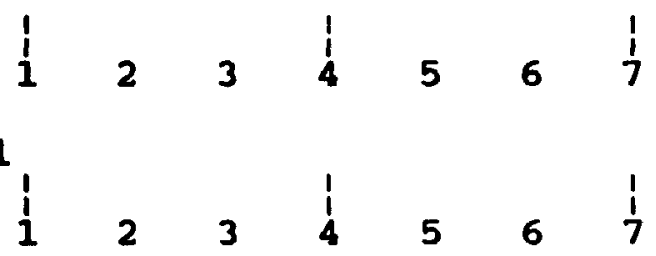

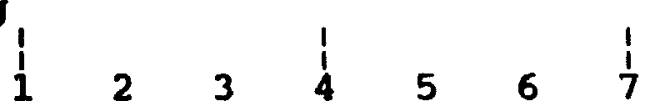


Connie's parents attended her trial, providing her with support. Testimony suggested that connie came from a loving family environment. She has just been convicted of assault resulting from a fight during which she punched her neighbour. This was connie's first offence.

i) What sentence would you give her?

a) absolute discharge

b) fine

c) compensation

d) community service order

e) probation

f) open custody

g) secure custody check one length or amount

ii) Rate how important you believe the following goals of sentencing are for the offender in this case (where $1=$ least important, $4=$ moderately important, and $7=$ very important).

Most

a) rehabilitation (to provide treatment in order to reduce reof fending)

b) general deterrence (to make an example of the \begin{tabular}{l|lllllll} 
of fender so that others \\
will not of fend)
\end{tabular}$\quad \begin{array}{lllllll}\mid & & & & & & \end{array}$

c) individual deterrence (to deter the individual from reoffending in the future)

d) incapacitation (to make sure that the of fender does not reoffend during the period of sentencing by placing him/hor in custody)

$\begin{array}{lllllll}1 & 2 & 3 & 4 & 5 & 6 & 7\end{array}$

e) just deserts (to give the offender a punishment that fits the crime without considering treatment or other alternatives)

f) compensation (making the offender give back to the victim the equivalent of the loss that was caused; i.e., through money or work hours, etc.)




Sharon has just been convicted of drug-trafficking after witnesses testified that they saw her trying to sell cocaine to a neighbour's son. This is Sharon's first offence. Both of her parents were present at her trial and were said to be supportive and to provide a loving family environment.

i) What sentence would you give her?
a) absolute discharge
b) fine
c) compensation
d) community service order
e) probation
f) open custody
g) secure custody check one

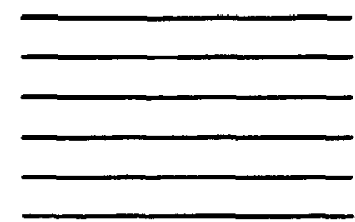

\section{length or amount}

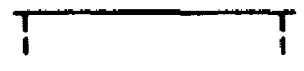

1i) Rate how important you believe the following goals of sentencing are for the offender in this case (where $1=$ least important, $4=$ moderately important, and $7=$ very important).

\section{Least} Moderately

Important Important Mrst

a) rehabilitation (to provide treatment in order to reduce reoffending)

b) general deterrence (to $\begin{array}{lllllll}1 & 2 & 3 & 4 & 5 & 6 & 7\end{array}$ make an example of the offender so that others will not offend)

c) individual deterrence (to deter the individual fr $m$ reoffending in the future)

d) incapacitation (to make sure that the offender does not reoffend during the period of sentencing by placing him/her in custody)

e) just deserts (to give the offender a punishment that fits the crime without considering treatment or other alternatives)

$\begin{array}{llll}1 & & & 1 \\ 1 & 2 & 3 & 4\end{array}$

$\begin{array}{lll}5 & 6 & 1\end{array}$

f) compensation (making the offender give back to the victim the equivalent of the loss that was caused; i.e. ', through money or work hours, etc.) Important 
Ted is a first-time offender. He has just been convicted of soliciting (prostitution). This resulted when he was caught trying to solicit money to perform sexual services. Both of his parents, present during the trial, were said to be caring and that they provided Ted with a nurturing family environment.

i) What sentence would you give him?

a) absolute discharge check one length or amount

b) fine

c) compensation

d) community service order

e) probation

f) open custody

g) secure custody

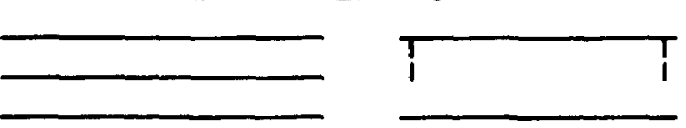

ii) Rate how important you believe the following goals of sentencing are for the offender in this case (where $1=$ least important, $4=$ moderately important, and $7=$ very important). Moderately Most Important Important

a) rehabilitation (to provide treatment in order to reduce reoffending)

b) general deterrence (to make an example of the offender so that others will not offend)

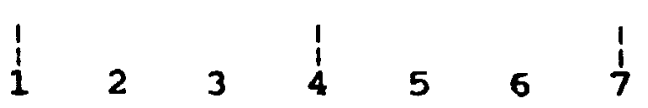

c) individual deterrence (to deter the individual from reoffending in the future)

d) incapacitation (to make sure that the of fender does not reoffend during the period of sentencing by placing him/her in custody)

e) iust deserts (to give the offender a punishment that fits the crime without considering treatment or other alternatives)

f) compensation (making the offender give back tn the victim the equivalenc of the loss that was caused; i.e., through money or work hours, etc.)$$
234
$$$$
4 \begin{array}{lll}
1 & 6 & 1
\end{array}
$$$$
234
$$

567


During Jennifer's trial, testimony revealed that she came from a happy home environment and that her parents were understanding and supportive. The current conviction of soliciting (prostitution) was Jennifer's first. She was caught asking for money to perform sexual favours.

i) What sentence would you give her?

a) absolute discharge

b) fine

c) compensation check one length or amount

d) community service order

e) probation

f) open custody

g) secure custody

ii) Rate how important you believe the following goals of sentencing are for the offender in this case (where $1=$ least important, $4=$ moderately important, and $7=$ very important).

a) rehabilitation (to Moderately Most Important Important Important provide treatment in order to reduce reoffending)

b) general deterrence (to make an example of the offender so that others will not offend)

$\begin{array}{lllllll}1 & 2 & 3 & 4 & 5 & 6 & 7\end{array}$

c) individual deterrence (to deter the individual from reoffending in the future)

d) incapacitation (to make $\begin{array}{lllllll}1 & 2 & 3 & 4 & 5 & 6 & 7\end{array}$ sure that the offender does not reoffend during the period of sentencing by placing him/her in custody)

$\begin{array}{lllllll}i & 2 & 3 & 4 & 5 & 6 & 7\end{array}$

e) just deserts (to give the offender a punishment that fits the crime without considering treatment or other alternatives)

$\begin{array}{lllllll}1 & & & 1 & & & ! \\ 1 & 2 & 3 & 4 & 5 & 6 & 7\end{array}$

f) compensation (making the offender give back to the victim the equivalent of the loss that was caused; i.... through money or work' hours, etc.) 
Appendix B

Consent Form

Present study: Effects of Young offender Gender, Prior Record, Type of Crime, and Family Functioning on Sentencing. Faculty Sponsor: Dr. Bob Hoge Department of Psychology

Telephone: 788-2600 ex.5773

Principal Investigator: Amel Loza

purpose: The purpose of this study is to see if certain factors contained within a criminal act contribute to the sentence given to young offenders.

Task Requirements: You will be required to assign what you :onsider to be appropriate sentences to 16 criminal events. Afterwards, you will be required to answer a few questions related to your sentencing decision.

Duration: This study will take approximately one hour and you will be given one experimental credit for your participation. Potential Discomfort: Some of the questions involve the reporting of previous victimization experience and criminal activity. You are under no obligation to answer questions that you do not wish to and you are free to withdraw from the study at any time without penalty.

Anonymity/Confidentiality: All data collected in this study will be strictly confidential and used for research purposes only. You will not be permitted to provided any personal information on the questionnaires.

If you want any more information about this study, you are free to ask the investigator or the faculty sponsor named above. You can also contact the following:

Chair of the Psychology Department:

Dr. W. Jones at 788-2600 ext. 2648

Chair of the Ethics Committee:

Dr. L. Paquet at 788-2600 ext. 2692

I have read the above description of the sentencing of Young offenders study and understard the conditions of my participation. By signing below, I give my consent to participate in this study.

participant's sianature:

date:

researcher's signature:

date: 
Appendix C

Debriefing Form

Thank-you for your co-operation and participation in this study. The purpose of this study is to see whether prior record, type of crime, and family functioning has an effect on the sentences given to male and female young offenders. We also wanted to see if the goal of sentencing, previous criminal involvement, and victimization experience had an impact on the length and type of sentences given. Previous research has suggested that male young of fenders are given heavier sentences than females for the same crimes except for those related to sexually acting-out. It has also been suggested that different sentencing goals lead to different types of sentences. So, for example, if the sentencing goal is incapacitation, you would expect to see a lot of custodial sentences.

Your participation in this study will help determine if and how these variables effect the sentencing decision for different criminal events. Feel free tc ask the investigator about the study. You may also direct your questions or concerns to one of the following:

Faculty Sponsor: Dr. Bob Hoge 788-2600 ext. 5773

Chair of the Psychology Department: Dr. Bill Jones 788-2600 ext. 2648

Chair of the Ethics Committee: Dr. Lise Paquet 788-2600 ext. 2692

It is hoped that the questions asked in this study did not cause you any pain or embarrassment. If this was the case, please contact one of the numbers below for assistance.

-Carleton Counselling Services: 788-6600

-Carleton Health Services: 788-6674

-Ottawa Rape Crisis Centre: 729-8889

- Ottawa Distress Centre: 238-3311

-The Carleton Chaplaincy: 788-4449

-Sexual Assault support centre: 234-2266

-Centre for Abused Women: 745-4818

once again, thank you for your time and cooperation. 
Appendix D

Analysis Using sentence Weights

Repeated Measures ANOVA using Sentence Weights

\begin{tabular}{|c|c|c|c|c|c|c|c|}
\hline source & of & souneres & dE & Me & In gounes & $P$ & $\mathbf{p}$ \\
\hline Prior & 23 & 698.69 & 1 & 23 & 698.69 & 18.69 & .00 \\
\hline error & 98 & 885.97 & 78 & 1 & 267.77 & & \\
\hline Gender & & 0.28 & 1 & & 0.28 & 0.00 & .95 \\
\hline Pri x Gen & & 197.43 & 1 & & 197.43 & 2.49 & .12 \\
\hline error & 6 & 182.13 & 78 & & 79.26 & & \\
\hline Crime & 76 & 715.03 & 3 & 25 & 571.68 & 60.96 & .00 \\
\hline $\operatorname{Pri} \times \operatorname{Cr} i$ & 1 & 379.00 & 3 & & 459.67 & 1.10 & .35 \\
\hline error & 98 & 159.69 & 234 & & 419.49 & & \\
\hline Abuse & 7 & 329.27 & 1 & 7 & 329.57 & 17.02 & .00 \\
\hline Pri $\times$ Abu & & 190.96 & 1 & & 190.96 & 0.44 & .51 \\
\hline error & 33 & 597.39 & 78 & & 430.74 & & \\
\hline Gen $x$ Crime & & 402.46 & 3 & & 134.15 & 1.09 & .35 \\
\hline PrixGenxCri & & 726.54 & 3 & & 242.18 & 1.97 & .12 \\
\hline error & 28 & 837.20 & 234 & & 123.24 & & \\
\hline Gen X Abu & & 21.40 & 1 & & 21.40 & 0.26 & .61 \\
\hline PrixGenxAbu & & 12.36 & 1 & & 12.36 & 0.15 & .70 \\
\hline error & 6 & 299.31 & 78 & & 80.76 & & \\
\hline $\mathrm{Cri} \times \mathrm{Abu}$ & 1 & 030.66 & 3 & & 343.55 & 2.78 & .04 \\
\hline PrixCrixabu & & 773.89 & 3 & & 257.96 & 2.09 & .10 \\
\hline error & 28 & 925.55 & 234 & & 123.61 & & \\
\hline GenxCrixAbu & & 119.56 & 3 & & 39.85 & 0.42 & .74 \\
\hline PrixGenxCrixAbl & & 213.17 & 3 & & 71.06 & 0.75 & .52 \\
\hline error & 22 & 052.40 & 234 & & 94.24 & & \\
\hline
\end{tabular}


Appendix D continued

Means and Standard deviations using Sentence Weights

\begin{tabular}{|c|c|c|c|c|}
\hline Bource & $\mathbf{H}$ & 8D & Partial & Power \\
\hline Prior & & & 0.19 & .99 \\
\hline Prior & 50.99 & 9.35 & & \\
\hline No Prior & 42.38 & 8.34 & & \\
\hline crime & & & 0.44 & 1.00 \\
\hline Assault & 30.21 & 12.88 & & \\
\hline $\mathbf{B} \& \mathbf{E}$ & 43.42 & 10.86 & & \\
\hline Drug & 59.20 & 15.40 & & \\
\hline Prostit. & 44.25 & 13.03 & & \\
\hline rbuse & & & 0.18 & .98 \\
\hline Abuse & 49.08 & 11.73 & & \\
\hline No Abuse & 44.29 & 10.48 & & \\
\hline CrixAbu & & & .03 & .67 \\
\hline AbusexAssault & 41.54 & 17.26 & & \\
\hline Abusex $B \& E$ & 46.54 & 14.45 & & \\
\hline AbusexDrug & 60.30 & 15.17 & & \\
\hline Abusexprostit. & 47.93 & 15.51 & & \\
\hline NoAbusexAssault & 34.88 & 13.71 & & \\
\hline NoAbusexB \& $\mathrm{E}$ & 40.29 & 10.97 & & \\
\hline NoAbusexDrug & $58 \cdot 10$ & 17.98 & & \\
\hline NoAbusexProstit & 43.90 & 14.09 & & \\
\hline
\end{tabular}


Appendix E

\section{Assigned Sentence Weights}

Absolute discharge 0

Fine under $\$ 500$ 23.01

Probation (under 6 months) 28.74

Compensation 30.26

Community service order (1-100 hours) 30.72

Fine $(\$ 501-\$ 1000)$ 37.95

Probation ( 6 to under 12 months) 38.73

Community service order (101-200 hours) 43.74

Probation (12 to under 18 months) 47.91

Probation (18 to 24 months) 51.46 Community service order (201-240 hours) 52.16

Open custody (under 6 months) 53.26

Open custody ( 6 to under 12 months) 60.26

open custody (12 to under 18 months) 64.32

Secure custody (under 6 months) 70.37

Open custody (18 to 24 months) 70.89

Secure custody (6 to under 12 months) 79.55

Secure custody (12 to under 18 months) 86.19

Secire custody (18 to 24 months) 100 

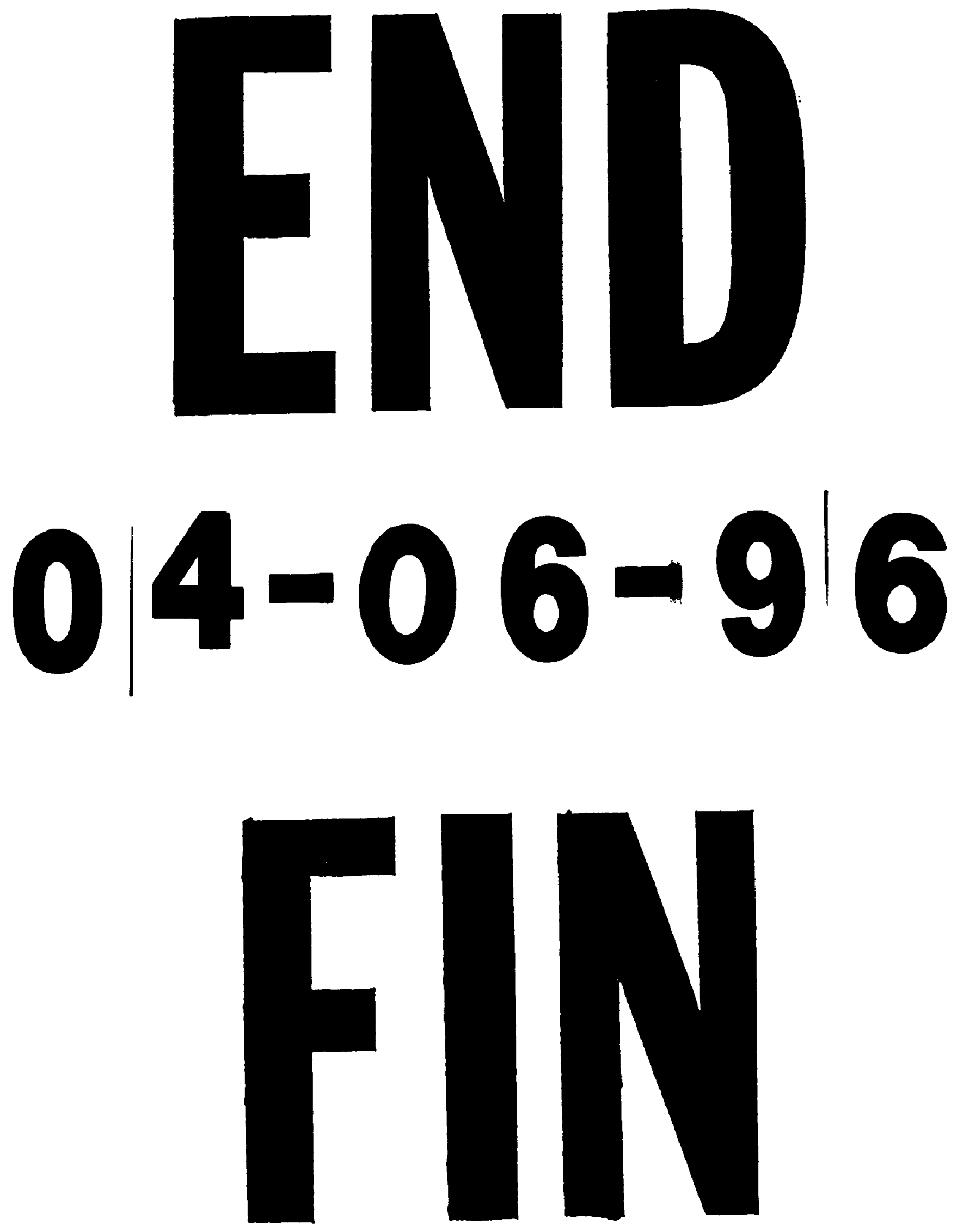